NBER WORKING PAPER SERIES

\title{
NONPARAMETRIC EVIDENCE ON THE EFFECTS OF FINANCIAL INCENTIVES ON RETIREMENT DECISIONS
}

\author{
Dayanand S. Manoli \\ Andrea Weber \\ Working Paper 17320 \\ http://www.nber.org/papers/w17320
NATIONAL BUREAU OF ECONOMIC RESEARCH
1050 Massachusetts Avenue
Cambridge, MA 02138

August 2011

We are grateful to Joe Altonji, Martin Browning, David Card, Raj Chetty, Courtney Coile, Julie Cullen, Eric French, John Friedman, Jon Gruber, Patrick Kline, Kathleen Mullen, Jesse Rothstein and numerous seminar and conference participants for insightful comments and suggestions. We are also grateful for financial support from the Steven H. Sandell Grant Program. Andrea Weber acknowledges research funding by the Leibniz Association (Pakt für Forschung und Innovation) and the Austrian Science Fund (NRN Labor Economics and the Welfare State). The views expressed herein are those of the authors and do not necessarily reflect the views of the National Bureau of Economic Research.

NBER working papers are circulated for discussion and comment purposes. They have not been peerreviewed or been subject to the review by the NBER Board of Directors that accompanies official NBER publications.

(C) 2011 by Dayanand S. Manoli and Andrea Weber. All rights reserved. Short sections of text, not to exceed two paragraphs, may be quoted without explicit permission provided that full credit, including (C) notice, is given to the source. 
Nonparametric Evidence on the Effects of Financial Incentives on Retirement Decisions Dayanand S. Manoli and Andrea Weber

NBER Working Paper No. 17320

August 2011

JEL No. H55,J22,J26

\begin{abstract}
$\underline{\text { ABSTRACT }}$
This paper presents new empirical evidence on the effects of retirement benefits on labor force participation decisions. We use administrative data on the census of private sector employees in Austria and variation from mandated discontinuous changes in retirement benefits from the Austrian pension system. We present graphical evidence documenting labor supply responses to the policy discontinuities. Next, we develop nonparametric procedures to estimate labor supply elasticities based on the graphical evidence and mandated financial incentives. We estimate elasticities of 0.12 for men and 0.38 for women. These relatively low elasticities highlight that many retirement decisions are likely to be affected by factors beyond only financial incentives from retirement benefits.
\end{abstract}

Dayanand S. Manoli

Department of Economics

University of California, Los Angeles

8283 Bunche Hall

Box 951477

Los Angeles, CA 90095-1477

and NBER

dsmanoli@econ.ucla.edu

Andrea Weber

University of Mannheim

Economics Department

L7, 3-4

68131 Mannheim

Germany

a.weber@uni-mannheim.de 


\section{Introduction}

How important are financial incentives for individual retirement decisions as opposed to other determinants such as social habits or norms? Understanding the answer to this question is essential for predicting the effects of reforms to social security systems. Policies designed to overhaul unsustainable pension systems in many countries predominantly rely on mechanisms operating through financial incentives. However, it is unclear if only using changes in financial incentives is an effective strategy to reach the goals of raising retirement ages and increasing labor force participation of older workers.

The literature studying the influence of social security policy on labor supply of older workers has come across several puzzles, which indicate the complex nature of retirement decisions and not a straight forward responsiveness to financial incentives. Most prominently, pronounced peaks in the distribution of age at retirement appear as an empirical regularity that has been hard to reconcile with financial incentives or conventional economic models. A range of studies investigating the effect of changes in social security policies in the US on labor supply of older workers conclude that social security rules have only a modest impact on retirement dates (Coile and Gruber 2007). At the same time, structural dynamic models of retirement have had a hard time predicting peaks in retirements at certain ages based only on social security rules or private pension plan rules (Burtless and Moffitt (1995), Stock and Wise (1990)). Arguments brought forward to explain the puzzles in retirement patterns include high risk aversion among older workers which makes them value Medicare health insurance (Rust and Phelan, 1997), significantly higher labor supply elasticities among older workers than among the young (French, 2002), private pensions (Gustman and Steinmeier, 1986), the salience of the social security tax-benefit link (Liebman, Luttmer, Seif 2009). Lumsdaine, Stock, and Wise (1996) conclude that the disproportionate fraction of retirements at age 65 in the US may be explained by a 'rule of the thumb' or social custom.

In this paper we investigate the extent of responsiveness in retirement entries to a financial incentive that operates along a dimension that is independent from age. This allows us to abstract from the retirement-age link that is the focus of most of the literature. Our setup exploits discontinuities in a nationally mandated rule for employer-provided retirement benefits in Austria. The employer-provided benefit system is largely independent from the rules of the public pension system, which allows us to study it in isolation of complicated social security rules. The eligibility rule is simple and salient: workers receive 
a lump-sum cash benefit (i.e. a severance payment) from their employer at entry into retirement. The amount of the severance pay depends on tenure in a step-wise function. Individuals are first eligible upon completing a tenure of 10 years, and further increases in benefits occur at thresholds of 15, 20, and 25 years of tenure.

The Austrian setup provides an ideal framework to study retirement responses to the policy discontinuities. The private sector is universally covered by mandatory, government provided pension and health insurance systems. The pension replacement rate in Austria is rather generous and there are virtually no transitions to employment after entry into retirement. In addition, we have access to rich register data from the pension administration which covers the entire labor market and earnings histories of the universe of workers retiring from the private sector.

To study retirement responses to the employer benefit system we first present nonparametric evidence on the distribution of retirement entries by tenure, which convincingly shows labor supply responses around the tenure discontinuities. In particular, we find spikes in the retirement frequency exactly at each tenure threshold and dips in retirements before the thresholds. This pattern indicates that the financial incentives motivate individuals to delay the entry into retirement. Although our evidence points to clear responses to the severance payments, the responsiveness is not universal. We find substantial heterogeneity in retirement patterns by health status, income, and gender.

To investigate the mechanisms behind the nonparametric retirement patterns, we formulate a dynamic model of retirement. In this model, retirement decisions are based on fully anticipated benefit changes according to the tenure discontinuities in the severance pay rule. Because of the limited interaction with the public pension system and the nature of the Austrian institutional framework, we can keep the model simple and focus exclusively on two factors: (1) the changes in benefits at the tenure thresholds and (2) the option value from qualifying for a (larger) severance payment in the future. We contrast simulated model solutions of retirements by tenure to a counterfactual model scenario without the severance pay system and show that the simple model predicts spikes in retirements at and dips before the tenure thresholds that resemble the nonparametric patterns in the data. The length of delay and the excess retirements at the tenure thresholds in the model depend on the amount of uncertainty and the size of shocks to the cost of working.

Based on the graphical evidence and the model simulations, we develop a nonparametric estimation strategy for the extensive margin intertemporal labor supply elasticities. The estimation strategy relates the observed retirement patterns to changes in financial incen- 
tives due to the mandated policy discontinuities. This estimator relies on discontinuities in individuals' budget constraints and is similar in spirit to previous bunching estimators that exploit kinks in individuals' budget constraints (see Saez (1999, 2010) and Chetty et al (2010)). ${ }^{1}$ Furthermore, we emphasize that the estimation strategy allows for estimation of policy-relevant elasticities without requiring ad hoc distributional or functional form assumptions. In line with the nonparametric evidence the estimated elasticities are relatively small: 0.12 for men and 0.38 for women. These estimates for men and women are consistent with earlier estimates from microeconometric studies. ${ }^{2}$ Furthermore, our estimated elasticities are amongst the most precise estimates found in the literature. The high degree of precision results from the large change in financial incentives due to the policy discontinuities, the high quality administrative data with minimal measurement error and the large sample size.

The small elasticity estimates indicate that responsiveness of retirement decisions to financial incentives is indeed relatively low. To emphasize this point and demonstrate the policy relevance of the estimated elasticities, we use the estimated elasticities to simulate responses to a hypothetical policy that provides financial incentives to delay retirement beyond the Early Retirement Age (ERA). The results highlight that, even in the presence of high-powered financial incentives to delay retirement, the spike in retirements at the ERA is only slightly reduced. Thus, many of the retirements at the ERA appear to be driven by factors beyond only financial incentives from retirement benefits.

Beside the literature on retirement decisions, our results on intertemporal labor supply elasticities also contribute to an important debate in the fields of labor economics, public finance and macroeconomics. ${ }^{3}$ Specifically, macroeconomic models explaining aggregate labor supply responses assume relatively high elasticities, while estimates based on micro data typically find small labor supply elasticities. Recent efforts to reconcile higher and lower elasticities have emphasized the importance of distinguishing between the intensive and extensive margins in labor supply decisions. As most previous studies examining individual-level labor supply have focused on intensive margin decisions, the responsiveness in labor supply along the extensive margin in micro data has been identified as a key issue.

\footnotetext{
${ }^{1}$ Friedberg (2000) examines bunching behavior in the context of the social security earnings test in the United States. She uses a maximum likelihood estimator as opposed to a bunching estimator.

${ }^{2}$ See Chetty, Guren, Manoli and Weber (2011) for a survey of estimates in the literature.

${ }^{3}$ For a detailed discussion of this debate, see the following papers from a recent session at the American Economic Association Meetings: Blundell, Bozio and Laroque (2011), Chang, Kim, Kwon, and Rogerson (2011), Chetty, Guren, Manoli and Weber (2011), and Ljungqvist and Sargent (2011).
} 
This paper is organized as follows. Section 2 discusses both the institutional background regarding the Austrian pension system and the administrative data from the Austrian Social Security Database. Section 3 presents a nonparametric graphical analysis of the data. Section 4 develops a dynamic model of retirement decisions and presents model simulations. Section 5 develops the elasticity estimation strategy and then presents the estimation results. Section 6 further investigates the heterogeneity in elasticities across the population. Section 7 concludes.

\section{Institutional Background \& Data}

\subsection{Retirement Benefits in Austria}

There are two forms of government-mandated retirement benefits in Austria: (1) governmentprovided pension benefits and (2) employer-provided severance payments. We start with the description of severance payments since these payments are the primary focus of the current study. The employer-provided severance payments are made to private sector employees who have accumulated sufficient years of tenure by the time of their retirement. Tenure is defined as uninterrupted employment time with a given employer and retirement is based on claiming a government-provided pension. The payments must be made within 4 weeks of claiming a pension according to the following schedule. If an employee has accumulated at least 10 years of tenure with her employer by the time of retirement, the employer must pay one third of the worker's last year's salary. This fraction increases from one third to one half, three quarters and one at 15, 20 and 25 years of tenure respectively. This schedule for the severance payments is illustrated in Figure 1. The payments are made in lump-sum and, since payments are based on an employee's salary, overtime compensation and other non-salary payments are not included when determining the amounts of the payments. Provisions to make these payments come from funds that employers are mandated to hold based on the total number of employees. Severance payments are also made to individuals who are involuntarily separated (i.e. laid off) from their firms if the individuals have accumulated sufficient years of tenure prior to the separation. The only voluntary separation that leads to a severance payment, however, is retirement. Employ-

ment protection rules hinder firms from strategically laying off workers to avoid severance payments and there is no evidence on an increased frequency of layoffs before the severance 
pay thresholds. ${ }^{4}$ In general, older workers approaching retirement age enjoy the highest level of job protection in Austria.

The Austrian income tax system, which is based on individual taxation, applies particular rules to tax income from severance payments. Specifically, all mandated severance payments are exempt from social security contributions and subject to a tax rate of $6 \%$. The income taxation of the severance payments differs from the general income tax rules. Generally, gross monthly earnings net of social security contributions ${ }^{5}$ are subject to the income tax with marginal tax rates in the different tax brackets of $0 \%, 21 \%, 31 \% 41 \%$ and $50 \%{ }^{6} 7$

Because the timing of the severance payments relates to pension claiming, eligibility for government-provided retirement pensions interacts with the severance payment system. Austria has a public pension system that automatically enrolls every person employed in the private sector. Fixed pension contributions are withheld from each individual's wage and annuitized benefits during retirement are then based on prior contributions (earnings histories). Replacement rates from the annual payments are roughly $75 \%$ of pre-retirement earnings and there are no actuarial adjustments for delaying retirement to a later age. ${ }^{8}$ Individuals can retire by claiming Disability pensions, Early Retirement pensions and Old Age pensions. Eligibility for each of these pensions depends on an individual's age and gender, as well as having a sufficient number of contribution years. Beginning at age 55, private sector male and female employees can retire by claiming Disability pensions, where disability is based on reduced working capacity of $50 \%$ relative to someone of a similar educational background. At age 55, women also become eligible to claim Early Retirement pensions, but the Early Retirement Age is age 60 for men. Lastly, men and women become eligible for Old Age pensions at age 65 and 60 respectively. ${ }^{9}$ Figure 2 illustrates survival

\footnotetext{
${ }^{4}$ For more details regarding the severance payments at times of unemployment, see Card, Chetty and Weber (2007).

${ }^{5}$ Contributions for pension, health, unemployment, and accident insurance of $39 \%$ are split in half between employer and employee and the employee's share is withheld from gross annual earnings up to a contribution cap.

${ }^{6}$ These tax brackets are based on legislation in 2002 ; there have subsequently been relatively small changes due to several small tax reforms.

${ }^{7}$ Additionally, Austrian employees are typically paid 13th and 14th monthly wage payments in June and December. These payments, up to an amount of one sixth of annual wage income, are also subject to a $6 \%$ tax rate; amounts in excess of one sixth of annual income are subject to the regular income tax rates.

${ }^{8}$ Given the generosity of the public pension system, private pensions are virtually non-existent in Austria.

${ }^{9}$ Benefits from disability and early retirement are entirely withdrawn if an individual earns more than about 300 Euros per month; therefore we see very few individuals returning to the labor force once they are retired.
} 
functions for exits from the labor force for the sample of private sector employees. The series are presented separately for men and women given the different eligibility ages. The survival functions illustrate sharp declines at ages 55 and 60 highlighting a significant amount of entry into the pension system once individuals become eligible for the Early Retirement pensions. Additionally, the figure demonstrates that, for both men and women, most retirements occur between ages 55 and 60. Further, the graph shows that roughly $25 \%$ of the male sample retire by claiming disability pensions prior to age 60 .

\subsection{Administrative Data \& Sample Restrictions}

Our empirical analysis is based on administrative registers from the Austrian Social Security Database (ASSD, see Zweimüller et al (2009)), which is collected with the principle aim of verifying individual pension claims. The data provide longitudinal information for the universe of private sector workers in Austria throughout their working lives. Specifically, information on employment and earnings as well as other labor market states relevant for computing insurance years such as military service, unemployment, and maternity leave is collected. Detailed electronic records with employer identifiers that allow the measurement of tenure are recorded in the period from 1972 onwards; here we use information up to 2006. For the years prior to 1972 retrospective information on insurance relevant states is available for all individuals who have retired by the end of the observation period. Combining the administrative data from 1972 onwards and the retrospective data prior to 1972 yields information on complete earnings and employment careers of retirees. Because firm identifiers are available only from 1972 onwards, uncensored tenure can be measured for jobs starting after January 1, 1972.

To investigate the effect of severance pay eligibility on retirement decisions we consider all individuals born between 1930 and 1945. For these individuals we observe sufficiently long uncensored tenure at retirement. ${ }^{10}$ We focus on workers who are still employed after their 55th birthday and follow them until entry into retirement or up to the age of 70 . We make several restrictions to the original sample of about 650,000 workers, which are summarized in Table 1. ${ }^{11}$ Most importantly, we exclude individuals who worked as civil servants or whose last job was in construction, because they are subject to different pension and severance pay rules. As we are interested in tenure at retirement, we further exclude

\footnotetext{
${ }^{10}$ In addition, these individuals retire after a pension reform in 1985 which changed the assessment basis for benefit calculation and the thereby the type of information recorded.

${ }^{11}$ For details on the selected sample see Appendix A.
} 
workers with left censored tenure at retirement and we only consider retirement entries which occur within 6 months of the worker's last job. Individuals with longer gaps between employment and retirement are only followed until the end of the last employment. With these restrictions, we have a final sample of 231, 251 retiring individuals.

Table 2 presents summary statistics separately for the full retirement sample and for the sub-sample of individuals that are used in the elasticity estimation. Specifically, the estimation sample consists of individuals with at least 6 years of tenure at retirement but not more than 28 year of tenure at retirement; this sample corresponds to Figure 3 which is discussed below. The median retirement age is 58.5 years in both groups, which reflects that most individuals retire through disability or early retirement $(66 \%$ and $63 \%$ in the full sample and estimation sample, respectively). ${ }^{12}$ Years of employment and annual earnings in the last year before retirement are slightly higher for workers with longer tenure and these workers also have lower years of unemployment. Overall the differences between both groups are minor.

\section{Nonparametric Graphical Analysis}

\subsection{Distribution of Tenure at Retirement}

Figure 3 presents the distribution of tenure at retirement for the full sample; tenure at retirement is measured at a monthly frequency. Several features are immediately evident from this graph. First, the plot shows discontinuous spikes in the number of retirements at the tenure thresholds. Second, there are dips in the number of retirements just before the tenure thresholds. These patterns are regularly repeated at each tenure threshold but are not apparent at any other point in the tenure distribution. This evidence suggests that individuals who would have retired just before the thresholds in the absence of the severance pay discontinuities end up delaying their retirements until they just qualify for the (larger) severance payments. Third, the plot indicates a seasonal pattern illustrated by small spikes in the number of retirement at each integer value of years of tenure at retirement. The seasonality can be explained by a relatively large fraction of job starts in January and corresponding retirement exits in December. Fourth, even though there are decreases prior to the thresholds, the frequency of retirements never goes to zero just prior

\footnotetext{
${ }^{12}$ The actual share of retirements through early retirement is higher than the presented number, as separate insurance categories for early retirement are only recorded as of 07/1993 and individuals retiring before the statutory pension age before that are coded as old age pension entries.
} 
to the thresholds. This means there appears to be a substantial number of individuals who are unresponsive to the severance pay system at retirement.

\subsection{Accounting for Covariates}

We exploit panel variation in the probability of retirement to examine whether or not other observable characteristics change around the tenure thresholds. In particular, we estimate the following regression

$$
r_{i t}=\sum_{s=0}^{34} \gamma_{s} d_{s}+X_{i t} \beta+\epsilon_{i t}
$$

where $r_{i t}$ is an indicator equal to 1 if individual $i$ retires within time period $t$. The set of observations per individual covers all quarters from age 55 to retirement or age 70 . The sample used for estimation includes all 380,737 individuals left at the last step of sample selection in Table 1, not only those observed retiring within 6 month of their last job. Including all job exits allows us to examine whether or not regularities in general job exits (as opposed to just retirements) after 5, 10, 15, ... year intervals are responsible for the observed retirement patterns in Figure 3. For computational reasons, time is measured at a quarterly frequency instead of the monthly frequency presented in Figure 3.

The regressors in the estimated equation are a set of indicators $d_{s}$ equal to 1 if the individual's quarterly tenure at time $t$ equals $s$. Further, we include a large set of timevarying control variables $X_{i t}$ relating to age, gender, calendar years, citizenship, industry, region, seasonality, earnings histories, firm size, health and experience. ${ }^{13}$ All of the variables in the regression are demeaned so that the coefficients on the tenure dummies reflect the mean probabilities of retirement within each tenure level.

\footnotetext{
${ }^{13}$ The estimated regression includes dummies for gender, calendar year, age measured at a quarterly frequency, birth month, birth year, Austrian citizenship, quarter of the year, industry, region, firm size, blue collar job status, job starting month, health status between age 42 through age 54 , contribution years between age 42 through 54 , sick leave in the current quarter, unemployment in the current quarter, topcoded earnings, insurance years (interacted with gender), and real earnings. Firm size is grouped into the following categories: $\leq 5,6-10,11-25,26-99,100-499,500-999, \geq 1000$. Health status between age 42 through age 54 is based on the following categories of sick leave from age 42 through age $54: \leq 0.03$ years, $0.03-0.18$ years, $0.18-0.33$ years, and $\geq 0.33$ years. Health and unemployment in the current quarter are based on the following categories for sick leave and unemployment days in the current quarter: 0 days, $1-30$ days, $31-60$ days, and $\geq 61$ days. Contribution years between ages 42 through age 54 is based on the following categories of contribution years: $\leq 5$ years, $5-8$ years, $8-13$ years, and $=13$ years. Real earnings dummies are created by creating 25 percentiles based on average earnings between ages 42 through 54 .
} 
Figure 4 plots the coefficients on the quarterly tenure dummies from the estimated regressions. The graph shows a pattern of dips before and large spikes at the thresholds that is very similar to Figure 3. The yearly seasonality pattern is now removed by controls for quarter of the year. We also plot confidence intervals for the estimated coefficients. Because of the large sample size, these intervals are very tight. Overall, Figure 4 confirms that incentives in the severance pay system are driving the retirement pattern around the tenure thresholds rather than other observable characteristics or regularities in job-leaving behavior.

\subsection{Job Starts}

We investigate whether individuals time the beginning of new jobs so that they can retire at the Early Retirement Ages (ERAs, respectively 55 and 60 for women and men) and also claim severance payments at the time of their retirements. To explore this idea, Figure $5 \mathrm{~A}$ plots the number of individuals starting new jobs (vertical axis) against age measured at a quarterly frequency (horizontal axis). ${ }^{14}$ If individuals are timing the beginning of their new jobs so that they can just complete 10, 15, or 20 years of tenure at the ERAs, then we would expect to see sharp increases in the number of individuals starting new jobs at ages 50, 45, and 40. The evidence in Figure 5A shows no discernible change in job starts at any age prior to the ERAs. This smoothness across age emphasizes that, while there is evidence that some individuals delay their retirements to qualify for (larger) severance payments at retirement, there is no evidence that individuals adjust their labor supply (or participation) at earlier ages in response to the sizeable anticipated incentives from the severance payments.

Figures $5 B$ and $5 C$ shed more light on the age at job start, by splitting up the sample into job starts resulting from job-to-job transitions versus job starts from unemployment. We do not see any pronounced increases at any ages in either graph. It is remarkable, however, that the relatively stable number of job starts before age 55 in Figure $5 A$ is the composition of a declining trend in new jobs from employment and a rising number of job starts from unemployment, especially for men. At age 40 the majority of new job starts are the result of job-to-job transitions, while at age 55 the majority is due to jobs started from

\footnotetext{
${ }^{14}$ For this graph we define a sample of job starters that closely resembles the definition of the retirement sample. Specifically, we select job starts of individuals who do not enter retirement before age 55, are still employed at age 55, and have a minimum employment experience of one year before age 55 . This sample composition implies that we observe a significant drop in new job starts after age 55 .
} 
unemployment. We can interpret the declining number of new jobs from employment as workers getting more reluctant to change jobs voluntarily as they age, potentially because severance pay at retirement limits their mobility. However, even if workers are aware of the long term consequences of changing jobs at older ages, they do not target new job starts to become eligible for severance pay exactly at the Early Retirement Ages.

\subsection{Heterogeneity in Responsiveness}

We start by investigating heterogeneity related to health status. We measure health based on the fraction of time between age 54 and retirement spent on sick leave. ${ }^{15}$ We define an individual as unhealthy if the fraction of time between age 54 and retirement spent on sick leave is above the median fraction of time for individuals with positive sick leave days (this median is 0.076). Figure 6 presents the distribution of tenure at retirement for unhealthy and healthy individuals, respectively. As expected, unhealthy individuals are not very flexible in the timing of their retirements. We basically see no response to the severance pay thresholds among retirees with health problems. Thus, some of the pre-threshold retirement is likely to be driven by negative health shocks and also more permanently poor health status.

Figure 7 examines heterogeneity related to gender and retirement age. Men and women are separately divided into age groups based on the survival functions illustrated in Figure 2 and the Early and Normal Retirement Ages. In particular, we distinguish retirements before age 60 and after age 60 . To check whether the large group of individuals retiring exactly at age 60 base their decisions on different incentives, we consider them as separate age group. The top row of the figure plots the distributions of tenure at retirement within each age group for men, and the plots for women are in the bottom panel. Overall the retirement patterns are remarkably similar across age and gender groups, except for men retiring prior to age 60 . They are not yet eligible for early retirement and have to qualify for disability to be eligible for benefits. As applications for disability take a while to be approved it is not surprising that men below age 60 appear to be unable to flexibly time their retirement. We further note that individuals retiring at age 60 show a similar responsiveness to severance pay incentives as the overall population. It is important to

\footnotetext{
${ }^{15}$ Roughly $35 \%$ of individuals in our sample have no sick leave days over their entire careers and $68 \%$ have no sick leave between ages 54 and retirement. Health status is highly correlated with the likelihood of claiming disability pension; about $64 \%$ of individuals with some sick leave between age 54 and retirement claim disability pensions as opposed to $15 \%$ of those with no sick leave between age 54 and retirement.
} 
keep in mind that the patterns in this graph should be interpreted as heterogeneity across individuals with different retirement ages rather than heterogeneity due to aging since there is clearly selection into different retirement ages.

Next, we examine heterogeneity across groups facing different financial incentives at retirement. In Figure 8, we focus on financial incentives related to pensions and earnings at retirement by computing the pension benefit replacement rate. For each individual, the replacement rate is defined as the percentage difference between the net of tax wage and the net of tax pension in the year of retirement. See Appendix B for the exact definition of these variables in our sample. Intuitively, the replacement rate captures the gains from continuing to work. Individuals with high pensions relative to their earnings will have higher replacement rates reflecting low incentives to continue working. Similarly, individuals with high earnings relative to their pensions will have lower replacement rates. In our sample, mean replacement rates are roughly between 0.75 and 0.80 at lower tenure levels; the mean replacement rates increase at higher levels of tenure and are generally between 0.80 and 0.90 .

To construct Figure 8, we compute percentiles of the replacement rates at retirement, and within each percentile, we compute the total number of retirements that occur just before and just after a tenure threshold. The figure highlights that the number of people retiring just prior to a tenure threshold does not vary based on replacement rates. In contrast, the number of people retiring just after a tenure threshold is relatively low at lower and at higher replacement rates. Intuitively, individuals with relatively generous pensions or with relatively high earnings may have lower marginal utilities of consumption from delaying their retirements to qualify for the (larger) severance payments.

Figure 9 examines heterogeneity relative to a tenure-adjusted measure of permanent income. Specifically, we compute average earnings by computing total earnings between ages 42 and 54 divided by 13 years. To account for returns to tenure and compare higher and lower earnings individuals with similar tenure levels at retirement, we create groups using tenure at age 55. Specifically, we group individuals by the calender year when they turn 55 and by tenure at the end of age 54; within each group, we compute percentiles of average earnings. Within each earnings percentile, we use tenure at retirement to compute the total number of people retiring within one quarter prior to a tenure threshold and within one quarter after a tenure threshold. Figure 9 plots the series of pre-threshold retirements and retirements at the thresholds across the earnings percentiles. Similar to the plot based on implicit tax rates, the figure highlights that the pre-threshold retirements do not vary 
across the earnings percentiles. Overall, individuals retiring just prior to a tenure threshold appear insensitive or unresponsive to financial incentives at retirement. In contrast, the number of people retiring at a tenure threshold diminishes at higher earnings percentiles. Individuals at higher earnings percentiles may have lower marginal utility of consumption at retirement and hence may be less likely to delay their retirement in response to the severance pay incentives.

Lastly we examine heterogeneity across firm sizes in Figure 10. Using the sample of firms that have retirements, we compute firm size percentiles. Within each firm size percentile, we compute the ratio of the total number of people retiring within one quarter after a tenure threshold to the total number of people retiring within one quarter prior to a tenure threshold. ${ }^{16}$ Figure 10 plots this ratio across the different firm size percentiles. The plot suggests that individuals at larger firms are more likely to retire just after reaching a tenure threshold compared to individuals are smaller firms. Even though larger firms may have more strategic incentives to layoff workers or make side payments to employees to avoid having to pay (larger) severance payments, the highest responsiveness is observed at these firms. This suggests that firms' legal and reputational costs of engaging in strategic behaviors is likely to be relatively high. Focusing more on smaller firms, individuals employed in smaller firms may be more restricted in choosing their retirement dates around the tenure thresholds. Small employers may face lower reputational costs and may put more pressure on their employees to retire prior to qualifying for a (larger) severance payment. Additionally, employees at smaller firms may have less ability to leave their firms just after reaching a tenure threshold since their employers may rely on them to complete their projects since there are fewer substitutable employees available to do so. The evidence presented in Figure 10 is consistent with these intuitions.

\section{Conceptual Framework}

\subsection{A Dynamic Model of Retirement Decisions}

To formalize the role financial incentives on retirement decisions, we develop a simple optimal stopping time model, which contrasts retirement decisions in a scenario without severance pay to a scenario where individuals become eligible for severance pay once they

\footnotetext{
${ }^{16}$ We focus on this ratio rather than the numerator and denominator separately since, by definition, there are more individuals retiring at larger firms.
} 
reach a tenure threshold. ${ }^{17}$ The model is designed to highlight the impacts of severance pay and therefore, following the graphical evidence, we simplify the model by abstracting from incentives to retire at certain ages. This simple model allows us to focus on two factors to explain the patterns in the graphical evidence: (1) the changes in benefits at the tenure thresholds and (2) the option value from continuing to work (see Stock and Wise, 1990 for a similar option value model).

We start with an employed individual at age 55 who decides whether to retire or continue to work based on the discounted flow of lifetime income under both options. Retirement is an irreversible decision, such that a retired individual does not have the choice to return to work and decisions are only possible as long as the individual stays employed. Considering first the scenario without severance pay, the decision in each period $t$, with $t=0$ at age 55 , is based on a set of state variables:

$$
\Omega_{t}= \begin{cases}t & \text { age } \\ b_{t} & \text { annual social security benefits if retiring at age } t \\ y & \text { annual earnings if working } \\ \alpha_{t} & \text { (disutility) costs of working at age } t\end{cases}
$$

The state variables evolve according to the following laws of motion. We assume that age increases by 1 each period and that earnings from employment $y$ are fixed over time, while the level of benefits $b_{t}$ rises deterministically with each year of delay in retirement such that $b_{t+1}>b_{t}$. The uncertainty in the model comes from $\alpha_{t}$, the cost of working, which evolves according to a stochastic process with $\alpha_{t+1}=\rho \alpha_{t}+\epsilon_{t+1}$, where $\epsilon_{t+1} \sim F_{t}\left(\eta_{t}\right)$.

At each age $t$ the individual bases her decision on the set of value functions: The value for retirement is given by

$$
V^{R}\left(t, b_{t}\right)=u\left(b_{t}\right)+\beta_{t} V^{R}\left(t+1, b_{t}\right)
$$

and the value of employment is

$$
V^{W}\left(\Omega_{t}\right)=u(y)-\alpha_{t}+\beta_{t} E_{t}\left[V\left(\Omega_{t+1}\right)\right]
$$

We assume that consumption equals income in each period with per period utility given by

\footnotetext{
${ }^{17}$ In the comparison of both scenarios we assume that severance pay only affects the retirement decisions of workers, but not any decisions at the employer's side such as wage setting policy or hiring decisions.
} 
$u$ and there is no saving. ${ }^{18}$ The series of discount factors $\beta_{t}$ of future utility is assumed to also capture the probability of survival. $E_{t}\left[V\left(\Omega_{t+1}\right)\right]$ captures the expected value of next period's decision

$$
V\left(\Omega_{t+1}\right)=\max \left\{V^{R}\left(t+1, b_{t+1}\right), V^{W}\left(\Omega_{t+1}\right)\right\} .
$$

The optimal strategy can be described by a reservation disutility value $\bar{\alpha}_{t}\left(\Omega_{t}\right)$, which determines the retirement decision: the individual retires if $\alpha_{t} \geq \bar{\alpha}_{t}\left(\Omega_{t}\right)$. $\bar{\alpha}_{t}$ is implicitly given by the indifference condition

$$
V^{R}\left(t, b_{t}\right)=V^{W}\left(t, b_{t}, y, \bar{\alpha}_{t}\right)
$$

Using a first order Taylor expansion of $u$ around $y$, we can express the reservation disutility as

$$
\bar{\alpha}_{t}=\lambda\left(y-b_{t}\right)+\beta_{t} O V_{t}
$$

where $\lambda$ denotes the marginal utility of consumption $\lambda=u^{\prime}(y)$. This expression highlights the dependence of the reservation disutility on two components: the gain from working $y-b_{t}$ in period $t$ and the option value $O V_{t}$ of retiring at a later age which is given by $O V_{t}=E_{t}\left[V^{W}\left(\Omega_{t+1}\right)\right]-V^{R}\left(t+1, b_{t}\right)$ and incorporates future earnings and benefits as well as expectations of future realizations of $\alpha_{t}$. Equation (1) defines $\bar{\alpha}_{t}$ dynamically and in order obtain a solution for $\bar{\alpha}_{t}$ we solve the equation recursively starting at a fixed maximum lifetime $T$. For details see the next section. Let us call the gain from working $\tilde{y}_{t}$ and

\footnotetext{
${ }^{18}$ This is potentially a very crude approximation, as it also implies that individuals have to consume severance pay in a single period in the model scenario with severance pay. It does not affect the main model properties, however. Importantly, the option value always takes the potential receipt of future severance pay into account. We make this simplifying assumption for two reasons. First, we have no data on consumption or savings and hence we cannot identify savings decisions. Second, this assumption allows us to write net wages and implicit tax rates in terms of income differences (i.e. earnings net of taxes and benefits) rather than consumption differences. See the next footnote for more information.
} 
re-write it in terms of the implicit tax rate $\tau_{t}$ defined as ${ }^{19}$

$$
\tilde{y}_{t}=y\left(1-\tau_{t}\right)=y-b_{t} .
$$

Based on a solution for $\bar{\alpha}_{t}$ we can express the hazard rate of retirement at age $t$ as

$$
h_{t}=\operatorname{Pr}\left\{\alpha_{t}>\lambda y_{t}\left(1-\tau_{t}\right)+\beta_{t} O V_{t}\right\} .
$$

Given the hazard rates, the distribution of retirements by age $n_{t}$ is determined based on the initial population size $N_{0}$.

In terms of policy tools we interpret the implicit tax rate $\tau_{t}$ as the key parameter through which financial incentives can be manipulated by policy makers. Let us elaborate on this idea by introducing severance pay into the model. Severance pay enters the model through the assumption that in addition to $b_{t}$ the individual receives a one time severance payment amount of $S P$ if she retires with a level of tenure higher than the threshold $s^{*}$. Based on the empirical findings we make two simplifying assumptions. First, we model the severance pay policy with only one tenure threshold and second, we assume that tenure at age 55 is randomly assigned. This implies that the individual threshold dates are exogenous with respect to the other determinants of retirement and thresholds vary across the population. To include severance pay into the retirement decision we include tenure $\mathrm{Ten}_{t}$ as an additional state variable in $\Omega_{t}^{S P}$. Tenure increases by one in each period as long as an individual remains employed and it is set equal to zero at retirement. Under this scenario the value functions change to

$$
\begin{aligned}
V^{R}\left(t, b_{t}\right) & =u\left(b_{t}+S P \times I\left(\text { Ten }_{t} \geq s^{*}\right)\right)+\beta_{t} V^{R}\left(t+1, b_{t}\right) \\
V^{W}\left(\Omega_{t}^{S P}\right) & =u(y)-\alpha_{t}+\beta_{t} E_{t}\left[V\left(\Omega_{t+1}^{S P}\right)\right]
\end{aligned}
$$

\footnotetext{
${ }^{19}$ In a more general model that allows for endogenous consumption decisions and hence consumption smoothing, the implicit tax rate could be defined in terms of consumption differences,

$$
\begin{aligned}
(1-\tau) c_{t}^{W} & =c_{t}^{W}-c_{t}^{R} \\
& \Rightarrow \tau=\frac{c_{t}^{R}}{c_{t}^{W}} .
\end{aligned}
$$

In this expression, $c_{t}^{W}$ denotes endogenous consumption if the individual were to choose to continue working at time $t$ and similarly $c_{t}^{R}$ denotes endogenous consumption if the individual were to choose to retire at time $t$.
} 
The equation for the reservation disutility $\bar{\alpha}_{t}^{S P}$ is given by

$$
\bar{\alpha}_{t}^{S P}=\left\{\begin{array}{cc}
\lambda\left(y-b_{t}\right)+\beta_{t} O V_{t}^{S P} & \text { if } \text { Ten }_{t}<s^{*} \\
\lambda\left(y-b_{t}-S P\right)+\beta_{t} O V_{t}^{S P} & \text { if } \text { Ten }_{t} \geq s^{*}
\end{array}\right.
$$

For tenure levels above the threshold we define the gain from working and the implicit tax rate to include severance pay

$$
\tilde{y}_{t}^{S P}=y\left(1-\tau_{t}^{S P}\right)=y-b_{t}-S P .
$$

The corresponding hazard rate is given by

$$
h_{t}^{S P}=\left\{\begin{array}{cc}
\operatorname{Pr}\left\{\alpha_{t}>\lambda y_{t}\left(1-\tau_{t}\right)+\beta_{t} O V_{t}^{S P}\right\} & \text { if } \text { Ten }_{t}<s^{*} \\
\operatorname{Pr}\left\{\alpha_{t}>\lambda y_{t}\left(1-\tau_{t}^{S P}\right)+\beta_{t} O V_{t}^{S P}\right\} & \text { if } \text { Ten }_{t} \geq s^{*}
\end{array}\right.
$$

In this model scenario future decisions take the potential receipt of severance pay into account and the option value of retirement at a later age $O V_{t}^{S P}$ includes the option of becoming eligible for severance pay. Note that individuals receive severance pay if they retire at any age after reaching the tenure threshold and the option value includes severance pay also at ages above the threshold. In other words, the option value of retiring at a later age changes permanently at the tenure threshold, while severance pay changes the gain from working only in a single period.

Equations (3) and (5) indicate that the option of severance pay will have different effects on the hazard rate depending on tenure. Prior to the tenure threshold severance pay increases the option value of delaying retirement and thus increases $\bar{\alpha}_{t}^{S P}$ and decreases $h_{t}^{S P}$. After the threshold severance pay increases the implicit tax rate and increases the hazard rate. The equations for $\bar{\alpha}_{t}^{S P}$ and $h_{t}^{S P}$ also indicate that induced by the jump in the implicit tax rate at the tenure threshold, there will be a discrete drop in the reservation disutility of work at the tenure threshold $s^{*}$ and a corresponding increase in the hazard rate. To investigate the shapes of the reservation disutility and hazard rates before and after the tenure threshold in both scenarios with and without severance pay we turn to model simulations. 


\subsection{Model Simulations}

To show the retirement decisions implied by our model over age and by tenure we simulate model solutions for the two scenarios with and without severance pay. For specific details and assumptions of the model simulations see Appendix C.

We start with retirement outcomes for a cohort of identical individuals, who all have the same level of tenure at age 55 . We choose $T e n_{0}=2$, which implies that they reach the tenure threshold $s^{*}$ at age 63 . The following graphs trace the disutility of work and hazard rate into retirement for the cohort of individuals in both scenarios.

Figure $11 A$ plots the simulated profiles of the reservation disutility of work $\bar{\alpha}_{t}$ and $\bar{\alpha}_{t}^{S P}$ by age. The downward sloping profile for the counterfactual scenario without severance pay reflects retirement decisions at older ages. Relative to the counterfactual we see a sharp increase in the disutility of work prior to the threshold for individuals who become eligible for severance pay. Right after the threshold the reservation cost of working drops below the counterfactual and moves more or less parallel as individuals stay eligible for severance pay if they retire at any age after the threshold.

Figure $11 B$ plots the corresponding simulated profiles of the hazard rate into retirement $h_{t}$ and $h_{t}^{S P}$ by age. Not surprisingly the hazard rates reflect the profile of the reservation disutility with higher disutilities implying lower hazards and vice versa.

After having established the results at a single tenure/age threshold, we mix cohorts of individuals with different levels of tenure at age 55 in the second set of simulations. Specifically we choose initial levels of tenure $T e n_{0}=s_{0}$ with $s_{0}$ ranging from 0 to 15 years. Individuals from the cohort with $T e n_{0}=s_{0}$ have tenure $s=t+s_{0}$ at age $t$ and reach the tenure threshold $s^{*}=10$ at age $t=65-s_{0}$.

For this group of individuals we focus on the average hazard rate to retirement by tenure shown in Figure 12A. This graph shows a constant average hazard of retirement in the counterfactual scenario, which results from averaging over different retirement ages. For the scenario with severance pay we see a dip in hazard rate prior to the tenure threshold reflecting the decline in the average hazards by age. We also see a large level shift in the hazard rate at the threshold and thereafter the hazard rate remains more or less constant.

The next graph, Figure 12B, relates the average hazard rate to the frequency of retirements by the level of tenure. Given the initial cohort sizes we can compute retirement frequencies by age and tenure $n_{t s}$ and obtain the aggregate retirement frequency by tenure from $n_{s}=\sum_{t=0}^{T} n_{t s}$. This figure represents the distribution of tenure at retirement or a simulated equivalent of Figure 3. The simulated distribution of tenure is remarkably similar 
to the pattern observed in the data in Figure 3. In the simulated distribution the spike in retirement frequencies at the tenure threshold is a result from two factors: (i) the level shift in the hazard rate and (ii) the fast decline in the population at risk of retiring after the tenure threshold. We further note that the in the simulated graph the frequency never goes to zero prior to the threshold, which is due to individuals retiring with very high values of $\bar{\alpha}$. In addition, the retirement frequency does not immediately drop to the counterfactual level in the period after the threshold, which reflects the constantly high retirement hazards as individuals stay eligible for severance pay if they retire in any period after the threshold.

\section{$5 \quad$ Estimating the Labor Supply Elasticity}

\subsection{Definition and Identification of the Elasticity of Labor Supply}

We have demonstrated in the empirical analysis and in the model simulations that severance pay establishes clear financial incentives to delay retirement until the tenure threshold relative to a model without severance pay. Now we exploit this discrete change in incentives at the tenure threshold to quantify labor supply responsiveness to the severance payments.

In the formulation of the model we have identified the implicit tax rate as the key parameter to manipulate financial incentives via severance payments. Therefore we aim at estimating the elasticity of retirement entry with respect to the implicit tax rate at tenure level $s$, which is given by

$$
\varepsilon_{s}=-\frac{d \ln p_{s}}{d \ln \left(1-\tau_{s}\right)}=\frac{\Delta p_{s} / p_{s}}{\Delta \tilde{y}_{s} / \tilde{y}_{s}}
$$

Here $p_{s}=n_{s} / N_{0}$ denotes the probability of retirement at tenure $s$ and $N_{0}$ is the total number of retirements in the population. This elasticity can be interpreted as the response in retirement entry to an increase in the implicit tax rate $\tau_{s}$ or to a decrease in the gain from working $\tilde{y}_{s}$.

Our empirical design offers an opportunity to identify the elasticity $\varepsilon_{s}$ at the tenure thresholds where the implicit tax rate jumps to a higher level in the scenario with severance pay, while it is smooth through the threshold in the scenario without severance pay. The idea is to compare the frequency of retirements at the tenure threshold in the model with severance pay to the frequency of retirements at the same tenure level in the model without severance pay. Then we construct a reduced form estimate of the labor supply elasticity 
by relating the difference in retirement frequencies to the change in the implicit tax rate at the tenure threshold. Following this intuition, we formulate the elasticity at the threshold tenure level $s^{*}$ via

$$
\varepsilon_{s^{*}}=\frac{\Delta p_{s^{*}} / p_{s^{*}}}{\Delta \tilde{y}_{s^{*}} / \tilde{y}_{s^{*}}}=\frac{\frac{n_{s^{*}}^{S P}-n_{s^{*}}}{n_{s^{*}}}}{-\frac{\left(1-\tau_{s^{*}}^{S P}\right) y-\left(1-\tau_{s^{*}}\right) y}{\left(1-\tau_{s^{*}}\right) y}}=\frac{\frac{n_{s^{*}}^{S P}-n_{s^{*}}}{n_{s^{*}}}}{\frac{S P}{\left(1-\tau_{s^{*}}\right) y}}
$$

using

$$
\frac{\Delta p_{s^{*}}}{p_{s^{*}}}=\frac{p_{s^{*}}^{S P}-p_{s^{*}}}{p_{s^{*}}}=\frac{n_{s^{*}}^{S P}-n_{s^{*}}}{n_{s^{*}}}
$$

We interpret this elasticity as an intertemporal, extensive margin labor supply elasticity because it measures the response in retirement decisions to an anticipated increase in net earnings. In the model, individuals fully incorporate this change in the budget set into their optimal, forward-looking labor supply strategies by taking into account the option value of retiring at a future date. Thus, the dynamic nature of the decision process is incorporated in the estimation of the labor supply elasticity based on comparing retirement frequencies at the tenure thresholds both with and without the severance payments.

\subsection{Estimation Procedures}

Now we explain the procedure for estimating the labor supply elasticity defined in equation (6). The basis of the estimation are the monthly retirement frequencies plotted

in Figure 3. We estimate $\varepsilon_{s^{*}}$ separately for each tenure threshold $s_{i}^{*} \in\left(s_{1}^{*}, \ldots, s_{4}^{*}\right)$ at 10,15 , 20 , and 25 years of tenure. In equation (6) the elasticity is defined at the threshold date $s^{*}$, but in the application we specify the elasticities over several time intervals. Specifically, we estimate $\varepsilon_{s^{*}}$ over monthly, quarterly, and annual intervals. The steps for estimating the numerator and the denominator in equation (6) are similar, but we explain each of them in turn. While the estimation procedures involve some assumptions, we have examined these assumption in detail in the Sensitivity to Parametric Assumptions in Appendix D; following this sensitivity analysis, we conclude that the estimation procedures are robust.

\section{Estimating $\Delta p / p$}

We estimate the change in retirements $\Delta p / p$ by computing differences between the increased retirement frequencies at the tenure thresholds and estimated counterfactual frequencies at the tenure thresholds. While we describe each step in detail, Figure 13 
illustrates the estimation of $\Delta p / p$. We start by fitting a polynomial approximations in the intervals between the tenure thresholds to the observed monthly frequencies of retirement $n_{s}$ at tenure level $s$ to estimate seasonally adjusted retirement frequencies $n_{s}^{a}$. For details on the polynomial specification see Appendix D. Figure $13 A$ compares the observed retirement frequencies with the seasonally adjusted frequencies.

Second, we use the seasonally adjusted retirement frequencies to estimate counterfactual retirement frequencies $\hat{n}_{s}$ to create the scenario without severance pay. The identification assumptions is that, in the absence of the severance payments, individuals retiring at the tenure thresholds would behave like individuals retiring further away or between the tenure thresholds. We therefore fit a continuous polynomial over the entire range of tenure levels and add dummy variables for the months around the tenure thresholds. Then we use predictions of this polynomial obtained by setting the dummies equal zero to construct counterfactual frequencies. For the exact regression specification and a discussion of robustness with respect to alternative specifications, see Appendix D. Figure $13 B$ illustrates the seasonally adjusted retirement frequencies and the counterfactual frequencies.

We use the seasonally adjusted and counterfactual frequencies to calculate the change in the probability of retirement just after the tenure thresholds. Specifically, we specify a number of months after each threshold $m$ and compute the change in the probability of retirement

$$
\frac{\Delta p_{s_{i}^{*}}}{p_{s_{i}^{*}}}(m)=\frac{\sum_{k=1}^{m}\left[n_{s_{i}^{*}+k}^{a}-\hat{n}_{s_{i}^{*}+k}\right]}{\sum_{k=1}^{m}\left[\hat{n}_{s_{i}^{*}+k}\right]} \text { for } 1=1, \ldots, 4 .
$$

For $m=1,3,12$ equation (7) reflects the increase in retirements at a monthly, quarterly and annual frequency.

We estimate standard errors for the changes in retirements using a block bootstrap procedure explained in the appendix. ${ }^{20}$ We use this block bootstrap procedure, which samples errors across different levels of tenure at retirement, rather than a bootstrap procedure that samples individuals with replacement because we aim to capture error due to polynomial misspecification rather than errors across individuals. Since we are working with a large sample of individuals, we place less emphasis on errors due to variation across individuals and more emphasis on errors due to misspecification. ${ }^{21}$

\footnotetext{
${ }^{20}$ For a general discussion of block bootstrap procedures, see Hall, Horowitz, and Jing (1995). Additionally, our application of the block bootstrap follows procedures used by Chetty et al (2010).

${ }^{21}$ We have also computed bootstrapped standard error by sampling individuals with replacement. These standard errors are smaller than the block bootstrapped standard errors presented in the tables.
} 


\section{Estimating $\Delta \tilde{y} / \tilde{y}$}

The change in the gain from working, $\Delta \tilde{y} / \tilde{y}$, measures the financial incentives to delaying retirement by capturing the difference in after-tax income with and without the severance payments. Consider an individual just prior the i-th tenure threshold $s_{i}^{*}$. In comparison to a scenario without severance payment, the gain from delaying retirement by $m>0$ months in the presence of severance payments is given by

$$
\Delta \tilde{y}_{s_{i}^{*}}=-\left(1-\tau_{s_{i}^{*}}^{S P}\right) y(m / 12)+\left(1-\tau_{s_{i}^{*}}\right) y(m / 12)=S P_{i}
$$

where $\tau_{s_{i}^{*}}^{S P}$ and $\tau_{s_{i}^{*}}$ are the implicit tax rates, and $S P_{i}$ is the increase in severance pay at the i-th tenure threshold. ${ }^{22}$

The relative change in the gains to working over $m$ months form the scenario without severance pay to the scenario with severance pay is thus is given by

$$
\frac{\Delta \tilde{y}_{s_{i}^{*}}}{\tilde{y}_{s_{i}^{*}}}(m)=\frac{S P_{i}}{\left(\frac{m}{12}\right)\left(1-\tau_{s_{i}^{*}}\right) y} .
$$

To formulate an estimator for this expression we start by computing implicit tax rates for all individuals retiring at their respective tenure levels $s$ at retirement. For a detailed description of this computation see Appendix B. ${ }^{23}$ Based on these implicit tax rates without severance pay, we compute mean implicit tax rates at each level of tenure at retirement, $\tau_{s}$. Subsequently, we use an adjustment procedure similar to the one described above and base the estimation of the change in implicit tax rates on the seasonally adjusted implicit tax rates denoted by $\hat{\tau}_{s} \cdot{ }^{24}$

$$
\frac{\Delta \tilde{y}_{s_{i}^{*}}}{\tilde{y}_{s_{i}^{*}}}(m)=\frac{S P_{i}}{\left(\frac{m}{12}\right)\left(1-\hat{\tau}_{s_{i}^{*}}\right) y} .
$$

where $m=1,3,12$ reflects changes the gain from working over a monthly, quarterly or annual time span. The standard errors for the changes in implicit tax rates are computed using a block bootstrap procedure similar to the procedure described above for the changes

\footnotetext{
${ }^{22}$ Note that we defined $\tau$ in term of annual earnings $y$ corresponding to $m=12$ in section 4.1. At the monthly frequency the definition has to be adjusted to $\Delta \tilde{y}_{s}(1)=-\left(1-\tau_{s}^{S P}\right) \frac{y}{12}+\left(1-\tau_{s}\right) \frac{y}{12}=$ $-\left(\frac{y}{12}-\frac{b}{12}-S P\right)+\left(\frac{y}{12}-\frac{b}{12}\right)=S P$. For the severance pay schedule see Figure 1 and Appendix D.

${ }^{23}$ For notational simplicity, we treat annual earnings $y$ as net earnings. The ASSD earnings variables correspond to gross earnings before taxes and social security contributions. In Appendix B we explain in detail how gross earnings are transformed into estimates of net earnings.

${ }^{24}$ For the exact regression specification see Appendix B.
} 
in retirements. ${ }^{25}$

Figure 14 illustrates our estimation strategy. The black dots correspond to the mean values of $\tau_{s}$ across all monthly levels of tenure and the blue line indicates the seasonally adjusted values $\hat{\tau}_{s}$ for the scenario without severance pay. To represent the changes in the gains from working relative to the scenario with severance pay, we also plot the values of $s_{i}^{* S P}$ at the tenure thresholds. Relative to the changes in retirements at the tenure thresholds, shown in Figure 13B, the changes in the gains from working appear to be large. As the elasticity is given by the ratio of the two, we expect our estimates to be small.

Combining the estimated numerators and denominators from equations (7) and (8), we estimate elasticities with respect to monthly, quarterly and annual earnings for each threshold,

$$
e_{s_{i}^{*}}(m)=\frac{\Delta p_{s_{i}^{*}} / p_{s_{i}^{*}}}{\Delta \tilde{y}_{s_{i}^{*}} / \tilde{y}_{s_{i}^{*}}}(m)
$$

The standard errors for the estimated elasticities are computed by taking the standard deviation of the 1000 estimates that result from the block bootstrap procedures used to compute the standard errors for the numerators and denominators.

\subsection{Estimation Results}

Table 3 presents estimation results for the full sample at monthly, quarterly and annual levels. Panel A presents estimates of the changes in retirements at each of the thresholds; Panel B presents results on the changes in implicit tax rates; Panel C combines the results of Panels A and B and presents the estimated elasticities. The results in Panel A indicate that, within one month of the 10-year threshold, there is roughly an $84 \%$ increase in retirements relative to the estimated counterfactual level of retirements. The changes in retirements across the remaining thresholds are even larger, ranging from roughly $112 \%$ to $126 \%$. These large changes in retirements are consistent with the large spikes observed in Figures 3 and 11. Turning to the annual frequency, the results indicate that, at the 10-year threshold, the number of people retiring between 10 and 11 years of tenure increases by roughly $22 \%$ relative to the estimated counterfactuals; at the other thresholds, the change in retirements at the annual frequency ranges from roughly $27 \%$ to $39 \%$.

The increases in retirements are accompanied by similarly large increases in implicit tax rates in Panel B. For working one month beyond the 10-year threshold, an individual's

\footnotetext{
${ }^{25}$ For details see Appendix B.
} 
implicit tax rate on monthly earnings increases by roughly $1643 \%$ due to the severance payments. The tax increases at the 15-year threshold are smaller relative to the 10-year threshold since severance payments increase by 4 months' pay at the 10-year threshold and two months' pay at the 15-year threshold. Similarly, the increases at the 20 and 25 year threshold are based on 3 additional months' pay. At the annual frequency, the changes in implicit tax rates due to the severance payments are still very large because of the relatively generous pensions and high income taxes.

Combining the results in Panels A \& B yields the results in Panel C. In particular, even though the changes in retirements are clearly evident in the graphical evidence, we estimate relatively small labor supply elasticities because the financial incentives from the severance payments are very large. The elasticities with respect to implicit tax rates at the monthly frequency range from roughly 0.05 to 0.13 ; the elasticities at the quarterly frequency range from 0.08 to 0.21 and the elasticities at the annual frequency range from 0.16 to 0.38 . These elasticities are estimated with a high degree of precision as indicated by the relatively small standard errors. The high degree of precision in these estimates reflects that there is only a relatively small degree of error when estimating the specifications for the seasonally adjusted and counterfactual retirement frequencies and implicit tax rates. At a more broad level, the small standard errors result from having a large change in financial incentives at the tenure threshold, high quality administrative data with minimal measurement error, and a large sample size.

\section{Heterogeneity \& Accounting for Differences in Ob- servables}

The graphical analysis in Section 3 suggests that there is heterogeneity in the labor supply responses to the shifts in earnings from severance payments along several dimensions. In Table 3 we have seen that the estimated elasticities differ across tenure thresholds with the largest elasticities estimated at the 15 and 20 year thresholds, but significantly smaller estimated elasticities at the 10 and 25 year thresholds. In this section we explore differences in responsiveness by gender and differences across tenure thresholds in more detail. We start by estimating elasticities for separate sub-samples and then investigate whether differences in these estimates are driven by heterogeneity across other dimensions. To see how the gender and tenure dimensions of heterogeneity depend on differences in sample composition, 
we use a decomposition method based on re-weighting.

\subsection{Re-weighting Methods}

Our re-weighting strategy relies on methods introduced by and Fortin, Lemieux, Firpo (2010) and DiNardo, Fortin, Lemieux (1996). We first explain the strategy for the example of decomposing differences in elasticity estimates for men and women and then extend to the discussion of differences across the tenure thresholds.

We can apply the method of estimating extensive margin labor supply elasticities described in Section 4 to separate subsamples and estimate an elasticity for females and for males. As indicated by the graphical analysis, responses vary by gender as well as by other observable characteristics such as earnings, implicit tax rates, or firm size. As long as the distribution of these characteristics, e.g. the distribution of earnings varies by gender in our sample, the estimated elasticities for males and females also pick up heterogeneity in earnings. To abstract from compositional differences in the male and female samples in all observable characteristics $X$ we estimate elasticities based on re-weighted samples. Specifically, we generate a re-weighting factor $\Psi(X)$ that replaces the marginal distribution of $X$ for females and the marginal distribution of $X$ for males with the marginal distribution of $X$ in the overall population. Formally the re-weighting factors are given by

$$
\Psi(X)=\left\{\begin{array}{cc}
\frac{1}{\operatorname{Pr}(X \mid \text { Female }=1)}=\frac{\operatorname{Pr}(\text { Female }=1)}{\operatorname{Pr}(\text { Female }=1 \mid X)} & \text { for females } \\
\frac{1}{\operatorname{Pr}(X \mid \text { Male }=1)}=\frac{\operatorname{Pr}(\text { Male }=1)}{\operatorname{Pr}(\text { Male }=1 \mid X)} & \text { for males }
\end{array}\right.
$$

DiNardo, Fortin, Lemieux (1996) show that an estimate of $\Psi(X)$ can be generated based on the predictions $\hat{p}$ from a simple probit model for the probability for $\operatorname{Pr}($ Female $=1 \mid X)$. When estimating the probits for the re-weighting, we include a large set of observable characteristics. In particular, we include covariates $X$ based on age, calendar years, citizenship, industry, region, seasonality, earnings histories, firm size, health and experience. ${ }^{26}$

\footnotetext{
${ }^{26}$ The estimated probits include dummies for calendar year, age measured at a quarterly frequency, birth month, birth year, Austrian citizenship, quarter of the year, industry, region, firm size, blue collar job status, job starting month, health status between age 42 through age 54 , contribution years between age 42 through 54 , sick leave in the current quarter, unemployment in the current quarter, top-coded earnings, insurance years (interacted with gender), and real earnings. Firm size is grouped into the following categories: $\leq 5$, $6-10,11-25,26-99,100-499,500-999, \geq 1000$. Health status between age 42 through age 54 is based on the following categories of sick leave from age 42 through age $54: \leq 0.03$ years, $0.03-0.18$ years, $0.18-0.33$ years, and $\geq 0.33$ years. Health and unemployment in the current quarter are based on the following categories for sick leave and unemployment days in the current quarter: 0 days, $1-30$ days, $31-60$ days, and $\geq 61$ days. Contribution years between ages 42 through age 54 is based on the following
} 
Consequently, we generate weights defined by

$$
\hat{\Psi}\left(X_{i}\right)=\left\{\begin{array}{cc}
\frac{\overline{\hat{p}}}{\hat{p}_{i}} & \text { for females } \\
\frac{1-\overline{\hat{p}}}{1-\hat{p}_{i}} & \text { for males }
\end{array}\right.
$$

In the case of the four different tenure thresholds, we are concerned whether differences in the estimated labor supply elasticities are related to differences in sample compositions, that is, whether individuals with characteristics related to lower labor supply elasticities are more likely to be located around the 10 tenure year and 25 tenure year thresholds than at the other thresholds. We split the sample in four subsamples based on tenure intervals. Specifically we compare individuals with tenure between 6 and 12.5 years, 12.5 and 17.5 years, 17.5 and 22.5 , and 22.5 and 28 years of tenure; these non-overlapping groups cover all tenure levels illustrated in Figure 3. To these samples we apply a similar re-weighting strategy as before. Our goal now is to generate weights that replace the marginal distribution of $X$ in each of the tenure intervals with the marginal distribution of $X$ in the overall population. This is done by estimating four different probit models for the probabilities of belonging to each of the tenure intervals $I_{j}$ with $j=1, \ldots, 4$; we denote this probability for observation $i$ by $p_{i j}=\operatorname{Pr}\left(I_{j}=1 \mid X_{i}\right)$. From the probits, we obtain predicted probabilities $\hat{p}_{i j}$ for each observation $i$ in interval $j$. The weight for observation $i$ in interval $j$ is then given by

$$
\hat{\Psi}_{j}\left(X_{i}\right)=\frac{\overline{\hat{p}}_{j}}{\hat{p}_{i j}} .
$$

\subsection{Re-weighting Results}

Table 4 reports estimates for changes in retirements, changes in implicit tax rates, and the implied labor supply elasticities by gender across the different tenure thresholds. We see that while changes in implicit tax rates are generally smaller for women, their retirement responses are significantly larger than those for males across all thresholds. Consequently, we estimate larger labor supply elasticities for women than for men. The re-weighted results show how the estimates change when we replace the marginal distribution of observable characteristics among females and males to equal the marginal distribution of observables

categories of contribution years: $\leq 5$ years, $5-8$ years, $8-13$ years, and $=13$ years. Real earnings dummies are created by creating 25 percentiles based on average earnings between ages 42 through 54 .

For the tenure re-weighting, we exclude calendar year, birth year and contribution year dummies because of common support problems. For example, we do not observe many individuals with high contribution years at the lower tenure thresholds since these individuals are very likely to have higher tenure. 
in the overall population. Across all tenure thresholds the elasticities for men are now closer to those for women mainly due re-weighting the changes in implicit tax rates. However, a considerable difference in the labor supply elasticities across genders still remains. We conclude that gender is an important dimension of heterogeneity in labor supply responses even for the older population around retirement.

Tables 5A and B investigate differences in sample composition across tenure thresholds for men and women. We see from the sample sizes around each threshold that the gender composition is almost balanced across thresholds. The fraction of females is between $59 \%$ and $57 \%$, except at the 25 year threshold where males dominate. When we re-weight the male and female samples based on observable characteristics, we see that changing the marginal distribution of $X$ affects mainly the retirements or the magnitudes of the spikes in the frequency graphs; re-weighting does not change the distributions of income changes. The resulting elasticity estimates become more similar across thresholds for both the female and male samples, which implies that some of the differences in responsiveness across thresholds can be explained by composition effects. Using weights based on the relative sample sizes at each tenure threshold, we take weighted averages of the re-weighted elasticities and obtain an average elasticity of 0.12 for men and an average elasticity of 0.38 for women.

Even after re-weighting, the estimated elasticities decrease with the payment sizes so that the elasticity at the 10-year threshold is still significantly smaller than the elasticities at the other thresholds. This decreasing pattern in the elasticities suggests that there is some fraction of the population that is unresponsive to the severance pay incentives regardless of the size of the incentives. Additionally, the low elasticity estimate at the 10-year threshold might be a result from assuming that severance pay level jumps from zero to one quarter of the annual earnings at this threshold, which would be the largest jump in the schedule. Since individuals become eligible for severance pay due to layoffs after they complete lower tenure levels, some individuals may be able to negotiate mutual agreements with their employers so that they would retire with some severance pay rather than no severance pay. As a result, there would still be discontinuity at 10 years of tenure when people qualify for a larger payment, but the discontinuity at the 10-year threshold may be smaller than the mandated discontinuity. This issue would not affect the higher tenure thresholds since the severance pay schedules for layoffs and retirements are the same beyond 10 years of tenure. Thus we interpret the re-weighting results as eliminating the main differences in responsiveness across thresholds with the caveat that the elasticity at 
the 10 year threshold is potentially the least accurately estimated.

\subsection{Pre-Threshold Retirement Patterns}

The dynamic model of retirement decisions predicts shifts in retirements in response to severance payments relative to a scenario without severance pay. These shifts can lead to delays in retirement as well as advanced retirement. This is best highlighted in Figure 12A showing the hazard rates into retirement around the tenure threshold in both scenarios. The dip in the hazard rate prior to the tenure threshold results in retirement delays, which are shifted to the threshold tenure level because of financial incentives. Consequently, the hazard rate jumps to a higher level at the tenure threshold. After the tenure threshold the hazard rate continues to lie above the counterfactual scenario, because individuals retiring in any period after the threshold receive higher benefits. This increase in the hazard rate will advanced some retirements.

In this section we test the importance of delays in retirements relative to advanced retirements due to severance payments by examining the pre-threshold retirement patterns. In particular, we relate the increased retirement frequencies relative to the counterfactual scenario at the tenure thresholds to the reduced retirement frequencies before the threshold resulting from individuals delaying their retirements.

The estimation strategy compares seasonally adjusted retirement frequencies and retirement frequencies in the scenario without severance pay before and after each threshold. We start by setting a fixed number of months prior to each tenure threshold denoted by $\underline{m}$. Then we compute the number of delays in retirements by summing the differences between the counterfactual frequencies and the seasonally adjusted retirement frequencies in the $\underline{m}$ months prior to each tenure threshold $s_{i}^{*}$ with $i=1, \ldots 4$, corresponding to $10,15,20$, or 25 years of tenure,

$$
\text { \# of Delays }{ }_{s_{i}^{*}}=\sum_{k=1}^{\underline{m}}\left[\hat{n}_{s_{i}^{*}-k}-n_{s_{i}^{*}-k}^{a}\right]
$$

To compute excess retirements at each tenure threshold, we select a fixed number of months $\bar{m}$ and sum differences between the counterfactual frequencies and the seasonally adjusted frequencies in the $\bar{m}$ months after each threshold $s_{i}^{*}$,

$$
\text { \# of Excess Retirement }{ }_{s_{i}^{*}}=\sum_{k=1}^{\bar{m}}\left[n_{s_{i}^{*}+k}^{s a}-\hat{n}_{s_{i}^{*}+k}\right]
$$


Finally, we compute the ratio of the number of delayed retirements to the number of excess retirements to see what fraction of the excess retirements can be explained by delayed retirements,

$$
\text { Delay_Ratio }_{s_{i}^{*}}=\frac{\# \text { of Delays }}{s_{i}^{*}} \text { \# of Excess Retirement }_{s_{i}^{*}}=\frac{\sum_{k=1}^{m}\left[\hat{n}_{s_{i}^{*}-k}-n_{s_{i}^{*}-k}^{a}\right]}{\sum_{k=1}^{\bar{m}}\left[n_{s_{i}^{*}+k}^{a}-\hat{n}_{s_{i}^{*}+k}\right]} .
$$

Intuitively, if the number of delayed retirements dominates the number of advanced retirements, we would expect this ratio to be closer to 1 .

Table 6 presents the estimated values of Delay_Ratio separately by gender for each of the tenure thresholds. We also report estimates for different values of the pre-threshold number of months, $\underline{m}$. For the number of months included in the computation of excess retirements, we pick $\bar{m}=18$. The results show that for all estimates by gender and tenure threshold the delay ratio does not change significantly by increasing the number $\underline{m}$ above 18. In some cases it stays unchanged even with $\underline{m} \geq 12$. This implies that an upper bound for the length of time by which individuals are willing to delay their retirement in response to severance payments is one and a half year.

For the interpretation of the size of the Delay_Ratio we now focus on the estimates with $\underline{m}=12$. For men, the results indicate that delayed retirements prior to the 15 -year and 20-year thresholds account for all of the excess retirements as the ratio is close to 1. At the 10-year and 25-year thresholds, the delayed retirements account for about $60 \%$ of the total excess retirements. The 10-year threshold creates the largest increase in severance pay and the 25-year threshold is the last severance pay threshold.

For women, the results at the 10-year and 15-year thresholds indicate that the delayed retirements can primarily account for all of the excess retirements at those thresholds. The delayed retirements account for less of the excess retirements only at the 20-year threshold; since women retire at younger ages than men, the 20-year threshold may effectively be the last severance pay threshold that many women consider. Since there are few women close to the 25-year threshold, the results are noisier. Overall, while the severance payments may cause some advanced retirements at the last tenure thresholds, the estimates indicate that delayed retirements account for most if not all of the total effects of the severance payments. 


\subsection{Policy Relevance}

The elasticity of retirement entry with respect to the implicit tax rate is highly policy relevant as it plays a central role in predicting labor supply responses to potential social security reforms. To illustrate the policy relevance and to highlight the limited role of financial incentives in retirement decisions, we choose a simple policy example designed to provide an incentive for individuals to delay their retirement past the popular retirement age of 60 . We use the estimated labor supply elasticities from above to predict responses to this hypothetical social security change in a simple calculation. Specifically, the policy introduced by the government is a one-time, lump-sum bonus of 5000 euros paid to individuals who retire at age 61 or older. After re-calculating the implicit tax rates with the retirement bonus, this policy translates into roughly a 109\% decrease in the net-of-tax rate, i.e. the median $1-\tau$ changes from 0.2203 to -0.0205 . Next, the estimated elasticities from above can be used to translate this change in the net-of-tax rate into a change in the probability of retirement at age 61 . Using the estimate of $\hat{e}=0.25$ for the elasticity ${ }^{27}$, the hypothetical policy change implies roughly a $27 \%(=\hat{e} * d \ln (1-\tau)=0.25 * 1.09)$ increase in the probability of retirement at age 61 . The retirement frequencies observed in the data indicate a baseline probability of retirement at age 61 equal to 0.1035 as 23,950 individuals out of the sample of 231,251 individuals retire at 61 . In response to the hypothetical policy change, this probability increases by $27 \%$ to about 0.1318 , implying that the new retirement bonus would cause an additional $6,545(=(0.1318-0.1035) * 231,251)$ individuals to retire at 61 . Based on the evidence from the severance payments, it is likely that these additional retirements at 61 would results from individuals delaying their retirements from age 60 .

Figure 15 illustrates the retirement frequencies by age under the baseline and hypothetical policy regimes. The plot illustrates that the hypothetical policy is predicted to increases the number of retirements at age 61. Additionally, the plot highlights that, even in the presence of high-powered financial incentives from the retirement bonus, the spike in retirements at age 60 would continue to persist. In particular, even with the extreme assumption that all of the excess retirements at age 61 would come from retirements at age 60 , the spike at age 60 only decreases by roughly $11 \%\left(=\frac{-6,545}{60016}\right)$.

The policy example demonstrates how the estimated elasticities can be used to translate the reactions to a one-time benefit payment into labor force participation responses in a

\footnotetext{
${ }^{27}>$ From Table 5, the weighted averages of the re-weighted elasticities are 0.12 for men and 0.38 for women; taking the raw average of these numbers yields the estimate of 0.25 .
} 
straight forward way. The estimates can also be used to simulate responses to policies such as changes in the pension benefit schedule at certain ages or the introduction of pension penalties for early retirement. These policies would affect long-term annuity payments after retirement instead of providing a one-time financial incentive. To simulate responses to this type of policy based on the current results, one could use a dynamic model with endogenous consumption decisions to translate changes in annuity payments into changes in consumption and implicit tax rates. Intuitively, once we have a model of how individuals smooth consumption over time, we can relate the present value of a hypothetical change in long-term annuity payments to a lump-sum payment and then simulate labor supply responses using the estimated elasticities.

\section{Conclusions}

Using responses to policy discontinuities in retirement benefits in Austria, this paper provides new empirical evidence on the effects of financial incentives on retirement decisions. We first present nonparametric graphical evidence clearly documenting individuals' labor supply responses to the policy discontinuities. Next, we develop a strategy to estimate extensive margin labor supply elasticities nonparametrically. The strategy exploits the observed retirement responses to the policy discontinuities and relates the changes in the retirement patterns to changes in the implicit tax rates on working at the policy discontinuities. The estimation results indicate relatively low labor supply elasticities that are driven primarily by individuals delaying their retirement dates to qualify for (larger) severance payments. Furthermore, the estimated elasticities suggest that older workers and

prime-age workers are similar in that both groups appear to be relatively inelastic in their labor supply decisions.

While the estimated elasticities reflect a low responsiveness to financial incentives at the time of retirement, we also emphasize the graphical evidence on job starts be age. The job start patterns show no evidence that individuals time their job starts in response to financial incentives at retirement from the severance payments. This evidence is relevant for models of responses to retirement benefits as it indicates that, while individuals are forward-looking, labor supply responses to retirement benefits appear to be concentrated at older ages around the time of retirement.

Our results are policy relevant as they suggest that, while financial incentives do affect retirement decisions, it may be difficult for policy to alter observed patterns by age using 
only financial incentives as a policy instrument. Thus, future research may seek to focus on the role of norms or other factors beyond financial incentives that could be used as alternative or additional policy instruments. 


\section{References}

Blundell, R., A. Bozio, and G. Laroque (2011). Labor Supply and the Extensive Margin. American Economic Review 101 (3), 482-86.

Burtless, G. and R. A. Moffitt (1985). The Joint Choice of Retirement Age and the Postretirement Hours of Work. Journal of Labor Economics 3(2), 209-236.

Card, D., R. Chetty, and A. Weber (2007). Cash-on-Hand and Competing Models of Intertemporal Behavior: New Evidence from the Labor Market. Quarterly Journal of Economics 122(4), 1511-1560.

Chang, Y., S.-B. Kim, K. Kwon, and R. Rogerson (2011). Interpreting Labor Supply Regressions in a Model of Full- and Part-Time Work. American Economic Review $101(3), 476-81$.

Chetty, R., J. Friedman, T. Olsen, and L. Pistaferri (2010). Adjustment Costs, Firm Responses, and Labor Supply Elasticities: Evidence from Danish Tax Records. Quarterly Journal of Economics (forthcoming).

Chetty, R., A. Guren, D. Manoli, and A. Weber (2011). Are Micro and Macro Labor Supply Elasticities Consistent? A Review of Evidence on the Intensive and Extensive Margins. American Economic Review 101 (3), 471-475.

Coile, C. and J. Gruber (2007). Future social security entitlements and the retirement decision. Review of Economics and Statistics 89(2), 234-246.

DiNardo, J., N. Fortin, and T. Lemieux (1996). Labor Market Institutions and the Distribution of Wages, 1973-1992: A Semiparametric Approach. Econometrica 64(5), 1001-1044.

Fortin, N., T. Lemieux, and S. Firpo (2010). Decomposition methods in economics. In O. Ashenfelter and D. Card (Eds.), Handbook of Labor Economics, Volume 4 of Handbook of Labor Economics. Elsevier.

French, E. (2005). The Effects of Health, Wealth, and Wages on Labor Supply and Retirement Behavior. Review of Economic Studies 72, 395-427.

Friedberg, L. (2000). The Labor Supply Effects of the Social Security Earnings Test. Review of Economics and Statistics 82(1), 48-63.

Gustman, T. and L. T. Steinmeier (1985). The 1983 social security reforms and labor supply adjustments of older individuals in the long run. Journal of Labor Economics 3(2), 
$237-253$.

Hall, P., J. L. Horowitz, and B.-Y. Jing (1995). On Blocking Rules for the Bootstrap with Dependent Data. Biometrika 82(3), 561-574.

Liebman, J. B., E. F. Luttmer, and D. G. Seif (2009). Labor supply responses to marginal social security benefits: Evidence from discontinuities. Journal of Public Economics 93, 1208-1223.

Ljungqvist, L. and T. J. Sargent (2011). A Labor Supply Elasticity Accord? American Economic Review 101(3), 487-91.

Lunsdaine, R. L., J. H. Stock, and D. A. Wise (1996). Why are retirement rates so high at age 65? In D. A. Wise (Ed.), Advances in the Economics of Ageing, pp. 61-82. University of Chicago Press.

Rust, J. and C. Phelan (1997). How Social Security and Medicare Affect Retirement Behavior in a World of Incomplete Markets. Econometrica 65(4), 781-831.

Saez, E. (1999). Do taxpayers bunch at kink points? Working Paper 7366, National Bureau of Economic Research.

Saez, E. (2010). Do Taxpayers Bunch at Kink Points? American Economic Journal: Economic Policy 2(3), 180-212.

Stock, J. H. and D. A. Wise (1990). Pensions, the Option Value of Work, and Retirement. Econometrica 58(5), 1151-1180.

Zweimüller, J., R. Winter-Ebmer, R. Lalive, A. Kuhn, J.-P. Wuellrich, O. Ruf, and S. Büchi (2009). Austrian social security database. NRN: The Austrian Center for Labor Economics and the Analysis of the Welfare State (Working Paper 0903). 


\section{Appendix A: Sample restrictions}

We start with the sample of individuals who have any entry as employed or retired in the ASSD, who were born from 1930 to 1940, and who have Austrian nationality. On this sample we impose a series of restrictions, which are summarized in Table 1. First, we consider only individuals who are still employed after age 55 . This restriction reduces the sample considerably, as we exclude individuals who moved to self-employment, left the country, or who had only a loose attachment to the labor force and left at a younger age. We also exclude individuals who ever worked as civil servants, as they are covered by a different pension scheme. The construction sector has a different severance pay regulation that takes the highly seasonal nature of jobs into account. Therefore we also excludes workers whose last job was in the construction industry. To get an accurate measure of tenure at retirement we have to restrict the sample to individuals who started their last job spell after 1972, which is when the employer identifiers are first recorded. We also exclude

workers with a gap between exit from the last job and start of claiming pension benefits that is longer than 6 months to focus on the link between severance pay and financial incentives from the pension system. Finally we restrict the sample to individuals with last earnings below the social security contribution cap. The reason is that we can only compute the implicit tax rate for uncensored earnings. See Appendix B.

\section{Appendix B: Construction of implicit tax rates}

The social security data report gross annual earnings at the individual level for each year and employer. To compute implicit tax rates we need information on pension benefits plus wages and pensions net of social security contributions and income taxes.

We use the following procedure to generate estimates of these additional variables: First, we calculate the pension benefit that the individual would receive if they retired in the current year based on earnings and employment histories according to the legislation of the pension system. We start calculating pensions in the year when the individual turns 55 up to the year of actual retirement. Second, we use information from tax records available for the years 1994-2005 to estimate the corresponding net wages and net pensions for our sample. In Austria taxes and social security contributions are withheld from wages or pensions for individuals who are in regular employment or who receive a governmentprovided pension. The tax records contain reports from each employer and tax agency to the treasury about gross earnings and take home pay. If an individual earns income from 
more than one employer they typically have to file income taxes at the end of the year, which is not available to us. Our tax records cover gross annual earnings separately for wages and pensions, social security contributions, and taxes that are withheld from the earnings and thus allow us to compute social security contribution rates and average tax rates for several income groups.

The ASSD reports gross earnings after the employer's share of social security contributions has been paid. Then the employee's share of social security contributions is deducted from the gross earnings and finally income taxes are withheld. The employee's contribution share covers health insurance, pension insurance, unemployment insurance and contributions to health insurance for retirees. The rates are constant across individuals and hardly change over time. We use average social security contribution rates from the tax files, which are $\mathbf{1 7 . 5 \%}$ for employees and $3.8 \%$ for retired workers. Taxes are based on gross earnings minus social security contributions. The tax schedule is progressive and is applied to the tax basis after individual deductions. Because these deductions vary by family composition and other characteristics unobservable to us, we estimate separate average tax rates for women and men, employed and retired workers. Over time tax rates and brackets were repeatedly adjusted to wage growth. We therefore divide the observable period into three different tax regimes, which cover the most important tax reforms: before 1996, 1996-2000, after 2000 .

The sample used for estimating average tax rates consists of all earnings records of wages and pensions of individuals born between 1930 and 1940 who are covered in the 1994 - 2005 tax records. We restrict the observations to earnings below the contribution cap, because of censoring in the social security data. To limit the problem with multiple records per individual we only consider records for income that was received for the full calender year. For each tax regime we pick one representative year: 1994, 1999, 2003. Then we compute 20 percentiles in each of these years to get a representative distribution of gross wages and pensions. Next we categorize the earnings in each regime according to the percentile distribution and compute in each earnings cell the average tax rates for men, women, wages, and pensions by the average ratio of taxes to gross wages minus social security contributions. The median of average tax rates increases from the first to the third tax regime from about $11 \%$ to $13 \%$ for wage income and from $7 \%$ to $9 \%$ for pension income. In all groups taxes on female earnings are slightly above taxes for males. The maximum average tax rates reach $20 \%$.

In the final step we apply the average tax rates to wage earnings and simulated pension 
benefits for the individuals of our retirement sample and compute implicit tax rates as

$$
\begin{aligned}
(1-\tau) g r o s s \_e a r n & =\text { gross_earn }- \text { ss_contrib-inc_tax }- \text { pension } \\
& \Rightarrow \tau=\frac{\text { ss_contrib+inc_tax }+ \text { pension }}{\text { gross_earn }} . \\
\tau & =1-\frac{\text { net_wage }- \text { net_pension }}{\text { gross_wage }} .
\end{aligned}
$$

\section{Appendix C: Model Simulations}

This appendix describes the assumptions and procedures used to simulate the optimal stopping time model described in the main text.

We assume that retirement decisions are made at a quarterly frequency from age 55 through age 65 (i.e. everyone is assumed to be retired at age 66). For simplicity, we assume that there is no uncertainty due to mortality; all individuals live to age 85 with certainty. The (quarterly) discount factor is $\beta=0.40^{1 / 4}$. We specify the utility function as $u(c)=\frac{c^{1-\gamma}}{1-\gamma}$ with $\gamma=0.5$. Quarterly earnings are $y=\frac{20}{4}$. Quarterly retirement benefits at age 55 are $b_{55}=\frac{12}{4}$; for individuals retiring beyond age 55 , retirement benefits increase by $1 \%$ with each additional quarter of age beyond age 55 . This increases in retirement benefits with retirement age continues up to a maximum level of retirement benefits equal to $0.99 y$. For the disutility of work $\alpha_{t}$, we set $\rho=0$ and $F_{t}$ as a uniform distribution over 0 and $\alpha^{H}$; to ensure that the disutility of work is on a similar scale as consumption (i.e. to avoid scenarios in which all individuals work or all individuals retire), the mean of this uniform distribution is set to $\eta_{t}=\frac{[0.04 * y]^{1-\gamma}}{1-\gamma}$ and $\alpha^{H}=2 \eta_{t}$. Next, following the rules of the Austrian severance pay system, we specify the severance payment amounts based on tenure and annual earnings. For expositional purposes, we scale the severance pay amounts by 0.25 (i.e. $S \tilde{P}=0.25 * S P$ ).

To run the simulation, we specify the number of simulated individuals $N_{0}=10,000$. For each individual, we draw initial tenure from a uniform distribution over [0,15]; we round tenure to the nearest quarter so that tenure is computed at a quarterly frequency. Given the parameter values and distributional assumptions above, we compute compute the individual's value functions recursively and solve for the individual's optimal retirement decision. In each period that the individual continues working, tenure and age both increase by 0.25 and the work disutility $\alpha_{t}$ is randomly drawn from the uniform distrib- 
ution described above. Once the simulated individual retires, we record the individual's retirement age, retirement tenure, work disutility $\left(\alpha_{t}\right)$ and reservation disutility $\left(\bar{\alpha}_{t}\right)$ and then continue to solve for the next simulated individual's retirement outcome.

\section{Appendix D: Estimation Procedures}

\section{Regression specifications}

We estimate a seasonally adjusted function of the observed retirement frequencies $n_{s}$ by tenure $s$, as illustrated in Figure 3 based on the following regression

$$
\begin{aligned}
n_{s} & =\sum_{i=1}^{5} g_{i}(s) *\left(T I_{i}\right)+\sum_{i=1}^{4} \beta_{i} * 1\left(s=s_{i}^{*}\right) \\
& +\sum_{i=1}^{4} \gamma_{i} * 1\left(s=s_{i}^{*}-24 \mid s=s_{i}^{*}+24\right)+\varepsilon_{s} .
\end{aligned}
$$

In this specification, $g_{1}(s), \ldots, g_{5}(s)$ are 4 th order polynomials in tenure at retirement defined on separate tenure intervals given by $T I_{1}=\left\{s \leq s_{1}^{*}\right\}, T I_{2}=\left\{s>s_{1}^{*} \& s \leq\right.$ $\left.s_{2}^{*}\right\}, \ldots, T I_{5}=\left\{s>s_{4}^{*}\right\}$ so that we estimate separate continuous functions between each severance pay threshold. We also include dummies at integer values around the tenure thresholds to capture seasonal effects at the tenure thresholds; i.e., some of the spike at 10 years of tenure may be drive by 10 years being an integer value of tenure. In addition, we use integer values at $+/-2$ years before and after the threshold rather than at $+/-1$ year because some of the seasonal effects at $+/-1$ year around the thresholds may be more likely to be affected by the severance pay thresholds. Lastly, we include dummies for tenure exactly equal to the tenure thresholds to capture the discontinuous increases in the retirement frequencies exactly at the severance pay thresholds. After estimating this regression, we obtain the seasonally adjusted frequencies, denoted by $n_{s}^{a}$, by setting all of the dummies to 0 and predicting retirement frequencies using only the estimated continuous polynomial functions, $\hat{g}_{1}(s), \ldots, \hat{g}_{5}(s)$. The frequencies exactly at the severance pay thresholds are then set to $n_{s}^{a}=\hat{\beta}_{s}-\hat{\gamma}_{s}$ for $s=s_{1}^{*}$ to capture the discontinuous increases at the severance pay thresholds while still netting out any seasonal effects at the thresholds. We re-scale the seasonally adjusted frequencies so that the total number of retirements is preserved. 
The counterfactual frequencies are estimated using the following regression specification,

$$
n_{s}^{a}=g(s)+\sum_{i=1}^{4} \sum_{k=-18}^{18} \alpha_{s_{i}^{*}+k} 1\left(s=s_{i}^{*}+k\right)+\eta_{s}^{a}
$$

In this specification, $g(s)$ is a 6 th order polynomial in tenure at retirement and the remaining indicator variables are dummies for tenure levels $+/-18$ months around the tenure thresholds. After estimating this regression, the counterfactual frequencies are obtained by setting the indicator variables to 0 and predicting retirement frequencies using only $\hat{g}(s)$. We re-scale these predicted counterfactuals so that the total number of counterfactual retirements is equal to the total number of observed retirements and denote the counterfactual frequencies by $\hat{n}_{s}$.

the fraction of the last year's salary that determines additional severance pay income; following Figure 1, $S P_{i}$ is given by

$$
S P_{i}= \begin{cases}\left(\frac{4}{12}-0\right) y & \text { if } s^{*}=10 \text { years } \\ \left(\frac{6}{12}-\frac{4}{12}\right) y & \text { if } s^{*}=15 \text { years } \\ \left(\frac{9}{12}-\frac{6}{12}\right) y & \text { if } s^{*}=20 \text { years } \\ \left(\frac{12}{12}-\frac{9}{12}\right) y & \text { if } s^{*}=15 \text { years }\end{cases}
$$

Next, we account for differences in sample composition due to seasonality by estimating the following regression

$$
\tau_{s}=f(s)+\sum_{i=1}^{4} \sum_{k=-18}^{18} \alpha_{s_{i}^{*}+k} 1\left(s=s_{i}^{*}+k\right)+\eta_{s}^{\tau}
$$

where $f(s)$ is a 6th order polynomial in tenure at retirement and the remaining indicator variables are dummies for tenure levels $+/-18$ months around the tenure thresholds. After estimating this regression, the seasonally adjusted implicit tax rates are obtained by setting the indicator variables to 0 and predicting retirement frequencies using only $\hat{f}(s)$. We denote these seasonally adjusted implicit tax rates by $\hat{\tau}_{s}$.

\section{Bootstrap procedure}

Specifically, from the regression model specifying the seasonally adjusted frequencies, equation (10), we obtain the estimated residuals $\hat{\varepsilon}_{s}$. We draw a new set of errors for each level of tenure, $\hat{\varepsilon}_{s}^{b}$, by sampling from the estimated residuals with replacement. We draw these new errors in blocks of 12 beginning at each integer value of tenure at retirement so 
that we account for the seasonal error structure. We then create bootstrapped retirement frequencies by adding the new set of errors to the seasonally adjusted retirement frequencies, $n_{s}^{b}=n_{s}^{a}+\hat{\varepsilon}_{s}^{b}$. We use the bootstrapped retirement frequencies and follow the same steps above to compute a new estimate for the change in retirements. This bootstrap procedure is repeated 1000 times; the standard error for the change in retirements is estimated by computing the standard deviation of the 1000 estimates.

The standard errors for the changes in implicit tax rates are computed using a block bootstrap procedure similar to the procedure described above for the changes in retirements. After estimating the regression to adjust for seasonal composition changes, we obtain the estimated residuals $\hat{\eta}_{t}^{\tau}$. We draw a new set of errors for each level of tenure, $\hat{\eta}_{s}^{\tau, b}$, by sampling from the estimated residuals with replacement. We draw these new errors in blocks of 12 beginning at each integer value of tenure at retirement so that we account for the seasonal error structure. We add then create bootstrapped implicit tax rates by adding the new set of errors to the seasonally adjusted implicit tax rates, $\tau_{s}^{b}=\hat{\tau}_{s}+\hat{\eta}_{s}^{\tau, b}$. We use the bootstrapped tax rates and follow the same steps above to compute a new estimate for the change in implicit tax rates. This bootstrap procedure is repeated 1000 times; the standard error for the change in implicit tax rates is estimated by computing the standard deviation of the 1000 estimates.

Sensitivity to parametric assumptions

We have examined the sensitivity of the estimation strategy to alternative windows around the tenure thresholds and polynomial specifications. First, while the estimation strategy estimates the counterfactual distribution of tenure at retirement using dummies for $+/-18$ months around the tenure thresholds, we have explored alternative specifications using dummies for 6,12 , and 24 months around the tenure thresholds. Figure A1 illustrates the estimated counterfactual distribution of tenure at retirement under these alternative windows around the tenure thresholds. As illustrated, the estimation strategy is not significantly affected by these alternative tenure windows. Intuitively, once the spikes and dips immediately before and after the tenure thresholds are accounted for, there are sufficiently many points between the tenure thresholds such that the estimated counterfactual frequencies are relatively stable. Second, while the estimation strategy estimates 4th order polynomials for the polynomials between the separate tenure intervals (i.e. $g_{1}(s) \ldots, g_{5}(s)$ ), we have also estimated the counterfactuals using 2nd, 6th and 8th order polynomials. Figure A2 illustrate the estimated counterfactual distribution of tenure at retirement under these alternative polynomial specifications. As illustrated, the estimation strategy is sen- 
sitive to using lower order polynomials. However, beyond the 4 th order polynomials, the counterfactuals are significantly affected by using higher order polynomials. Intuitively, the 4th order polynomials appear to be sufficiently flexible to capture the patterns in the retirement frequencies between the tenure thresholds. Thus, the counterfactuals estimated using the 4 th order polynomials are robust. 
Table 1

Sample Selection

\begin{tabular}{lcc}
\hline \hline & Number of Individuals & $\begin{array}{c}\text { Percentage } \\
\text { change }\end{array}$ \\
\hline Individuals in cohorts born 1930 - 1940 & $1,578,549$ & $-59 \%$ \\
Still employed at age 55 & 651,336 & $-4 \%$ \\
More than one year employment experience before age 55 & 625,251 & $-13 \%$ \\
Excluding workers ever employed as civil servant & 546,308 & $-11 \%$ \\
Excluding workers withlast job in construction & 487,019 & $-22 \%$ \\
Excluding left censored tenure in last job & 380,737 & $-29 \%$ \\
Workers retiring withing 6 months of their last job & 269,411 & $-14 \%$ \\
Excluding individuals with un-censored earnings at retirement & 231,251 & \\
& & \\
\hline \hline
\end{tabular}

Notes: Numbers based on the ASSD 
Table 2: Summary Statistics

\begin{tabular}{|c|c|c|}
\hline & Full Sample & Estimation Sample \\
\hline \# of Individuals & 231,251 & 155,283 \\
\hline Fraction Female & 0.53 & 0.57 \\
\hline \multirow[t]{3}{*}{ Retirement Age } & 58.43 & 58.41 \\
\hline & 58.50 & 58.50 \\
\hline & 2.51 & 2.52 \\
\hline \multirow[t]{3}{*}{ Tenure } & 11.00 & 14.68 \\
\hline & 10.42 & 14.17 \\
\hline & 7.59 & 5.50 \\
\hline \multirow[t]{3}{*}{ Annual Earnings } & 24666.68 & 25646.12 \\
\hline & 23950.24 & 24821.64 \\
\hline & 10923.06 & 10280.21 \\
\hline \multirow[t]{3}{*}{ Implicit Tax Rate } & 0.81 & 0.79 \\
\hline & 0.78 & 0.77 \\
\hline & 0.28 & 0.22 \\
\hline \multirow[t]{3}{*}{ Years of Employment } & 32.40 & 33.10 \\
\hline & 34.13 & 34.51 \\
\hline & 9.45 & 8.71 \\
\hline \multirow[t]{3}{*}{ Years of Unemployment } & 0.55 & 0.28 \\
\hline & 0.00 & 0.00 \\
\hline & 1.23 & 0.66 \\
\hline \multirow[t]{3}{*}{ Years of Sick Leave } & 0.21 & 0.20 \\
\hline & 0.05 & 0.04 \\
\hline & 0.36 & 0.35 \\
\hline \multirow[t]{3}{*}{ Firm Size } & 1690.73 & 2186.98 \\
\hline & 86.00 & 129.00 \\
\hline & 4919.57 & 5635.91 \\
\hline \multicolumn{3}{|l|}{ Fractions: } \\
\hline Claiming Disability Pensions & 0.303 & 0.271 \\
\hline Claiming Early Retirement Pensions & 0.354 & 0.360 \\
\hline Claiming Old Age Pensions & 0.343 & 0.369 \\
\hline Agriculture \& Mining & 0.045 & 0.036 \\
\hline Manufacturing & 0.249 & 0.245 \\
\hline Sales & 0.190 & 0.178 \\
\hline Tourism & 0.048 & 0.028 \\
\hline Transportation & 0.054 & 0.048 \\
\hline Services & 0.415 & 0.466 \\
\hline
\end{tabular}

Notes: Except for the Fractions, the mean, median and standard deviations are reported for each variable. All earnings variables are expressed in 2008 euros. The Estimation Sample consists of individuals with at least 6 years of tenure at retirement but not more than 28 years of tenure at retirement. 
Table 3: Participation Elasticities by Tenure Thresholds

\begin{tabular}{|c|c|c|c|c|}
\hline \multicolumn{5}{|c|}{ Panel A: Changes in Retirements (dp/p) } \\
\hline Frequency & 10 Year Threshold & 15 Year Threshold & 20 Year Threshold & 25 Year Threshold \\
\hline Monthly, m=1 & $\begin{array}{r}0.8436 \\
(0.0514)\end{array}$ & $\begin{array}{r}1.1225 \\
(0.0342)\end{array}$ & $\begin{array}{r}1.1708 \\
(0.0581)\end{array}$ & $\begin{array}{r}1.2641 \\
(0.1245)\end{array}$ \\
\hline Quarterly, m=3 & $\begin{array}{r}0.4649 \\
(0.0231)\end{array}$ & $\begin{array}{r}0.5789 \\
(0.0220)\end{array}$ & $\begin{array}{r}0.6941 \\
(0.0377)\end{array}$ & $\begin{array}{r}0.6934 \\
(0.0791)\end{array}$ \\
\hline Annual, $m=12$ & $\begin{array}{r}0.2232 \\
(0.0130)\end{array}$ & $\begin{array}{r}0.2695 \\
(0.0166)\end{array}$ & $\begin{array}{r}0.3735 \\
(0.0247)\end{array}$ & $\begin{array}{r}0.3878 \\
(0.0604)\end{array}$ \\
\hline \multicolumn{5}{|c|}{ Panel B: Changes in Impicit Tax Rates (dy/y) } \\
\hline Frequency & 10 Year Threshold & 15 Year Threshold & 20 Year Threshold & 25 Year Threshold \\
\hline Monthly, $m=1$ & $\begin{array}{r}16.4315 \\
(0.2506)\end{array}$ & $\begin{array}{r}8.3984 \\
(0.1133)\end{array}$ & $\begin{array}{r}14.1021 \\
(0.2161)\end{array}$ & $\begin{array}{r}16.9955 \\
(0.4800)\end{array}$ \\
\hline Quarterly, $m=3$ & $\begin{array}{r}5.4723 \\
(0.0834)\end{array}$ & $\begin{array}{r}2.8032 \\
(0.0379)\end{array}$ & $\begin{array}{r}4.7120 \\
(0.0730)\end{array}$ & $\begin{array}{r}5.6893 \\
(0.1599)\end{array}$ \\
\hline Annual, $m=12$ & $\begin{array}{r}1.3638 \\
(0.0205)\end{array}$ & $\begin{array}{r}0.7053 \\
(0.0096)\end{array}$ & $\begin{array}{r}1.1912 \\
(0.0195)\end{array}$ & $\begin{array}{r}1.4513 \\
(0.0393)\end{array}$ \\
\hline \multicolumn{5}{|c|}{ Panel C: Elasticities (e) } \\
\hline Frequency & 10 Year Threshold & 15 Year Threshold & 20 Year Threshold & 25 Year Threshold \\
\hline Monthly, m=1 & $\begin{array}{r}0.0513 \\
(0.0032)\end{array}$ & $\begin{array}{r}0.1337 \\
(0.0045)\end{array}$ & $\begin{array}{r}0.0830 \\
(0.0042)\end{array}$ & $\begin{array}{r}0.0744 \\
(0.0077)\end{array}$ \\
\hline Quarterly, m=3 & $\begin{array}{r}0.0849 \\
(0.0045)\end{array}$ & $\begin{array}{r}0.2065 \\
(0.0086)\end{array}$ & $\begin{array}{r}0.1473 \\
(0.0083)\end{array}$ & $\begin{array}{r}0.1219 \\
(0.0146)\end{array}$ \\
\hline Annual, $m=12$ & $\begin{array}{r}0.1637 \\
(0.0102)\end{array}$ & $\begin{array}{r}0.3821 \\
(0.0249)\end{array}$ & $\begin{array}{r}0.3136 \\
(0.0218)\end{array}$ & $\begin{array}{r}0.2672 \\
(0.0436)\end{array}$ \\
\hline $\mathrm{N}$ & 61,999 & 44,900 & 32,607 & 15,777 \\
\hline
\end{tabular}

Notes: Numbers in parentheses are bootstrapped standard errors based on 1000 replications. 


\begin{tabular}{|c|c|c|c|c|}
\hline \multicolumn{5}{|c|}{ Panel A: Changes in Retirements (dp/p) } \\
\hline & 10 Year Threshold & 15 Year Threshold & 20 Year Threshold & 25 Year Threshold \\
\hline \multirow[t]{2}{*}{ Men } & 0.1702 & 0.1707 & 0.2509 & 0.3441 \\
\hline & $(0.0116)$ & $(0.0155)$ & (0.0199) & $(0.0413)$ \\
\hline \multirow[t]{2}{*}{ Women } & 0.2593 & 0.3387 & 0.4678 & 0.4477 \\
\hline & $(0.0166)$ & $(0.0206)$ & $(0.0313)$ & $(0.0961)$ \\
\hline \multirow[t]{2}{*}{ Re-weighted Men } & 0.1965 & 0.1742 & 0.2177 & 0.2670 \\
\hline & $(0.0143)$ & $(0.0219)$ & $(0.0284)$ & $(0.0427)$ \\
\hline \multirow[t]{2}{*}{ Re-weighted Women } & 0.3067 & 0.3156 & 0.4826 & 0.4311 \\
\hline & $(0.0201)$ & $(0.0234)$ & $(0.0354)$ & $(0.0975)$ \\
\hline \multicolumn{5}{|c|}{ Panel B: Changes in Implicit Tax Rates (dy/y) } \\
\hline & 10 Year Threshold & 15 Year Threshold & 20 Year Threshold & 25 Year Threshold \\
\hline \multirow[t]{2}{*}{ Men } & 1.9769 & 0.9471 & 1.4253 & 1.5524 \\
\hline & $(0.0489)$ & $(0.0176)$ & $(0.0373)$ & $(0.0625)$ \\
\hline \multirow[t]{2}{*}{ Women } & 1.1076 & 0.5961 & 1.0539 & 1.3566 \\
\hline & $(0.0126)$ & $(0.0071)$ & $(0.0122)$ & $(0.0261)$ \\
\hline \multirow[t]{2}{*}{ Re-weighted Men } & 1.5211 & 0.7815 & 1.2204 & 1.3959 \\
\hline & $(0.0533)$ & $(0.0245)$ & $(0.0341)$ & $(0.0578)$ \\
\hline \multirow[t]{2}{*}{ Re-weighted Women } & 1.0205 & 0.5961 & 1.1290 & 1.5163 \\
\hline & $(0.0186)$ & $(0.0092)$ & (0.0181) & $(0.0443)$ \\
\hline \multicolumn{5}{|c|}{ Panel C: Elasticities (e) } \\
\hline & 10 Year Threshold & 15 Year Threshold & 20 Year Threshold & 25 Year Threshold \\
\hline \multirow[t]{2}{*}{ Men } & 0.0861 & 0.1802 & 0.1761 & 0.2216 \\
\hline & $(0.0064)$ & $(0.0170)$ & (0.0149) & $(0.0301)$ \\
\hline \multirow[t]{2}{*}{ Women } & 0.2341 & 0.5682 & 0.4439 & 0.3300 \\
\hline & (0.0149) & $(0.0348)$ & $(0.0306)$ & $(0.0719)$ \\
\hline \multirow[t]{2}{*}{ Re-weighted Men } & 0.1292 & 0.2229 & 0.1784 & 0.1913 \\
\hline & $(0.0103)$ & $(0.0287)$ & $(0.0235)$ & $(0.0335)$ \\
\hline \multirow[t]{2}{*}{ Re-weighted Women } & 0.3006 & 0.5294 & 0.4275 & 0.2843 \\
\hline & $(0.0190)$ & $(0.0384)$ & $(0.0302)$ & $(0.0631)$ \\
\hline \multicolumn{5}{|c|}{ Panel D: Sample Sizes (N) } \\
\hline & 10 Year Threshold & 15 Year Threshold & 20 Year Threshold & 25 Year Threshold \\
\hline Men & 26,781 & 18,377 & 13,799 & 8,289 \\
\hline Women & 35,218 & 26,523 & 18,808 & 7,488 \\
\hline
\end{tabular}

Notes: Numbers in parentheses are bootstrapped standard errors based on 1000 replications. For the reweighted results, the weights are based on differences in observables across gender groups. 
Table 5A: Heterogeneity across Tenure Thresholds, Annual Frequency, Men

\begin{tabular}{|c|c|c|c|c|}
\hline \multicolumn{5}{|c|}{ Panel A: Changes in Retirements (dp/p) } \\
\hline & 10 Year Threshold & 15 Year Threshold & 20 Year Threshold & 25 Year Threshold \\
\hline \multirow[t]{2}{*}{ Unweighted } & 0.1702 & 0.1707 & 0.2509 & 0.3441 \\
\hline & $(0.0116)$ & $(0.0155)$ & (0.0199) & $(0.0413)$ \\
\hline \multirow[t]{2}{*}{ Re-weighted } & 0.1924 & 0.1380 & 0.1648 & 0.2418 \\
\hline & (0.0199) & $(0.0233)$ & $(0.0273)$ & $(0.0590)$ \\
\hline \multicolumn{5}{|c|}{ Panel B: Changes in Implicit Tax Rates (dy/y) } \\
\hline & 10 Year Threshold & 15 Year Threshold & 20 Year Threshold & 25 Year Threshold \\
\hline \multirow[t]{2}{*}{ Unweighted } & 1.9769 & 0.9471 & 1.4253 & 1.5524 \\
\hline & $(0.0489)$ & $(0.0176)$ & $(0.0373)$ & $(0.0625)$ \\
\hline \multirow{2}{*}{ Re-weighted } & 1.9744 & 0.9219 & 1.4122 & 1.6377 \\
\hline & $(0.0442)$ & $(0.0188)$ & $(0.0497)$ & $(0.1155)$ \\
\hline \multicolumn{5}{|c|}{ Panel C: Elasticities (e) } \\
\hline & 10 Year Threshold & 15 Year Threshold & 20 Year Threshold & 25 Year Threshold \\
\hline \multirow[t]{2}{*}{ Unweighted } & 0.0861 & 0.1802 & 0.1761 & 0.2216 \\
\hline & $(0.0064)$ & $(0.0170)$ & $(0.0149)$ & $(0.0301)$ \\
\hline \multirow[t]{2}{*}{ Re-weighted } & 0.0975 & 0.1497 & 0.1167 & 0.1476 \\
\hline & (0.0106) & $(0.0251)$ & (0.0190) & (0.0373) \\
\hline $\mathrm{N}$ & 26,781 & 18,377 & 13,799 & 8,289 \\
\hline
\end{tabular}

Notes: Numbers in parentheses are bootstrapped standard errors based on 1000 replications. For the re-weighted results, the weights are based on differences across groups around each tenure threshold. 
Table 5B: Heterogeneity across Tenure Thresholds, Annual Frequency, Women

\begin{tabular}{|c|c|c|c|c|}
\hline \multicolumn{5}{|c|}{ Panel A: Changes in Retirements (dp/p) } \\
\hline & 10 Year Threshold & 15 Year Threshold & 20 Year Threshold & 25 Year Threshold \\
\hline \multirow[t]{2}{*}{ Unweighted } & 0.2593 & 0.3387 & 0.4678 & 0.4477 \\
\hline & $(0.0166)$ & $(0.0206)$ & $(0.0313)$ & $(0.0961)$ \\
\hline \multirow[t]{2}{*}{ Re-weighted } & 0.2755 & 0.2759 & 0.3346 & 0.4452 \\
\hline & $(0.0240)$ & $(0.0219)$ & $(0.0294)$ & $(0.1402)$ \\
\hline \multicolumn{5}{|c|}{ Panel B: Changes in Implicit Tax Rates (dy/y) } \\
\hline \multirow{3}{*}{ Unweighted } & 10 Year Threshold & 15 Year Threshold & 20 Year Threshold & 25 Year Threshold \\
\hline & 1.1076 & 0.5961 & 1.0539 & 1.3566 \\
\hline & $(0.0126)$ & $(0.0071)$ & $(0.0122)$ & $(0.0261)$ \\
\hline \multirow[t]{2}{*}{ Re-weighted } & 1.0573 & 0.5277 & 0.8469 & 1.0190 \\
\hline & $(0.0370)$ & $(0.0175)$ & (0.0229) & $(0.0396)$ \\
\hline \multicolumn{5}{|c|}{ Panel C: Elasticities (e) } \\
\hline & 10 Year Threshold & 15 Year Threshold & 20 Year Threshold & 25 Year Threshold \\
\hline \multirow[t]{2}{*}{ Unweighted } & 0.2341 & 0.5682 & 0.4439 & 0.3300 \\
\hline & (0.0149) & $(0.0348)$ & $(0.0306)$ & (0.0719) \\
\hline \multirow[t]{2}{*}{ Re-weighted } & 0.2606 & 0.5228 & 0.3951 & 0.4369 \\
\hline & $(0.0247)$ & $(0.0454)$ & $(0.0363)$ & $(0.1374)$ \\
\hline$N$ & 35,218 & 26,523 & 18,808 & 7,488 \\
\hline
\end{tabular}

Notes: Numbers in parentheses are bootstrapped standard errors based on 1000 replications. For the re-weighted results, the weights are based on differences across groups around each tenure threshold. 
Table 6: Pre-Threshold Retirement Patterns Ratio of Delayed Retirements to Excess Retirements (Within 18 Months after Threshold)

\begin{tabular}{|c|c|c|c|c|}
\hline \multicolumn{5}{|c|}{ Men } \\
\hline Months Prior to Tenure Threshold & 10 Year Threshold & 15 Year Threshold & 20 Year Threshold & 25 Year Threshold \\
\hline \multirow[t]{2}{*}{12} & 0.5370 & 0.8985 & 0.8871 & 0.5364 \\
\hline & $(0.0891)$ & $(0.1140)$ & $(0.1307)$ & $(0.1057)$ \\
\hline \multirow[t]{2}{*}{18} & 0.5677 & 1.0555 & 1.0507 & 0.5823 \\
\hline & $(0.1057)$ & $(0.1305)$ & $(0.1515)$ & $(0.1219)$ \\
\hline \multirow[t]{2}{*}{24} & 0.5875 & 1.1460 & 1.1348 & 0.6036 \\
\hline & $(0.1190)$ & $(0.1393)$ & $(0.1616)$ & $(0.1310)$ \\
\hline \multirow[t]{2}{*}{36} & 0.7051 & 1.2525 & 1.1939 & 0.6807 \\
\hline & $(0.1201)$ & $(0.1417)$ & $(0.1591)$ & $(0.1311)$ \\
\hline \multicolumn{5}{|c|}{ Women } \\
\hline Months Prior to Tenure Threshold & 10 Year Threshold & 15 Year Threshold & 20 Year Threshold & 25 Year Threshold \\
\hline \multirow[t]{2}{*}{12} & 0.8691 & 0.7420 & 0.5326 & 0.6457 \\
\hline & $(0.1051)$ & $(0.0883)$ & $(0.0918)$ & $(0.2276)$ \\
\hline \multirow[t]{2}{*}{18} & 0.9777 & 0.8327 & 0.5757 & 0.6615 \\
\hline & (0.1191) & $(0.1013)$ & $(0.1028)$ & $(0.2468)$ \\
\hline \multirow[t]{2}{*}{24} & 1.0223 & 0.8778 & 0.5975 & 0.6958 \\
\hline & $(0.1275)$ & $(0.1083)$ & $(0.1083)$ & $(0.2592)$ \\
\hline \multirow[t]{2}{*}{36} & 1.1380 & 0.9872 & 0.6977 & 0.9206 \\
\hline & $(0.1326)$ & $(0.1091)$ & $(0.1075)$ & $(0.2707)$ \\
\hline
\end{tabular}

Notes: Numbers in parentheses are bootstrapped standard errors based on 1000 replications. These results are un-weighted. 


\section{Fig. 1. Payment Amounts based on Tenure at Retirement}

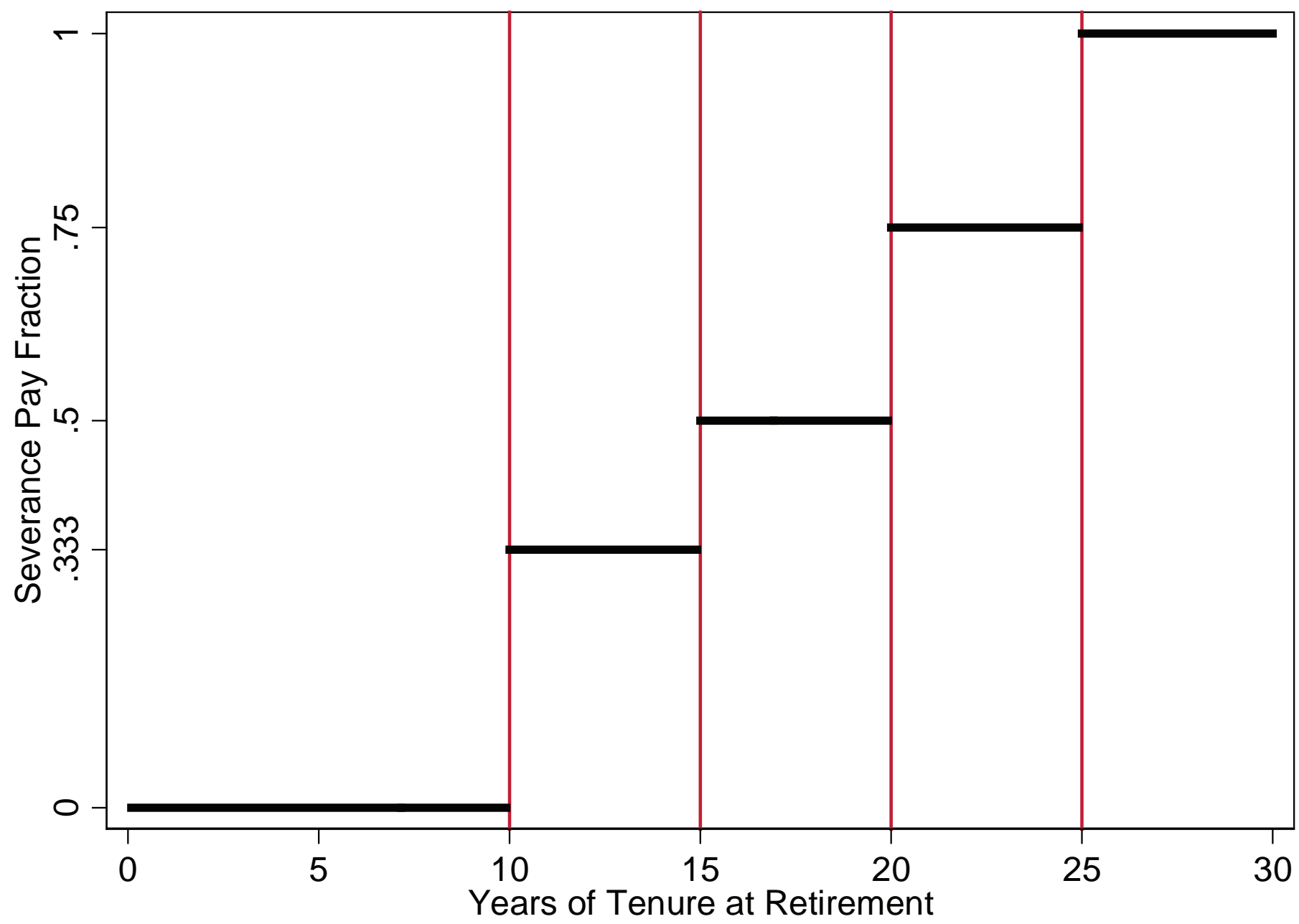

Notes: There are two forms of government-mandated retirement benefits in Austria: (1) government-provided pension benefits and (2) employer-provided severance payments. The employer-provided severance payments are made to private sector employees who have accumulated sufficient years of tenure by the time of their retirement. Tenure is defined as uninterrupted employment time with a given employer and retirement is based on claiming a government-provided pension. The payments must be made within 4 weeks of claiming a pension according to the following schedule. If an employee has accumulated at least 10 years of tenure with her employer by the time of retirement, the employer must pay one third of the worker's last year's salary. This fraction increases from one third to one half, three quarters and one at 15, 20 and 25 years of tenure respectively. Since payments are based on an employee's salary, overtime compensation and other non-salary payments are not included when determining the amounts of the payments. Provisions to make these payments come from funds that employers are mandated to hold based on the total number of employees. Severance payments are also made to individuals who are involuntarily separated (i.e. laid off) from their firms if the individuals have accumulated sufficient years of tenure prior to the separation. The only voluntary separation that leads to a severance payment, however, is retirement. Employment protection rules hinder firms from strategically laying off workers to avoid severance payments and there is no evidence on an increased frequency of layoffs before the severance pay thresholds. 


\section{Fig. 2. Exits from Labor Force into Retirement}

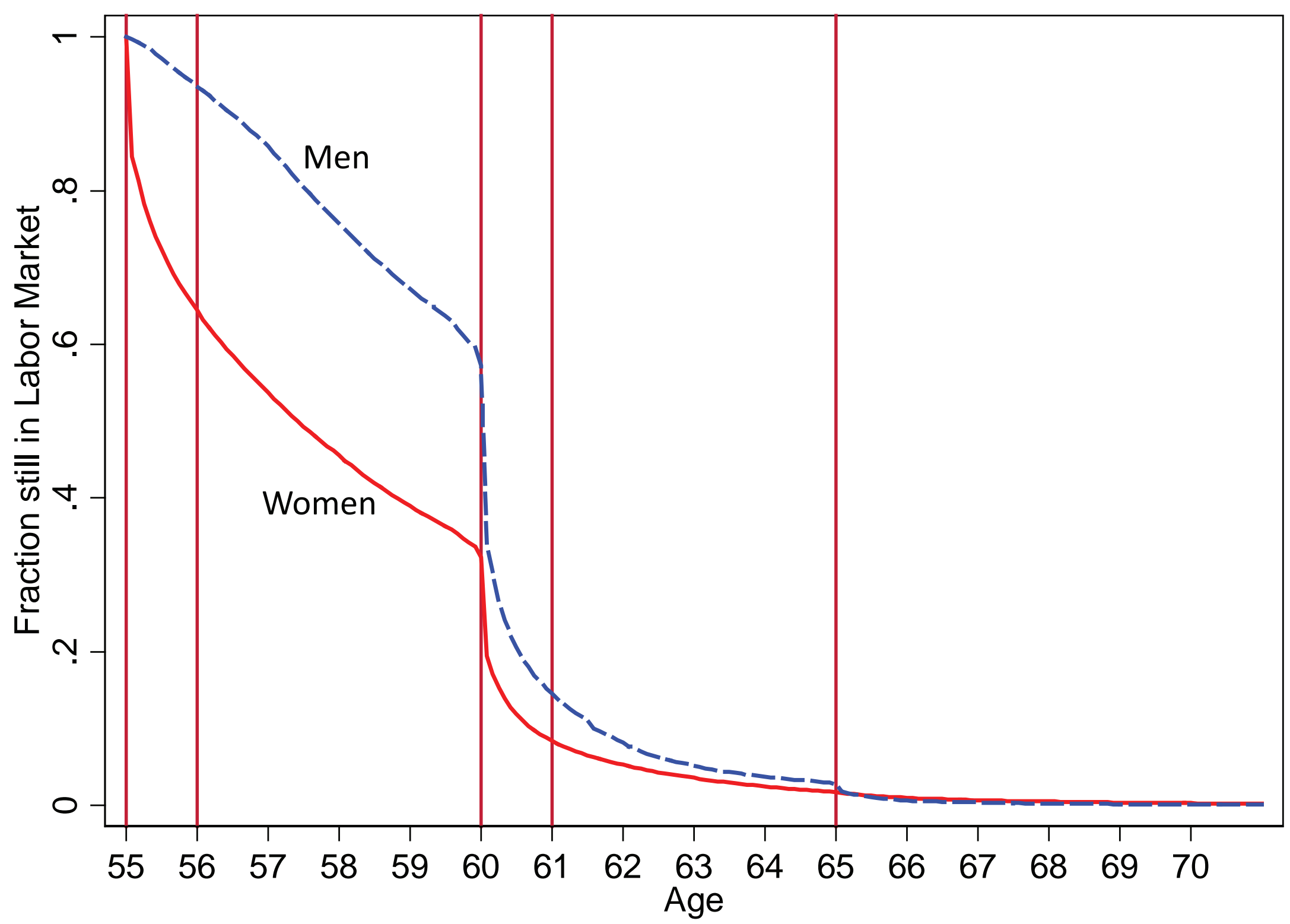

Notes: This figure plots the survival functions for exits from the labor force for the sample of private sector employees; the survival functions are computed at a monthly frequency using birthdates and last observed job ending dates. The solid red line is the survival function for women; the Early Retirement Age and Normal Retirement Age for women are respectively 55 and 60. The dashed blue line is the survival curve for men; the Early Retirement Age and Normal Retirement Age for men are respectively 60 and 65 . Prior to age 60 , men can retire through disability pensions. 


\section{Fig. 3. Distribution of Tenure at Retirement, Full Sample}

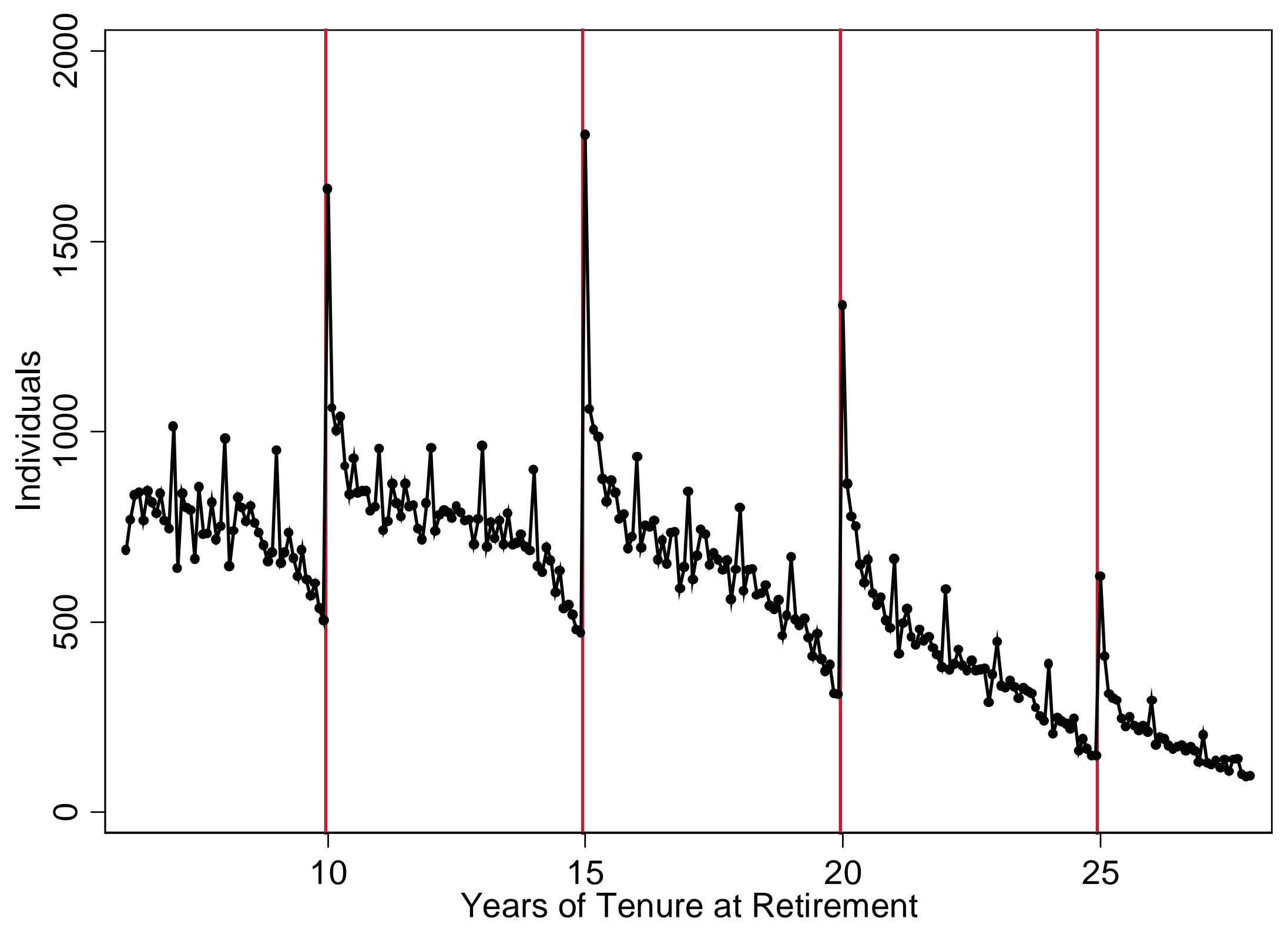

Notes: This figure plots the distribution of tenure at retirement at a monthly frequency. Each point captures the number of people that retire with tenure greater than the lower number of months, but less than the higher number of months. Tenure at retirement is computed using observed job starting and job ending dates. Since firm-level tenure is only recorded beginning in January 1972, we restrict the sample to individuals with uncensored tenure at retirement (i.e. job starting after January 1972). 


\section{Fig. 4. Controlling for Covariates}

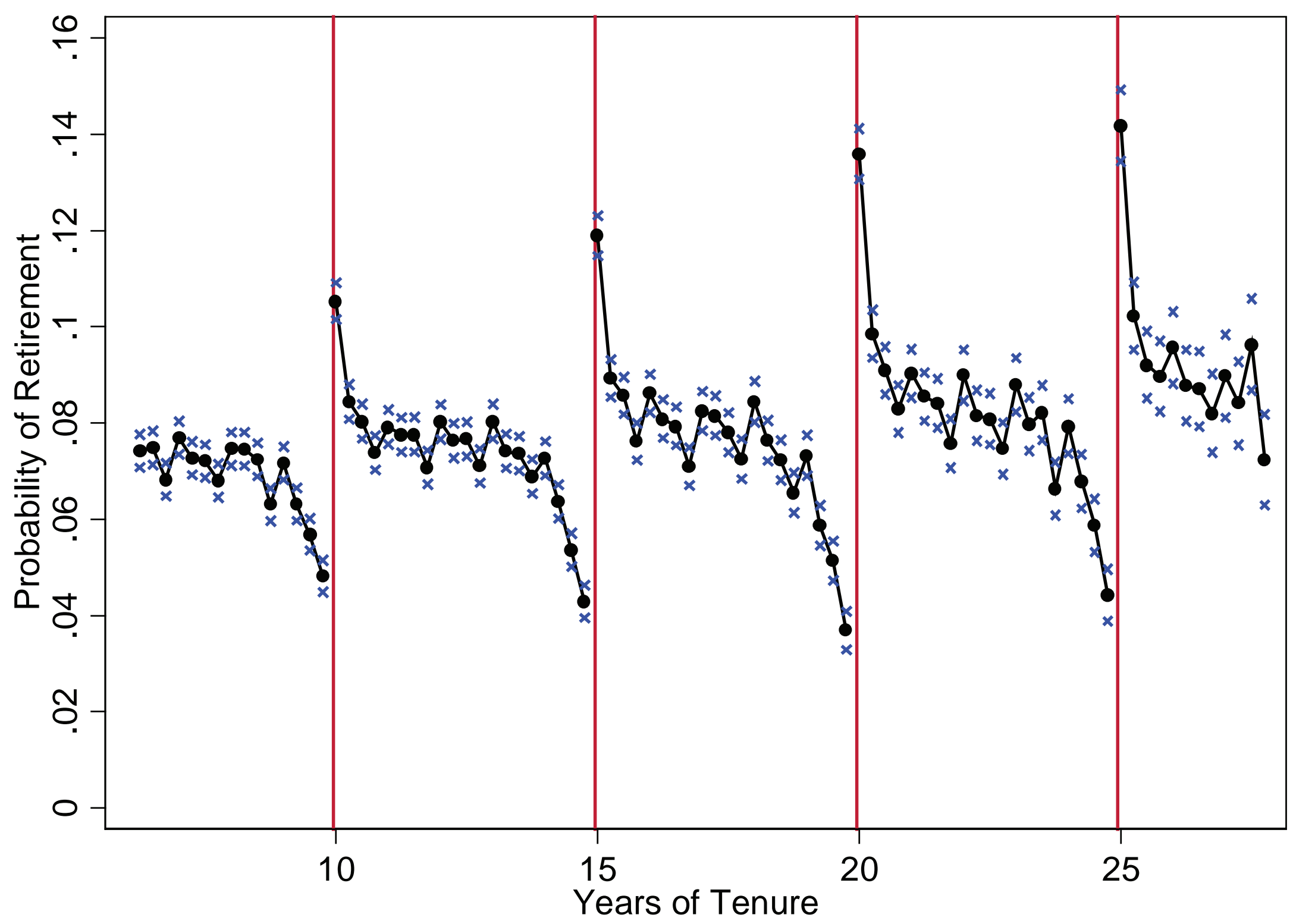

Notes: We regress a quarterly retirement indicator on quarterly tenure dummies and controls for age, gender, calendar years, citizenship, blue collar job status, industry, region, current calendar quarter, job starting month, earnings histories, firm size, health and years of experience. The black circles are the estimated coefficients on the tenure dummies. The blue $x$ 's above and below each circle represent $+/-2$ standard errors around each point estimate. 


\section{Fig. 5A. Total Job Starts by Age}

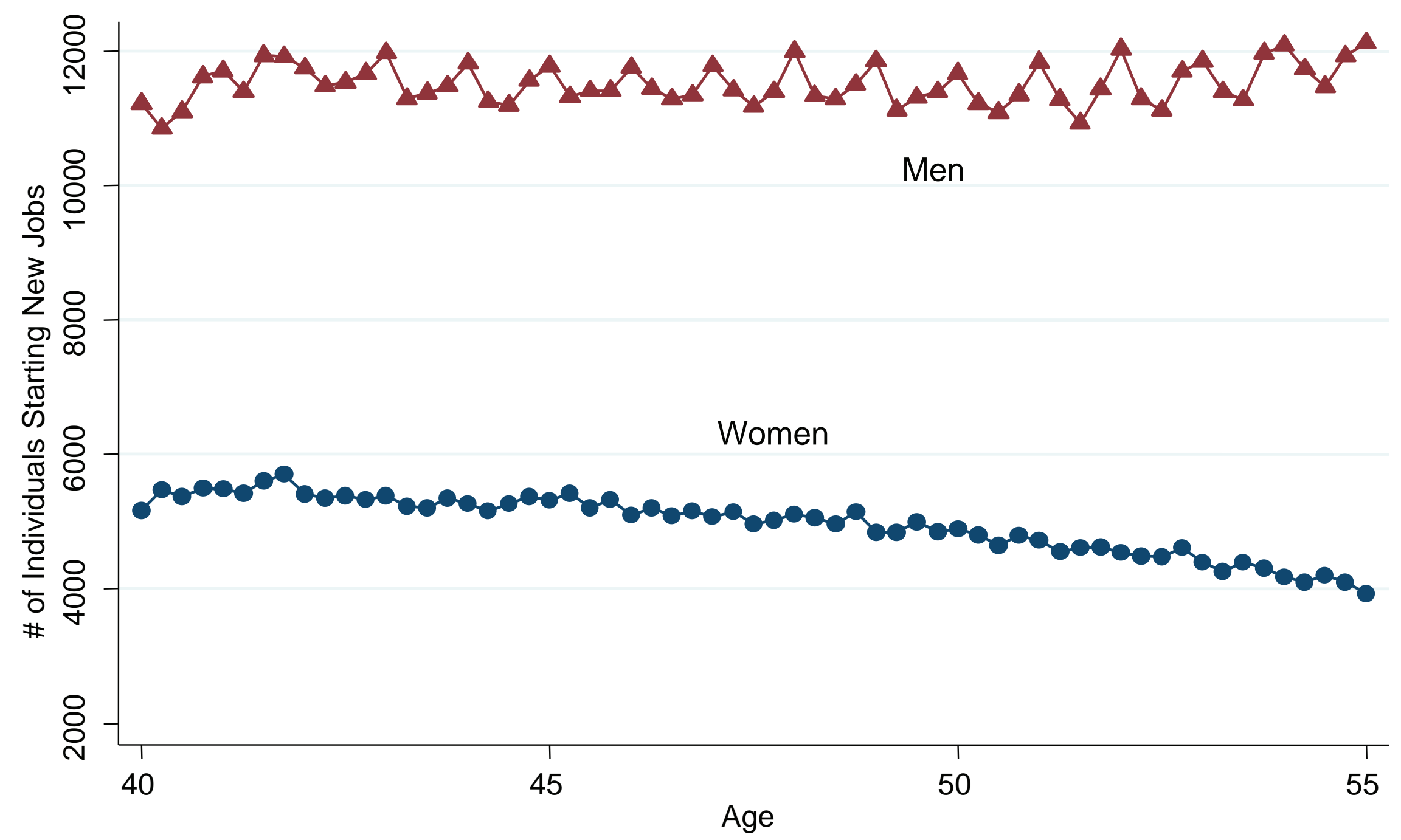

Notes: This figure plots the total numbers of men and women starting new jobs at each age. The sample consists of all men and women, including those with uncensored tenure at retirement. Age is measured at a quarterly frequency. The blue triangles capture the number of men starting new jobs and the red circles captures the number of women starting new jobs. 


\section{Fig. 5B. Job Starts from Previous Employment by Age}

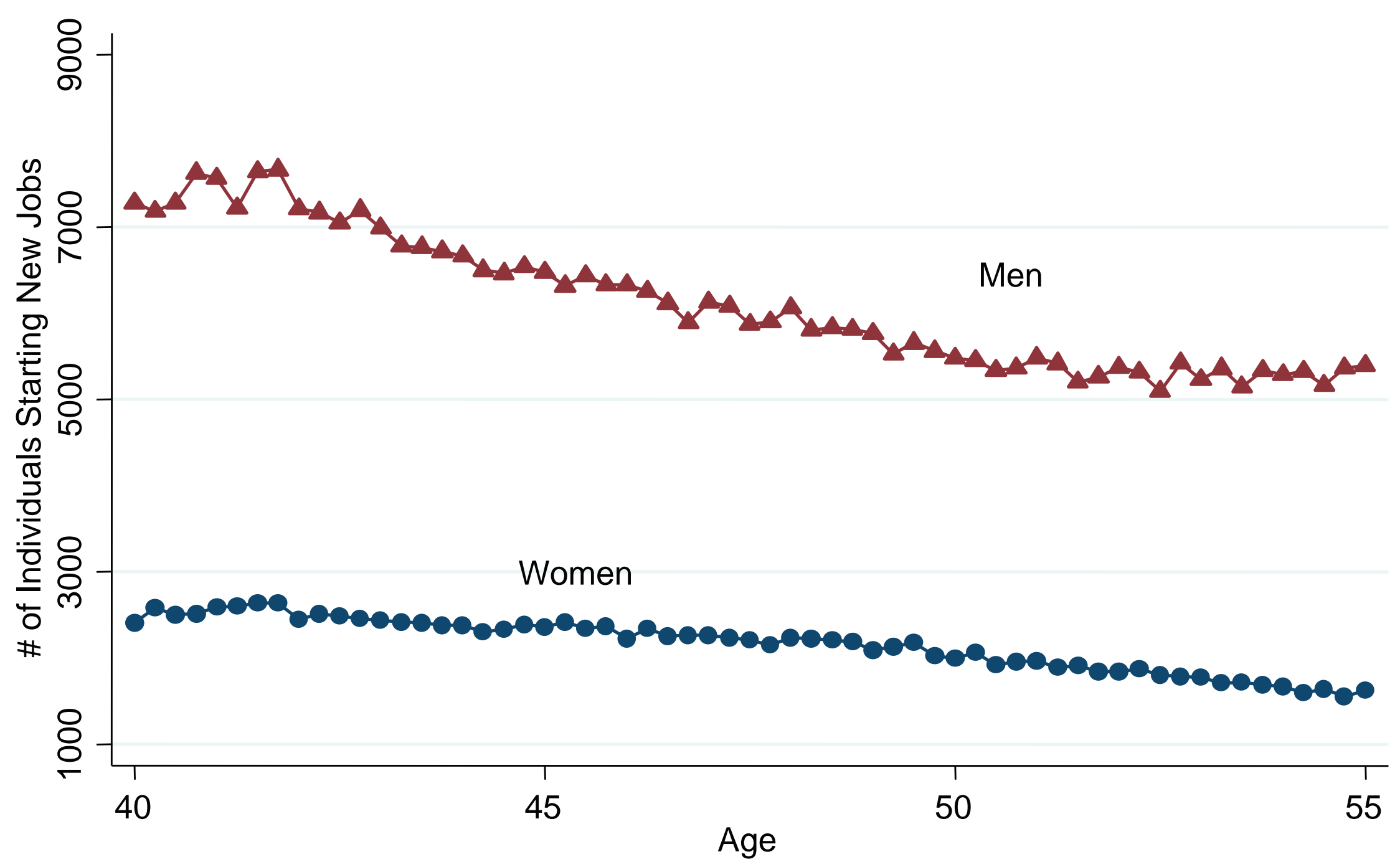

Notes: This figure plots the numbers of previously employed men and women starting new jobs at each age. The sample consists of all men and women who were employed at different establishments prior to their new job start, including those with uncensored tenure at retirement. Age is measured at a quarterly frequency. The blue triangles capture the number of men starting new jobs and the red circles captures the number of women starting new jobs. 


\section{Fig. 5C. Job Starts from Previous Unemployment by Age}

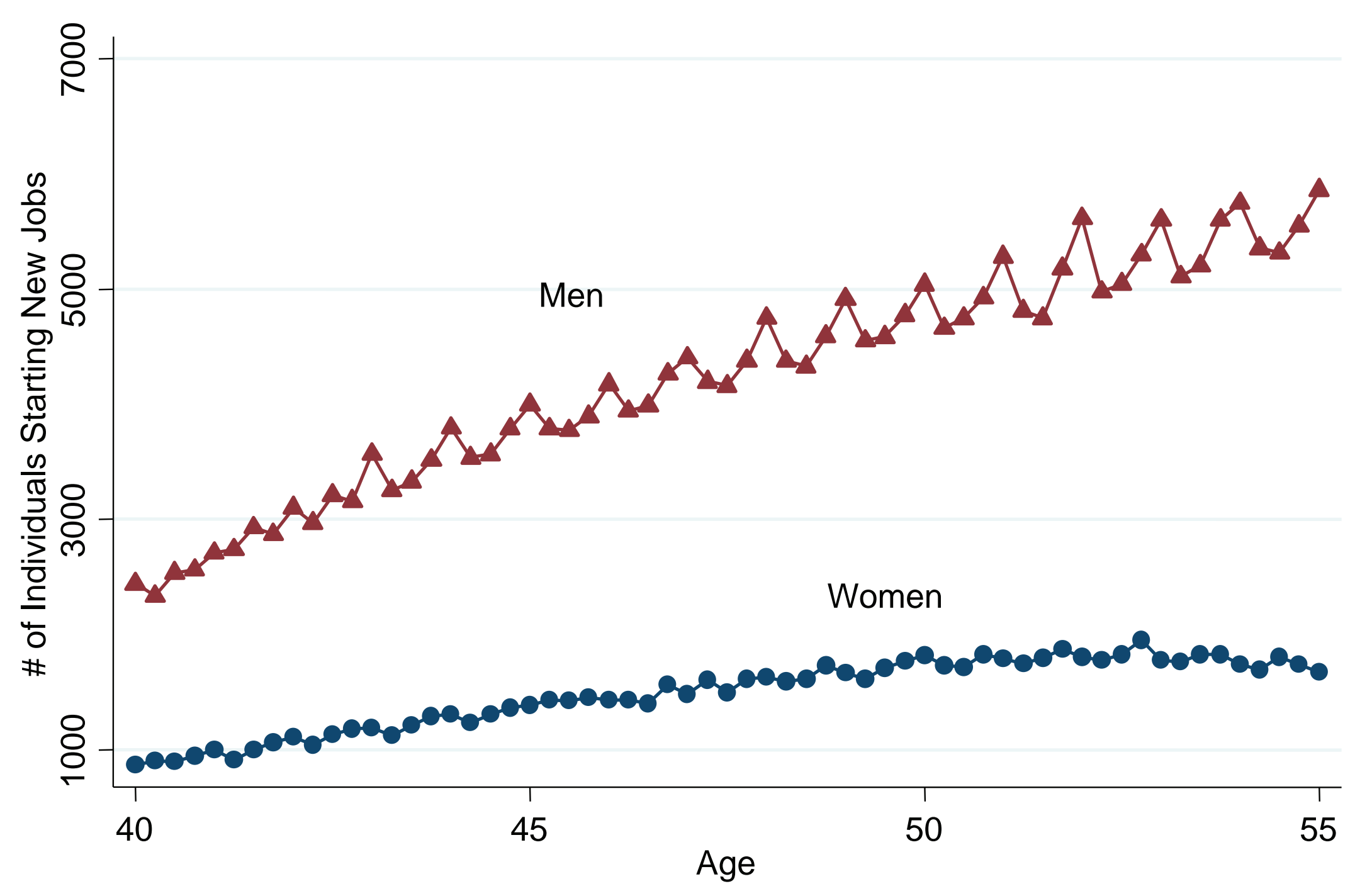

Notes: This figure plots the numbers of previously unemployed men and women starting new jobs at each age. The sample consists of all men and women who were unemployed prior to their new job start, including those with uncensored tenure at retirement. Age is measured at a quarterly frequency. The blue triangles capture the number of men starting new jobs and the red circles captures the number of women starting new jobs. 


\section{Fig. 6. Tenure at Retirement by Health Status}
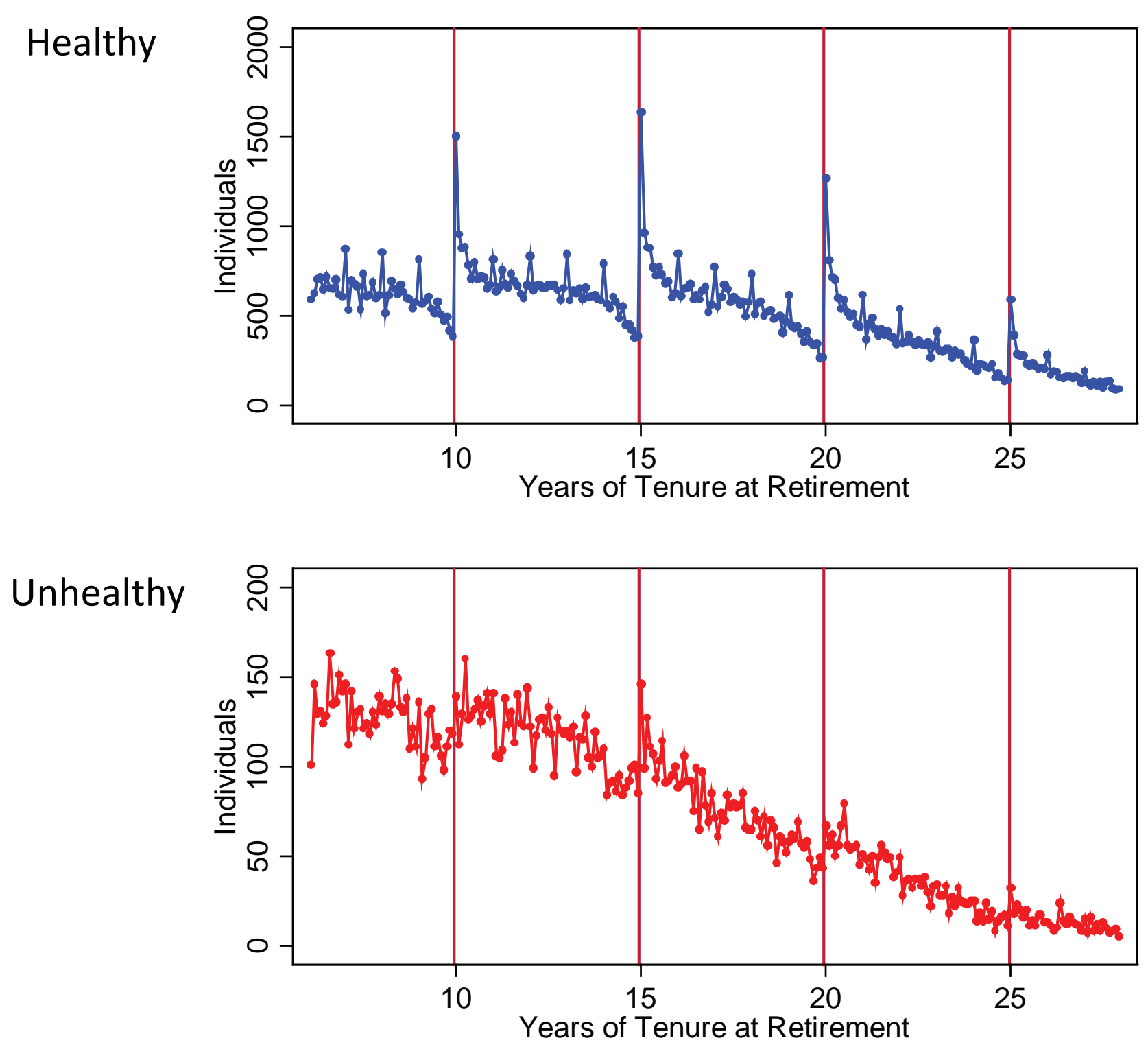

Notes: Health status is measured based on the fraction of time between age 54 and retirement that is spent on sick leave. An individual is classified as unhealthy if his health status is below the median level. The median health status is computed within the sample of individuals with positive sick leave and uncensored tenure at retirement.; this median health status is 0.076 . 


\section{Fig. 7. Tenure at Retirement by Gender \& Retirement Age}

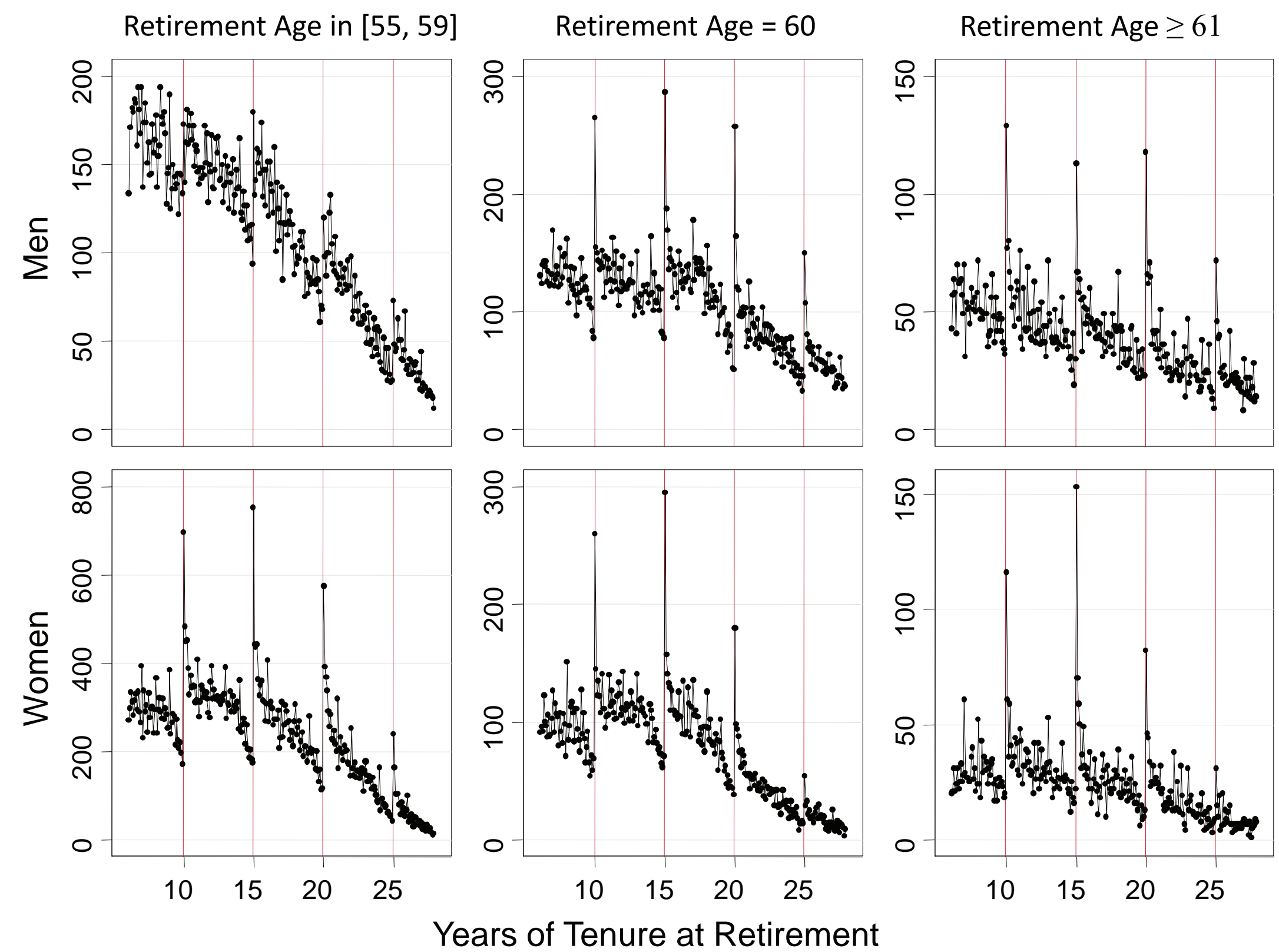

Notes: The age groups for men and women are chosen based on the survival curves illustrated in Figure 2. The Early Retirement Age and Normal Retirement Age for women are 55 and 60; the corresponding ages for men are 60 and 65 respectively. Prior to age 60, men can retire and claim disability pensions. 


\section{Fig. 8. Tenure at Retirement by Replacement Rates}

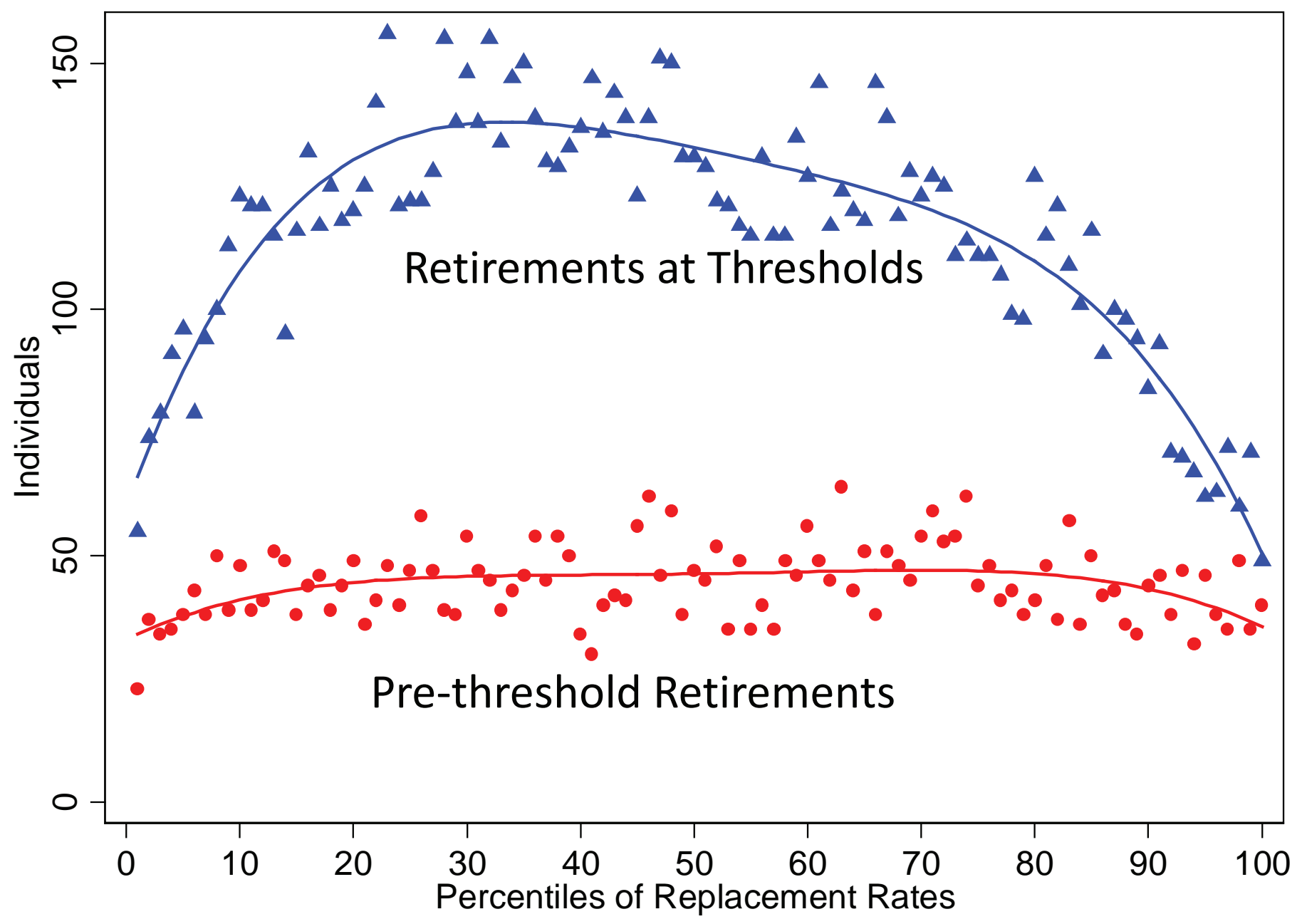

Notes: This figure is constructed via the following steps. First, we compute percentiles of replacement rates across the sample of individuals with uncensored tenure at retirement. Second, we calculate tenure at retirement at a quarterly frequency. Third, within each percentile of replacement rates, we compute the total number of people retiring within one quarter prior to a threshold; this series or pre-threshold retirements across replacement rate percentiles is plotted in red circles. The solid red line captures predicted values from regressing the pre-threshold counts on a $4^{\text {th }}$ order polynomial in percentiles of replacement rates. Fourth, within each percentile of replacement rates, we also compute the total number of people retiring within one quarter after a threshold; this series or retirements at thresholds across replacement rate percentiles is plotted in blue triangles. The solid blue line captures predicted values from regressing the threshold counts on a $4^{\text {th }}$ order polynomial in percentiles of replacement rates. 


\section{Fig. 9. Tenure at Retirement by Tenure-Adjusted Permanent Income}

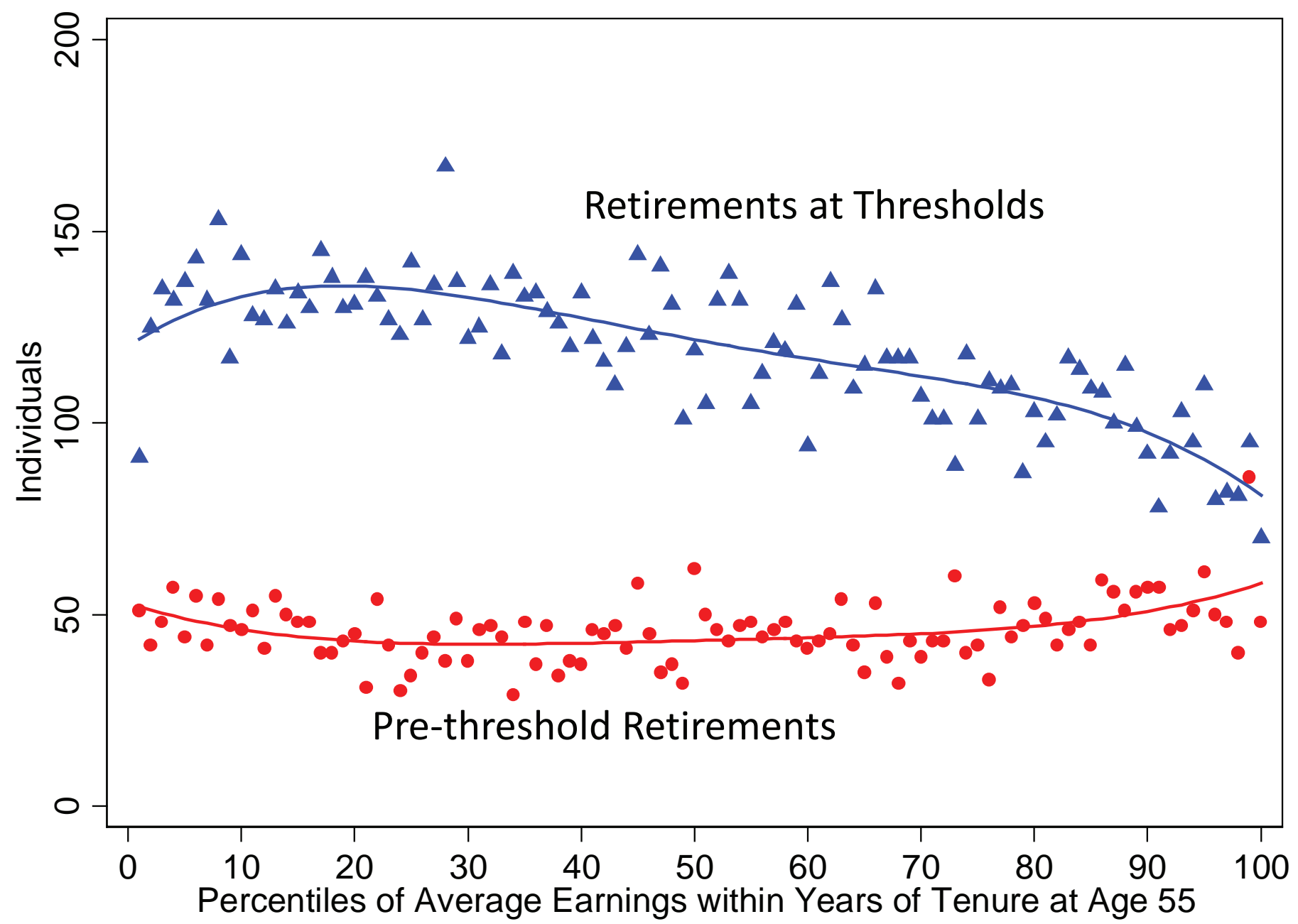

Notes: This figure is constructed via the following steps. First, we compute average earnings between ages 42 through 54 for all individuals in the sample. We sum earnings over these ages and divide by 13 . Second, we compute tenure at age 55 for each individual. Third, within each calendar year and integer value of tenure at age 55, we compute percentiles of average earnings. Fourth, we compute tenure at retirement at a quarterly frequency. Fifth, within each percentile of average earnings, we compute the total number of people retiring within one quarter prior to a tenure threshold. This series of pre-threshold retirements across earnings percentiles is plotted in red circles; the solid red line captures predicted values from regressing the pre-threshold retirements on a $4^{\text {th }}$ order polynomial in earnings percentiles. Lastly, within each percentile of average earnings, we compute the total number of people retiring within one quarter after a tenure threshold. This series of retirements at thresholds is plotted in blue triangles; the solid blue line captures predicted values from regressing the retirements at thresholds on a $4^{\text {th }}$ order polynomial in earnings percentiles. 


\section{Fig. 10. Retirements at Tenure Thresholds by Firm Size}

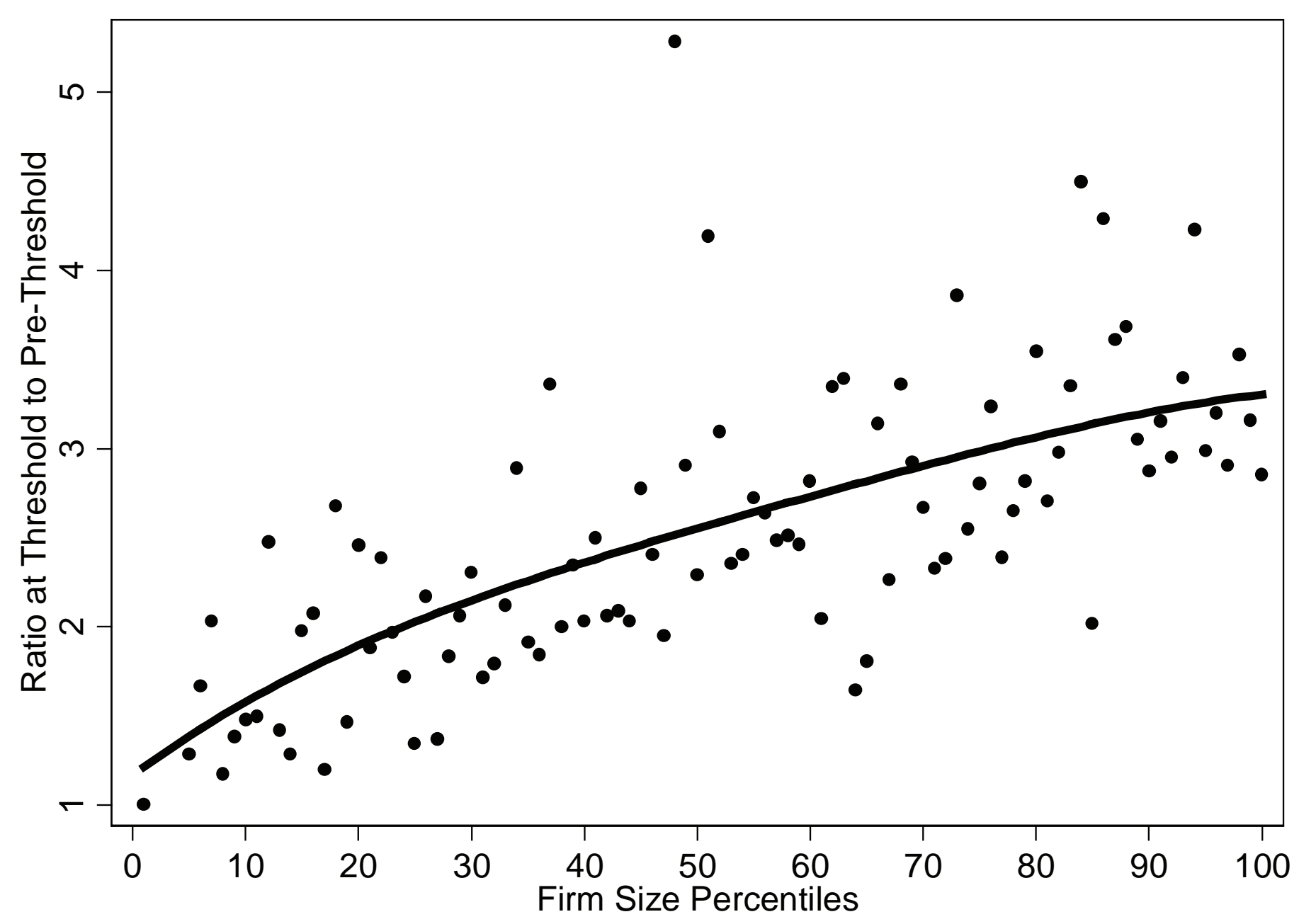

Notes: Firm size is computed as the number of employees at the beginning of each calendar quarter. We construct firm size percentiles using the sample of firms with retirements. For each individual at retirement, we keep the firm identifier and calendar date of the last employment date. We create a dataset with the sample of firms with retirements by dropping any duplicates so that the resulting dataset has one observation per unique firm-calendar date observation. Within each calendar date, we compute firm size percentiles. Next, we compute tenure at retirement at a quarterly frequency. Finally, within each firm size percentile, we compute the ratio of the total number of people retiring within one quarter after a tenure threshold to the total number of people retiring within one quarter prior to a tenure threshold. Each point in the figure plots this ratio within each firm size percentile. The solid line captures predicted values from regressing the ratios on a $4^{\text {th }}$ order polynomial in firm size percentiles. 


\section{Fig. 11A. Individual Reservation Disutility by Tenure}

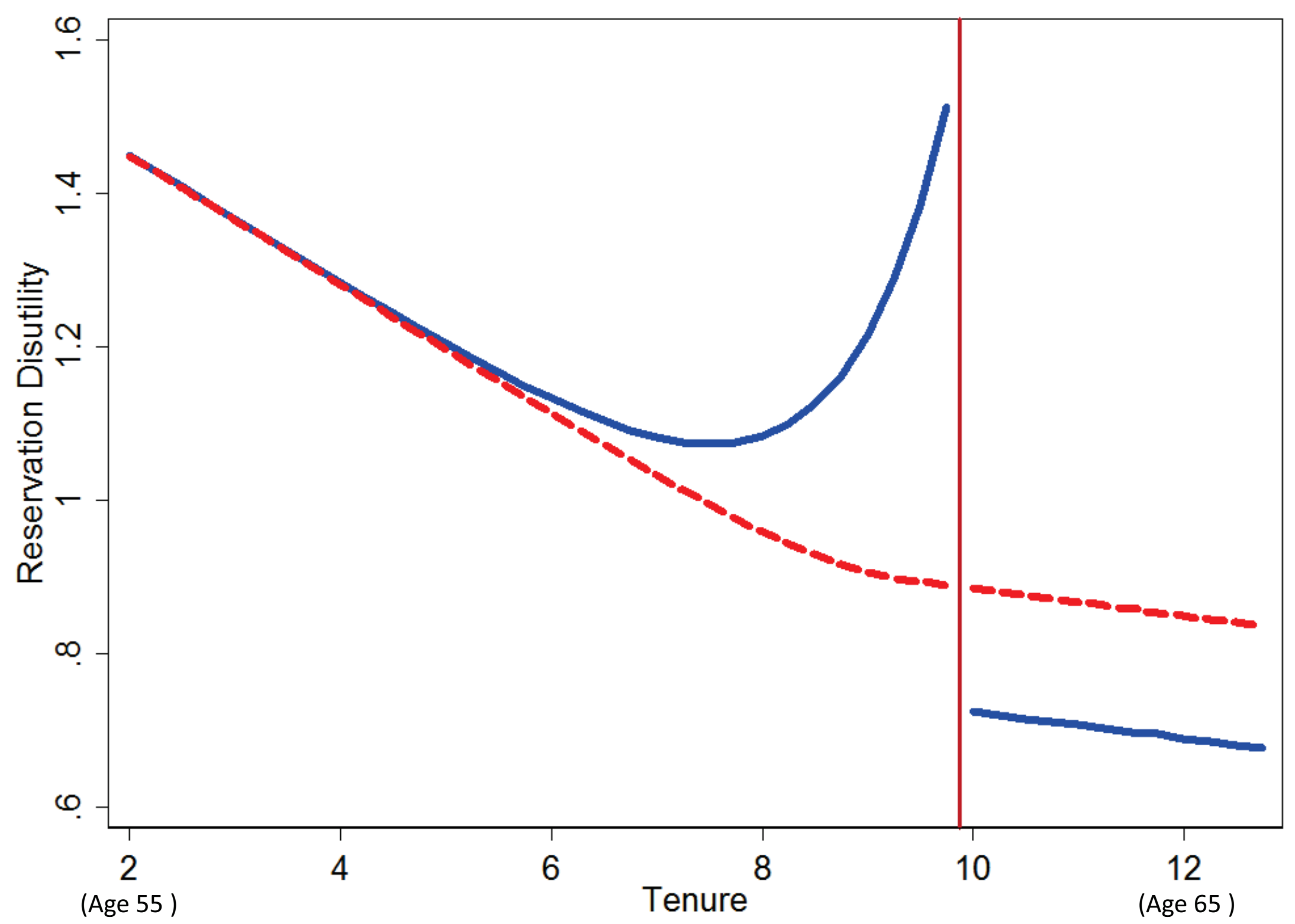

Notes: This figure plots the simulated profiles of the reservation disutility across years of tenure for a given individual who starts with 2 years of tenure at age 55. Following the model, the individual ages as he accumulates more tenure. The solid blue line presents the profile in the presence of the severance pay policy. The dashed red line presents the counterfactual profile with no severance pay. The curvature in the counterfactual profile reflects changes in retirement benefits at older retirement ages. Please see the simulation appendix for technical details on the simulation. 


\section{Fig. 11B. Individual Retirement Hazard by Tenure}

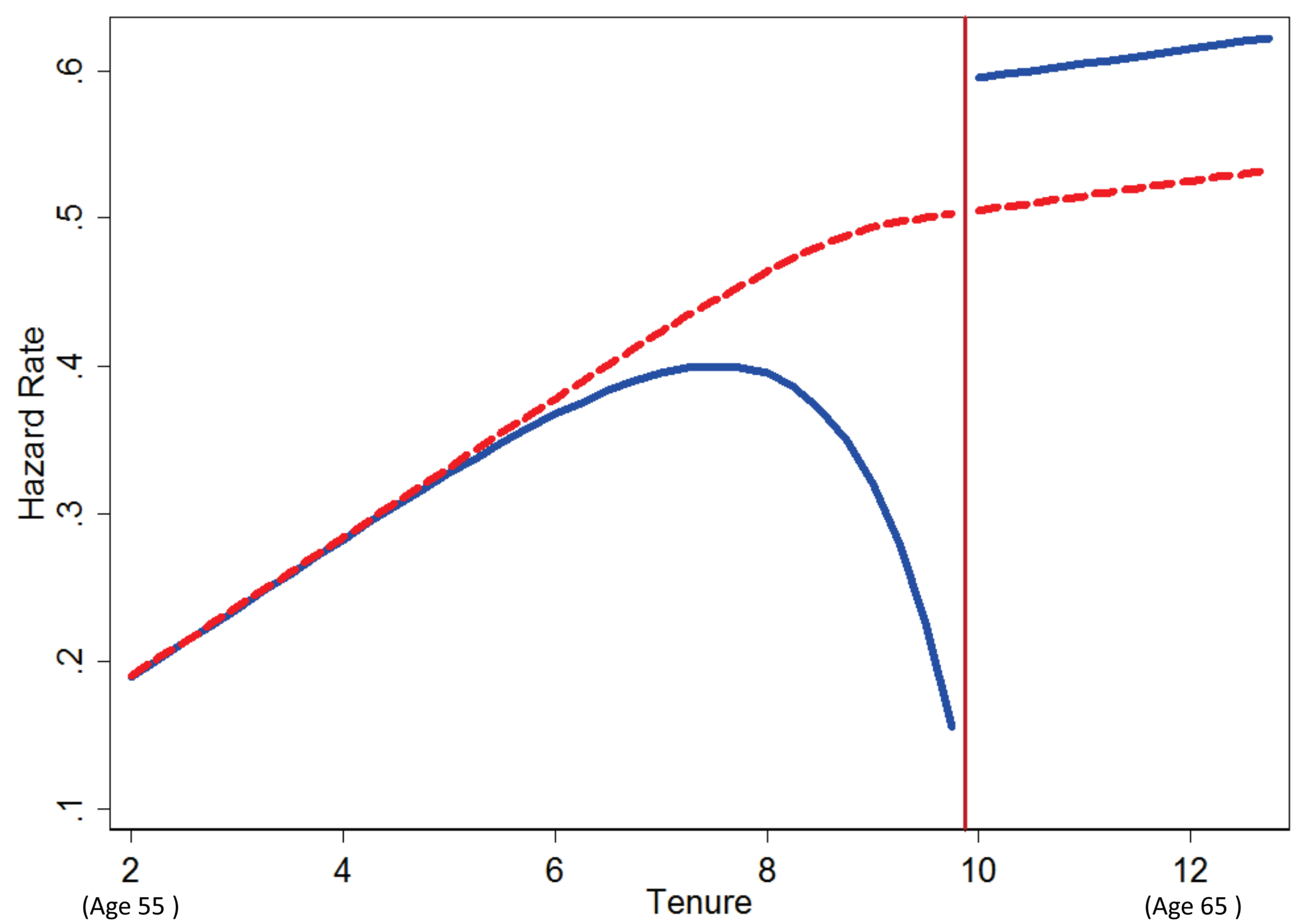

Notes: This figure plots the simulated profile of the retirement hazard rate (i.e. the probability of retirement conditional on remaining in the labor market) across years of tenure for a given individual who starts with 2 years of tenure at age 55 . Following the model, the individual ages as he accumulates more tenure. The solid blue line presents the profile in the presence of the severance pay policy. The dashed red line presents the counterfactual profile with no severance pay. The curvature in the counterfactual profile reflects changes in retirement benefits at older retirement ages. Please see the simulation appendix for technical details on the simulation. 


\section{Fig. 12A. Average Retirement Hazard by Tenure}

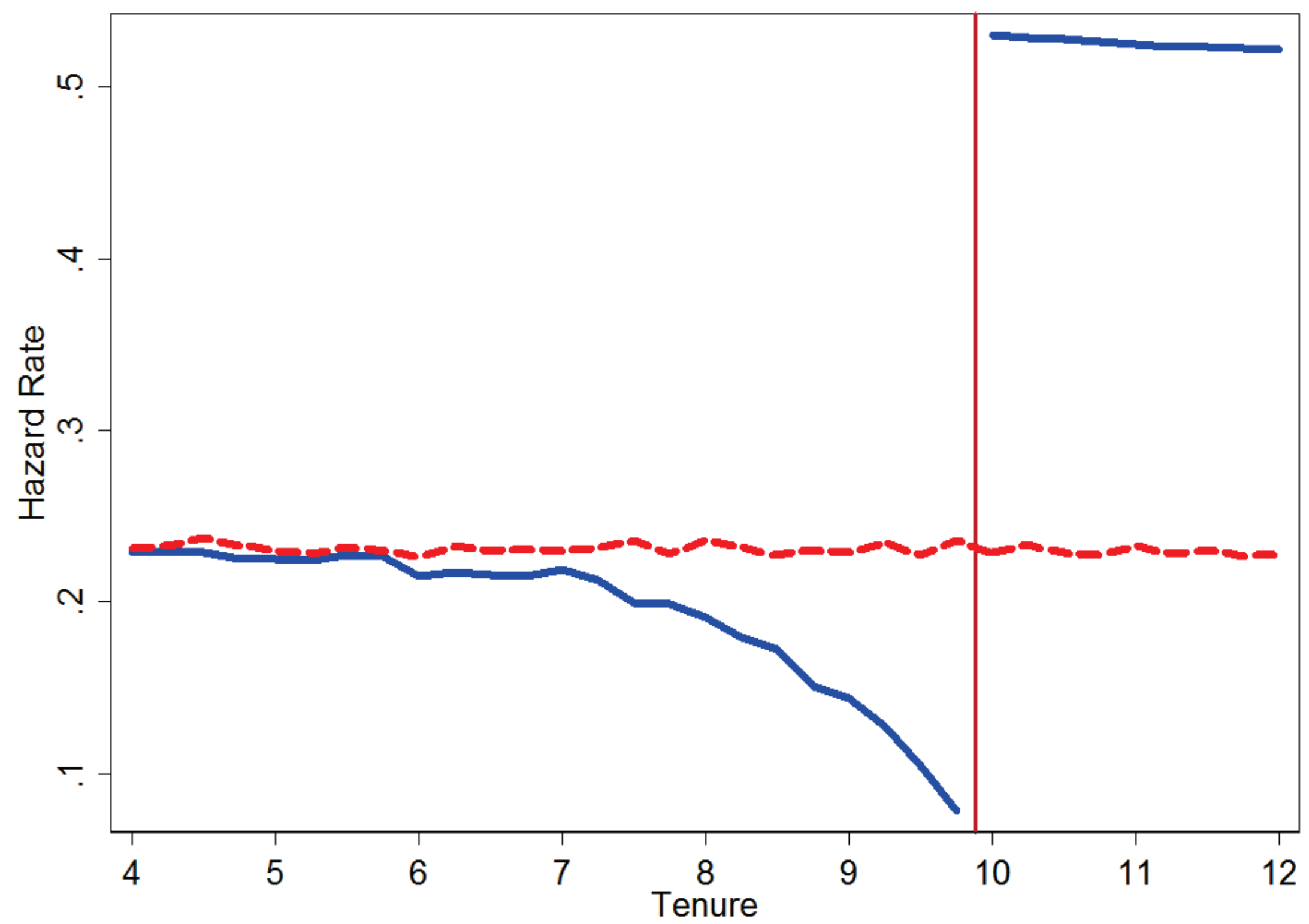

Notes: This figure plots the average simulated retirement hazard rate, conditional on remaining in the labor market, by tenure. The average retirement hazard rate at each level of tenure is computed by the following steps. First, retirement outcomes are computed for each simulated individual. Second, at each observed retirement, the reservation disutility and corresponding hazard rate are computed. Third, at each level of tenure at retirement, the average retirement hazard rate is computed by averaging over individuals retiring at different ages. The solid blue line and triangle present the hazard rates in the presence of the severance pay policy. The dashed red line and circle present the counterfactual hazard rates with no severance pay. Please see the simulation appendix for technical details on the simulation. 


\section{Fig. 12B. Simulated Distribution of Tenure at Retirement}

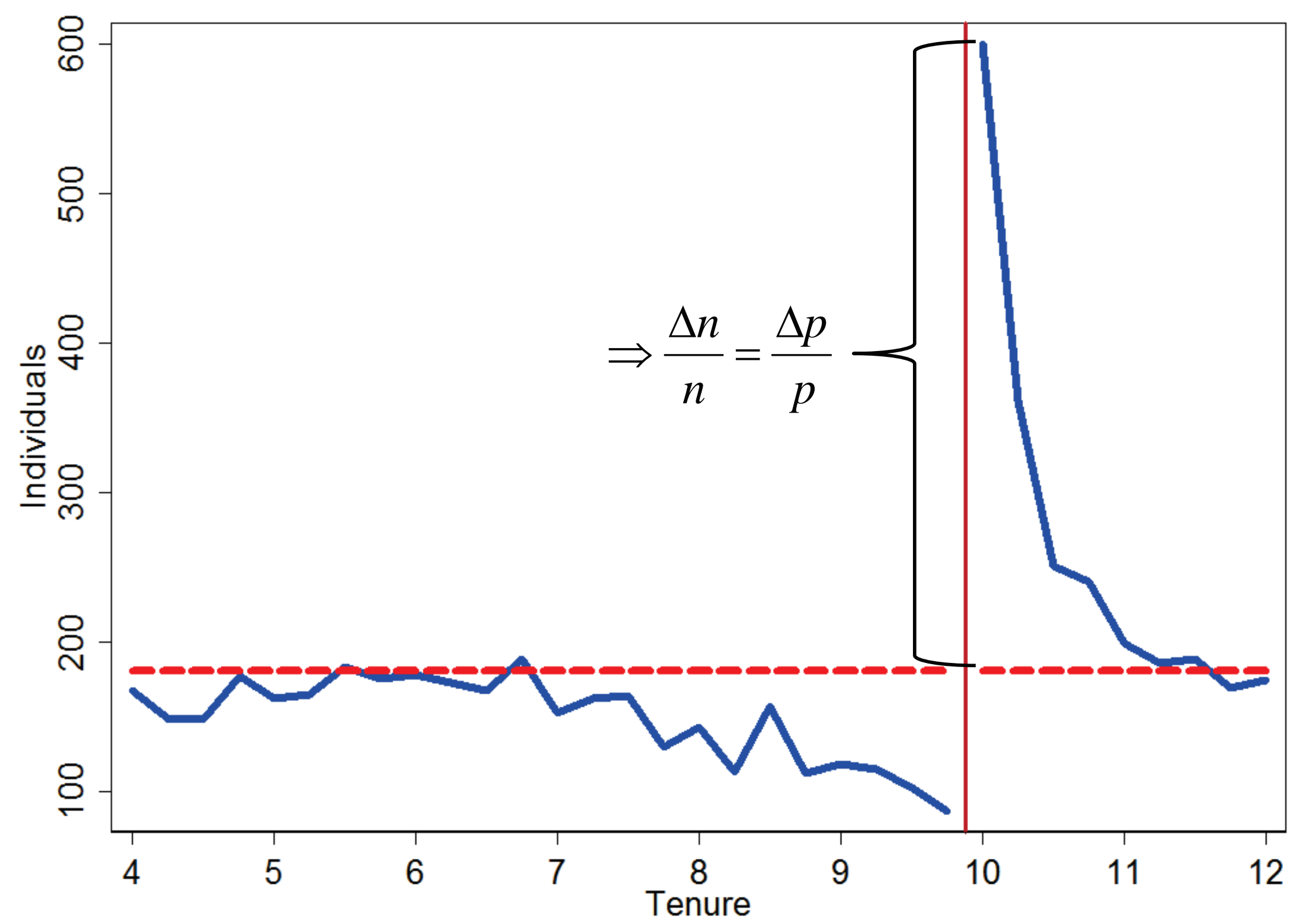

Notes: This figure plots the simulated distribution of tenure at retirement based on simulated retirement outcomes for 10,000 simulated individuals. The solid blue line presents the distribution in the presence of the severance pay policy. The dashed red line presents the counterfactual distribution with no severance pay. Please see the simulation appendix for technical details on the simulation. 


\section{Fig. 13A. Estimating the Changes in Retirements}

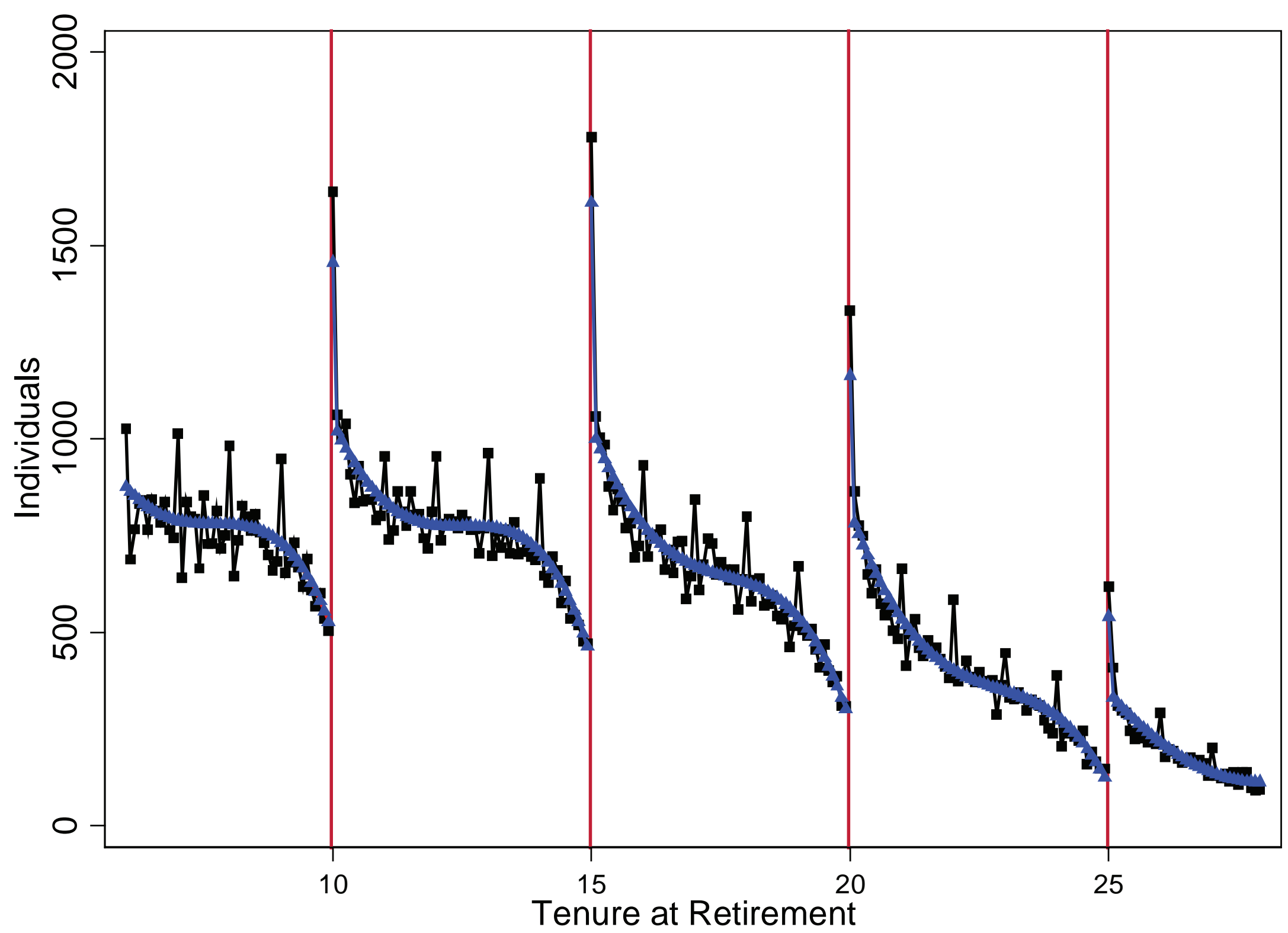

Notes: The black squares plot the observed retirement frequencies at each monthly level of tenure at retirement, as in Figure 3 . The blue triangles plot retirement frequencies adjusted for seasonality patterns. The adjustment for seasonality is based on estimating separate polynomials in tenure at retirement between each tenure threshold and discontinuous spikes at each tenure threshold. The spikes at each threshold are adjusted for seasonality by adjusting for being at an integer value of tenure at retirement. The seasonally adjusted retirement frequencies are re-scaled so that the total number of seasonally adjusted retirements is equal to the total number of observed retirements. 


\section{Fig. 13B. Estimating the Changes in Retirements}

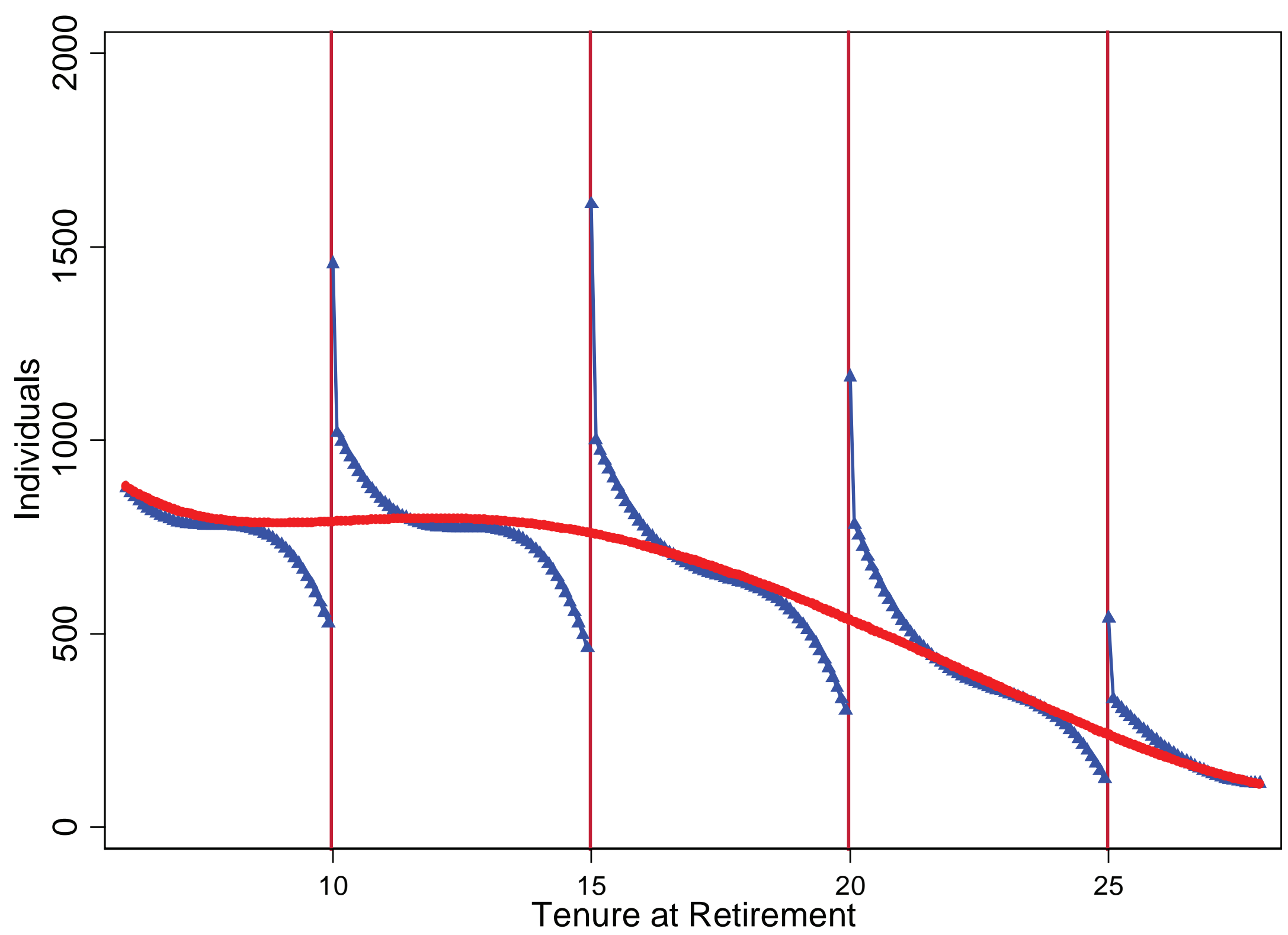

Notes: The blue triangles plot retirement frequencies adjusted for seasonality patterns. The red circles plot estimated counterfactual retirement frequencies. The counterfactual frequencies are estimated by regressing the seasonally adjusted frequencies on a continuous $6^{\text {th }}$ order polynomial in tenure at retirement and dummies around each tenure threshold. The dummies around each threshold are set to 0 and the counterfactual frequencies are obtained by predicting frequencies using only the estimated continuous polynomial function. The counterfactual frequencies are re-scaled so that the total number of counterfactual retirements equals the total number of observed retirements. 
Fig. 13C. Estimating the Changes in Retirements

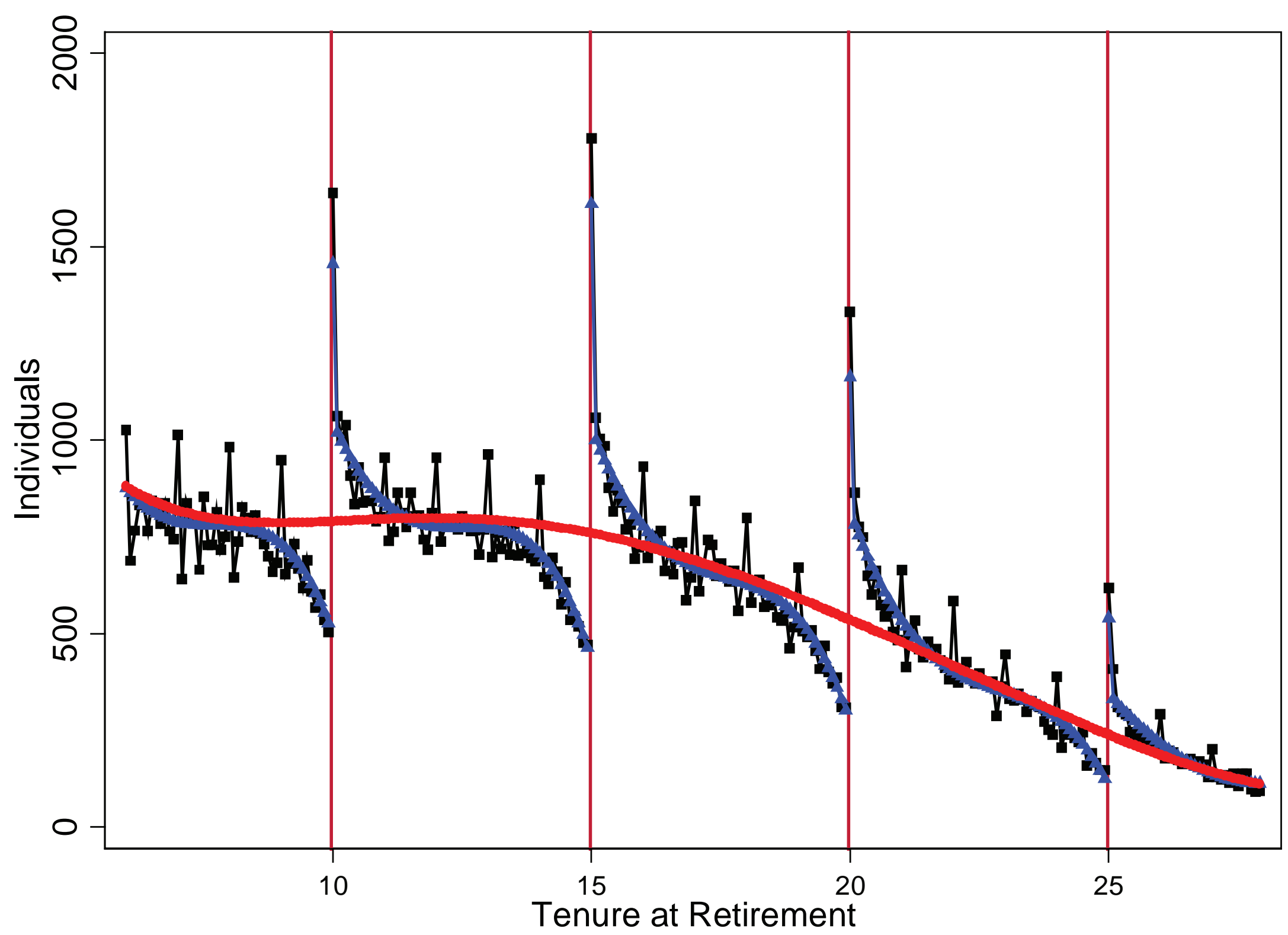

Notes: This figure combines plots for the observed retirement frequencies (black squares), the seasonally adjusted retirement frequencies (blue triangles) and the counterfactual retirement frequencies (red circles). 


\section{Fig. 14. Changes in Implicit Tax Rates}

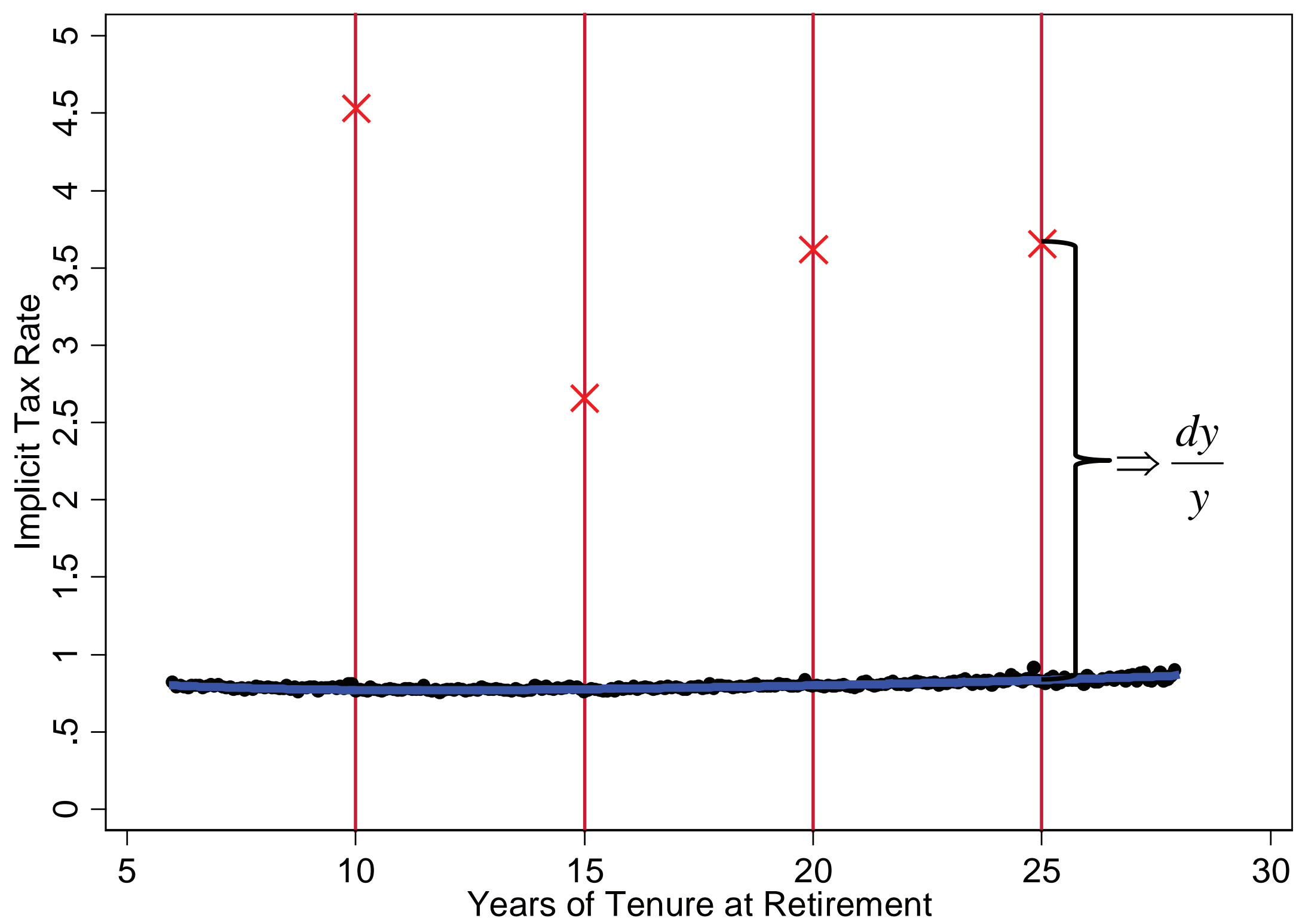

Notes: Implicit tax rates for each individual are computed based on gross annual earnings in the calendar year prior to claiming a pension. The implicit tax rate is the sum of social security contributions, income taxes and pensions divided by gross annual earnings. Each black point in the figure reflects the mean implicit tax rate amongst individuals retiring with the corresponding level of tenure at retirement. The solid blue line captures predicted values from regression the mean implicit tax rates on a $4^{\text {th }}$ order polynomial in tenure at retirement. The red $x^{\prime} s$ mark the implicit tax rates at the tenure thresholds when including the severance payments at retirement. The implicit tax rates are calculated at a monthly frequency. 


\section{Fig. 15. Labor Supply Responses to Retirement Bonus at 61 or Older}

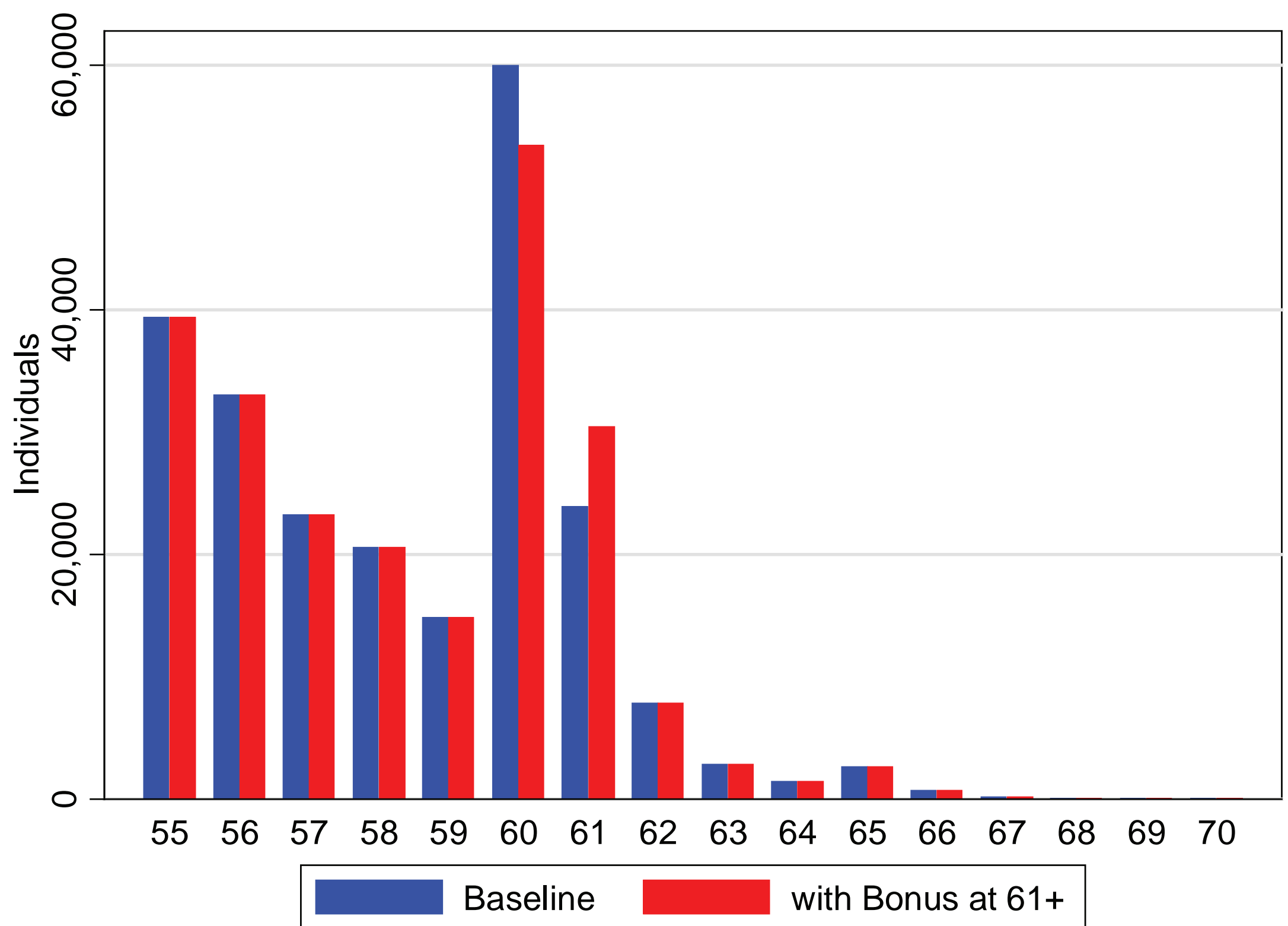

Notes: This figure plots retirement frequencies by age (horizontal axis). The blue bars present the frequencies observed in the data for the full sample of 231,251 individuals. The red bars present the frequencies under a hypothetical policy that provides a one-time, lump-sum retirement bonus of 5000 euros paid to individuals who retire at ages 61 or older. 
Fig. A1. Estimated Counterfactuals with Alternative Windows around Tenure Thresholds

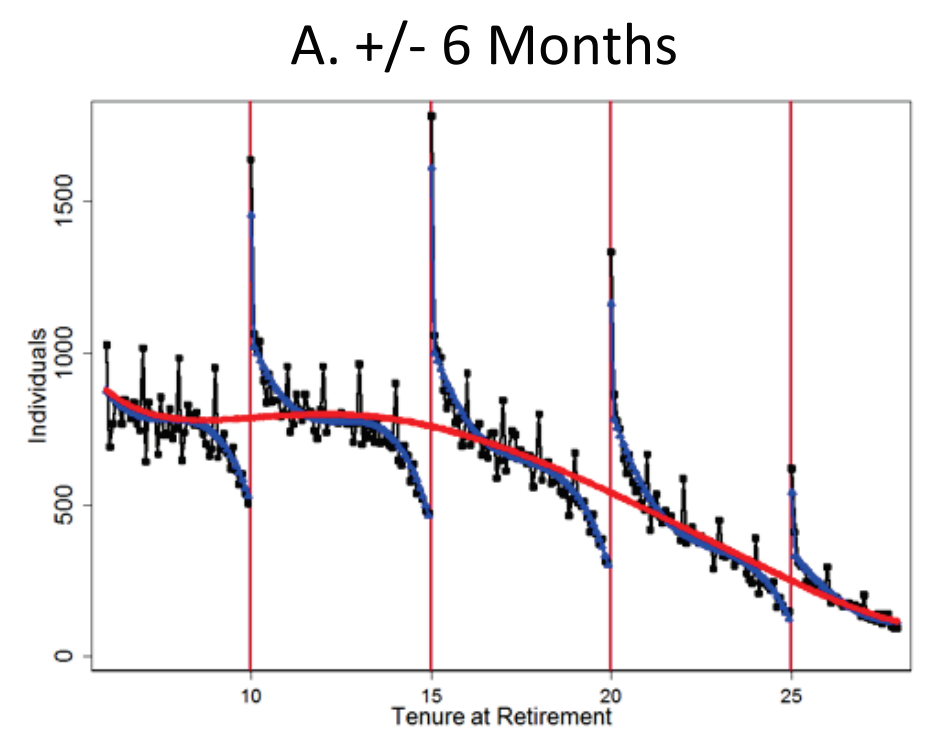

C. +/- 18 Months

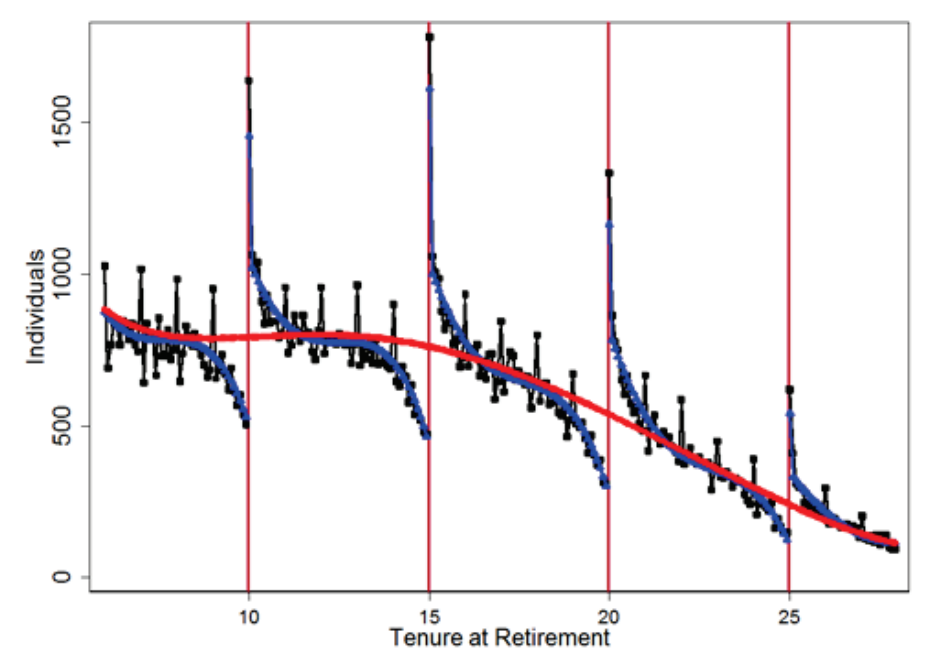

B. +/- 12 Months

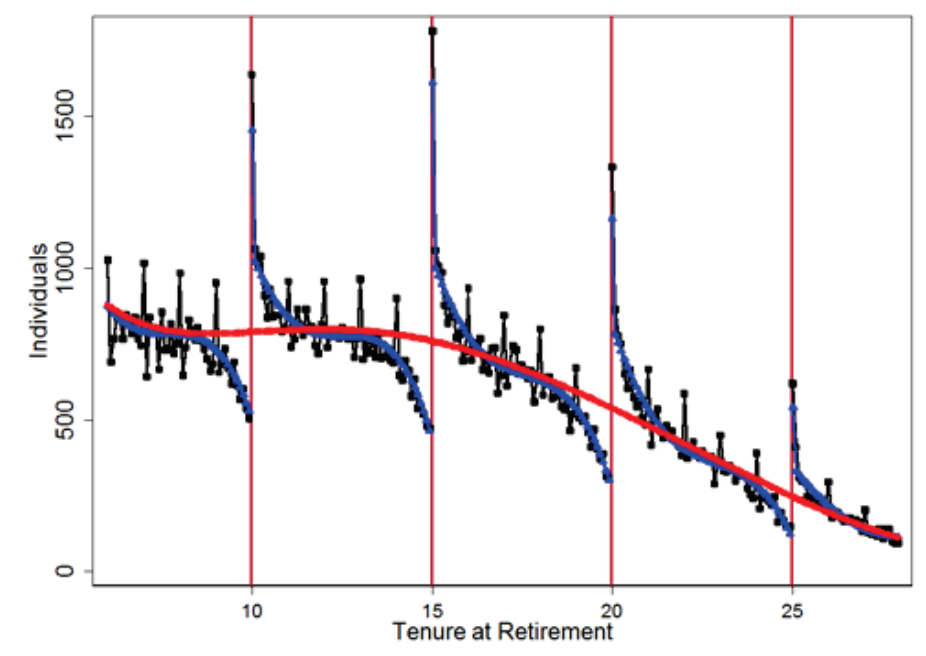

D. +/- 24 Months

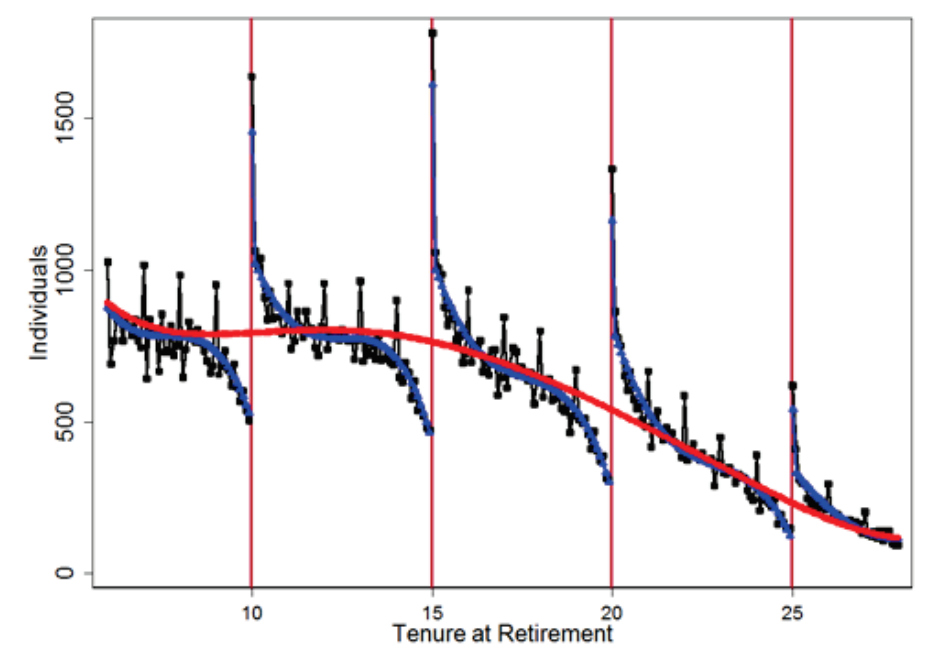

Notes: Please see the notes for Figure 13 for specific details on each figure. The main estimation uses +/- 18 months. 


\section{Fig. A2. Estimated Counterfactuals with}

Alternative Polynomial Specifications between Tenure Thresholds

A. $2^{\text {nd }}$ Order Polynomials

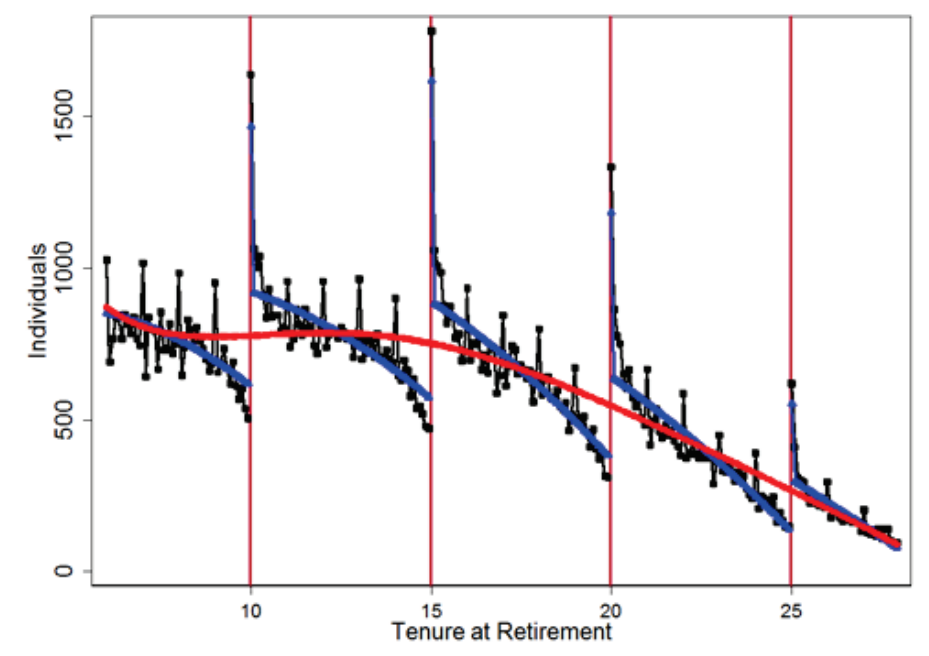

C. $6^{\text {th }}$ Order Polynomials

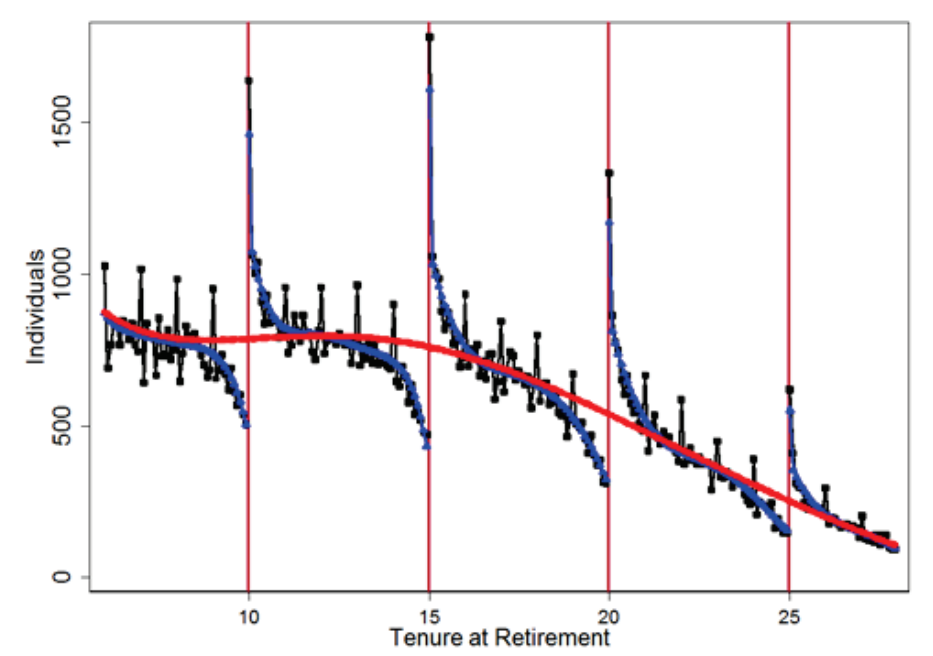

B. $4^{\text {th }}$ Order Polynomials

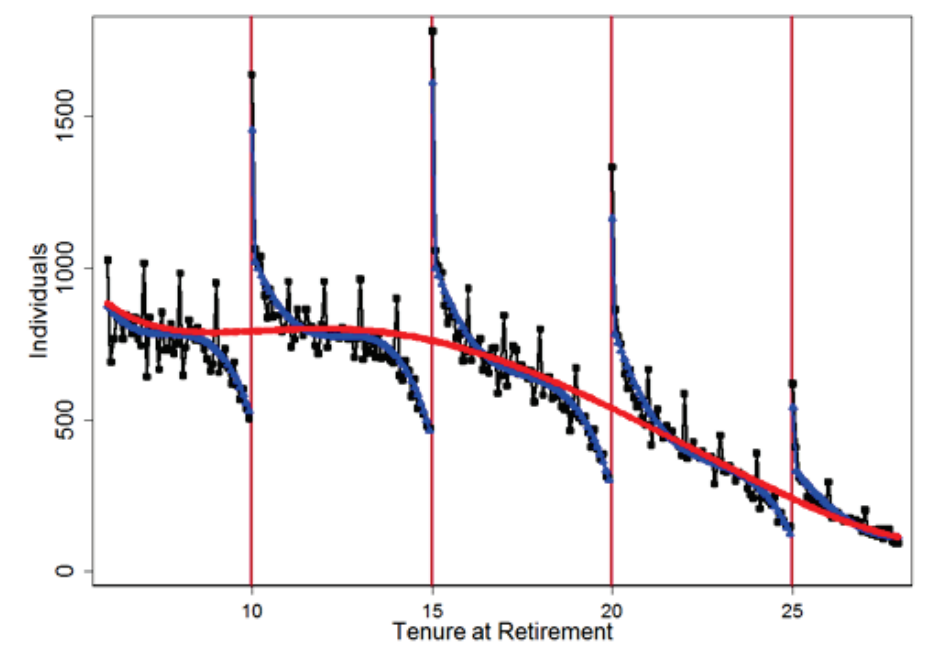

D. $8^{\text {th }}$ Order Polynomials

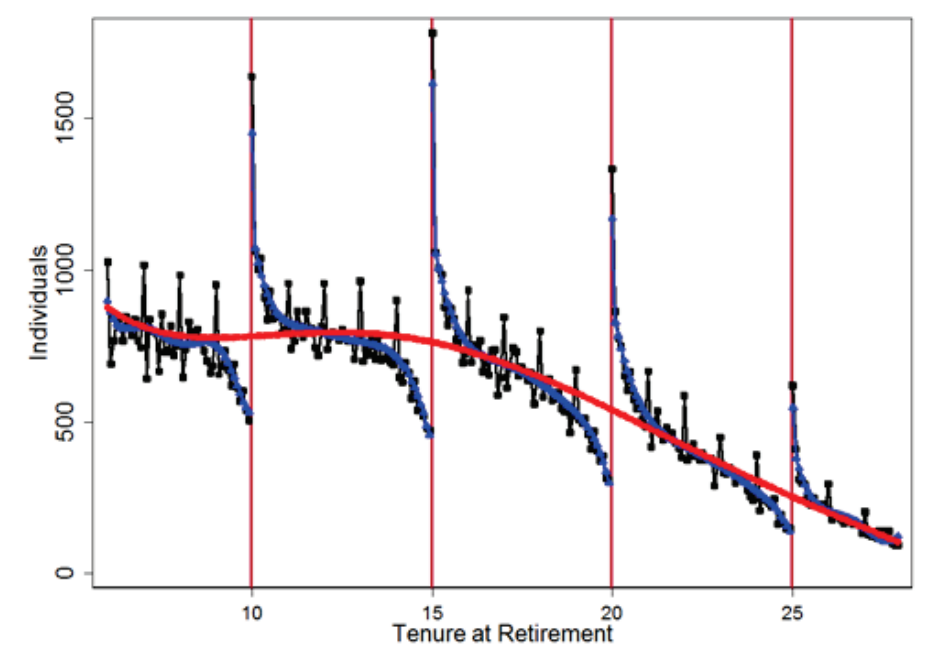

Notes: Please see the notes for Figure 13 for specific details on each figure. The main estimation uses $4^{\text {th }}$ order polynomials. 